\title{
Sliding Wear of Conventional and Suspension Sprayed Nanocomposite WC-Co Coatings: An Invited Review
}

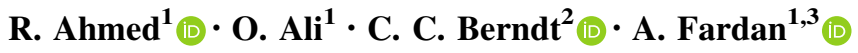

Submitted: 23 October 2020/in revised form: 14 January 2021/Accepted: 15 February 2021/Published online: 6 April 2021

(C) The Author(s) 2021

\begin{abstract}
The global thermal spray coatings market was valued at USD 10.1 billion in 2019 and is expected to grow at a compound annual growth rate of $3.9 \%$ from 2020 to 2027. Carbide coatings form an essential segment of this market and provide cost-effective and environmental friendly tribological solutions for applications in aerospace, industrial gas turbine, automotive, printing, oil and gas, steel, and pulp and paper industries. Almost $23 \%$ of the world's total energy consumption originates from tribological contacts. Thermal spray WC-Co coatings provide excellent wear resistance for industrial applications in sliding and rolling contacts. Some of these applications in abrasive, sliding and erosive conditions include sink rolls in zinc pots, conveyor screws, pump housings, impeller shafts, aircraft flap tracks, cam followers and expansion joints. These coatings are considered as a replacement of the hazardous chrome plating for tribological applications. The microstructure of thermal spray coatings is however complex, and the wear mechanisms and wear rates vary significantly when compared to cemented WC-Co carbides or vapour deposition WC coatings. This paper provides an expert review of the tribological considerations that dictate the sliding wear performance of thermal spray WC-Co coatings. Structure-property relationships and failure
\end{abstract}

R. Ahmed

R.Ahmed@hw.ac.uk

1 School of Engineering and Physical Sciences, Heriot-Watt University, Edinburgh EH14 4AS, UK

2 Surface Engineering for Advanced Materials (SEAM), Swinburne University of Technology, Hawthorn, Victoria 3122, Australia

3 Department of Industrial and Materials Science, Chalmers University of Technology, SE-412 96 Göteborg, Sweden modes are discussed to grasp the design aspects of WC-Co coatings for tribological applications. Recent developments of suspension sprayed nanocomposite coatings are compared with conventional coatings in terms of performance and failure mechanisms. The dependency of coating microstructure, binder material, carbide size, fracture toughness, post-treatment and hardness on sliding wear performance and test methodology is discussed. Semiempirical mathematical models of wear rate related to the influence of tribological test conditions and coating characteristics are analysed for sliding contacts. Finally, advances for numerical modelling of sliding wear rate are discussed.

Keywords finite element modelling - nanocomposite sliding Wear · structure-property · thermal spray coating · tribology $\cdot$ WC-Co $\cdot$ wear mechanism $\cdot$ wear rate

$\begin{array}{ll}\text { Abbreviations } \\ \text { AE } & \text { Acoustic emission } \\ \text { AISI } & \text { American iron and steel institute } \\ \text { ALE } & \text { Arbitrary Lagrangian-Eulerian } \\ \text { APS } & \text { Air plasma spray } \\ \text { ASTM } & \text { American Society for Testing and Materials } \\ \text { CGS } & \text { Carbide grain size } \\ \text { CoF } & \text { Coefficient of friction } \\ \text { CS } & \text { Cold spray } \\ \text { CVD } & \text { Chemical vapour deposition } \\ \text { DCT } & \text { Deep cryogenic treatment } \\ \text { DGS } & \text { Detonation gun spraying } \\ \text { DJ } & \text { Diamond jet } \\ \text { EDS } & \text { Energy-dispersive spectroscopy } \\ \text { EHC } & \text { Electrolytic hard chrome } \\ \text { FCC } & \text { Face centred cubic } \\ \text { FEA } & \text { Finite element analysis }\end{array}$




$\begin{array}{ll}\text { FEM } & \text { Finite element method } \\ \text { HCP } & \text { Hexagonal close packed } \\ \text { HIPing } & \text { Hot isostatic pressing } \\ \text { HVAF } & \text { High velocity air-fuel } \\ \text { HVOF } & \text { High velocity oxygen fuel } \\ \text { LPPS } & \text { Low pressure plasma spray } \\ \text { PVD } & \text { Physical vapour deposition } \\ \text { RCF } & \text { Rolling contact fatigue } \\ \text { RT } & \text { Room temperature } \\ \text { SEM } & \text { Scanning electron microscopy } \\ \text { S-HVOF } & \text { Suspension high velocity oxygen fuel } \\ \text { TEM } & \text { Transmission electron microscopy } \\ \text { VPS } & \text { Vacuum plasma spray } \\ \text { WS } & \text { Warm spray } \\ \text { WC } & \text { Tungsten carbide } \\ \text { WC-Co } & \text { Tungsten carbide cobalt } \\ \text { XRD } & \text { X-ray diffraction }\end{array}$

\section{List of symbols}

\begin{tabular}{|c|c|}
\hline$a$ & Average indent half-diagonal size \\
\hline$C_{L}$ & Total crack length \\
\hline$C_{P}$ & Hertzian contact pressure \\
\hline$D$ & Diagonal of Vickers indentation \\
\hline$D_{\mathrm{WC}}$ & Average diameter of WC grains \\
\hline$E$ & Young's modulus \\
\hline$E_{\text {ball }}$ & Young's modulus of the ball \\
\hline$E_{\text {coating }}$ & Young's modulus of the coating \\
\hline$f$ & Volume fraction of the dispersed phase \\
\hline$h$ & Linear wear \\
\hline$h_{j}$ & Total wear up to the $j$ th increment \\
\hline$h_{j}-1$ & Total wear up to the $(j-1)$ th increment \\
\hline$\Delta h_{j}$ & Wear depth of the current increment \\
\hline$H$ & Hardness \\
\hline$H_{\text {ball }}$ & Hardness of the ball \\
\hline$H_{\text {coating }}$ & Hardness of the coating \\
\hline$K$ & Dimensionless wear coefficient \\
\hline$K_{\text {Ic }}$ & Fracture toughness \\
\hline$K_{\mathrm{IC} \text { ball }}$ & Fracture toughness of the ball \\
\hline$K_{\mathrm{IC} \text { coating }}$ & Fracture toughness of the coating \\
\hline$K_{\mathrm{IC} \text { pin }}$ & Fracture toughness of the pin \\
\hline$k_{\mathrm{D}}$ & Wear rate \\
\hline$K_{L}$ & Empirical constant \\
\hline$l$ & Sliding distance \\
\hline$L$ & Mean free path of the binder \\
\hline$N$ & Normal force in sliding wear test \\
\hline$N_{L}$ & Number of non-contagious grains intersected \\
\hline$N_{S}$ & Number of non-contiguous grains per unit area \\
\hline$P$ & Indentation load \\
\hline$P_{n}$ & Contact pressure at node \\
\hline$Q$ & Wear volume \\
\hline$v$ & Poisson's ratio \\
\hline
\end{tabular}

\section{Introduction}

\section{The Need for Coatings Resistant to Wear}

Almost $23 \%$ of the world's total energy consumption originates from tribological contacts (Ref 1). The global thermal spray coatings market size was valued at USD 10.1 billion in 2019 and is expected to grow at a compound annual growth rate (CAGR) of 3.9\% from 2020 to 2027 (Ref 2). Carbide coatings form an essential segment of this market and provide a cost-effective and environmentally friendly tribological solution to many applications (Ref 2). The microstructure (Ref 3-5) of thermal spray coatings is, however, complex and the wear mechanisms and wear rates vary significantly when compared to cemented WCCo carbides (Ref 6-10) or vapour deposition WC coatings (Ref 11).

Thermal spray coatings improve the wear and frictional performance of components (Ref 3). These coatings are deposited through a line of sight process where the coating material is heated and propelled on to the substrate to form a lamella coating (Ref 4). Thermal spray methods allow for the deposition of hard metals, or their composites, on large surfaces where parts cannot be produced using other techniques due to technical or economic reasons (Ref 3,4). These coatings are used to provide a combination of coating and substrate properties to improve the service life, restore dimensions of machined parts and repair expensive worn components (Ref 12,13). Thermal spray carbide coatings are used for a range of tribological applications in abrasive, sliding, corrosive and erosive conditions for the aforementioned industrial sectors. In particular, WC-Co coatings are used for applications such as steel rolls, sink rolls in zinc pots, corrugating rollers, agricultural rasp bars, conveyor screws, pump housings, impeller shafts, conveyor screws, compressor stators, impeller shafts, aircraft flap tracks, cam followers, and expansion joints (Ref 12). Thermal spray coatings can also replace electrolytic hard chrome (EHC) plating, which is considered environmentally hazardous, for industrial applications (Ref 13).

Thermal spray coatings are deposited through various generations of high velocity oxygen fuel (HVOF), vacuum plasma spray (VPS), air plasma spray (APS), warm spray (WS), cold spray (CS), and high velocity air fuel (HVAF) systems (Ref 4). Although conventional HVOF and APS systems have been used to deposit nanocomposite WC-Co coatings, recent progress has introduced suspension sprayed HVOF (S-HVOF) coating systems, which can deposit nanocomposite coatings using liquid suspensions (Ref 14-16). Coating particle temperature and velocity in thermal spray systems dictate the coating microstructure and mechanical strength. Figure 1 shows the range of 
temperature and velocity of spray particles for thermal and cold spray systems (Ref 4). Thermal sprayed coatings are formed by the continuous layering of splats, and the process creates an anisotropic coating microstructure, where the mechanical properties such as fracture toughness show relatively low values parallel to the coating surface (Ref 4, 17, 18).

Ceramic carbides are often used to form wear-resistant coatings for tribological applications; whereas other ceramic oxides and nitrides are used for applications such as thermal or electrical resistance (Ref $3,12,13)$. Table 1 summarises commonly used carbides such as $\mathrm{WC}, \mathrm{Cr}_{3} \mathrm{C}_{2}$ and $\mathrm{TiC}$ for tribological applications (Ref 10). The selection of these carbides is based on their solubility and wettability in metal binders during thermal spraying. WC generally exhibits good wettability with metallic liquids, e.g., $\mathrm{Ni}$ and $\mathrm{Fe}$, but its wettability with $\mathrm{Co}$ in particular is excellent (Ref 10). Similarly, the dissolution of carbides harden the binder (Ref 3,10). WC-Co coatings are generally used for wear resistance applications up to an operating temperature of $500{ }^{\circ} \mathrm{C}$, whereas $\mathrm{Cr}_{3} \mathrm{C}_{2}$ and $\mathrm{WC}$ $\mathrm{Co}-\mathrm{Cr}$ is preferred for corrosion resistance applications (Ref 10, 19-21). WC-Co has long been used as a cemented carbide for producing wear-resistant parts, which has then been brought forward to thermal sprayed coatings (Ref $3,10)$.

\section{WC-Co Materials and Deposits}

Figure 2 illustrates applications for WC-Co cemented carbides along with their design features such as the WC carbide size, binder content and hardness (Ref 10). Thermal spray WC-Co coatings share applications in areas such as those for wear resistance (Ref 3, 4, 12, 13). Figure 3 shows a comparison of the mechanical properties of cemented WC-Co with other engineering materials that are either used as a (i) wear-resistant material, e.g., SiC, alumina and Stellites ${ }^{\mathrm{TM}}$ (typically of composition; BalanceCo, 28-32\%Cr, 4-17.5\%W, 1-3.3\%C, in weight percentages), (ii) a counter body or (iii) substrate material for coatings in sliding contacts (Ref 10). The properties presented in Fig. 3 show the high bound and low bound values of hardness, toughness, elastic modulus and compressive strength achievable for these materials. The properties of thermal spray coatings are generally towards the lower values due to their complex microstructure as summarised in Table 2 (Ref 21-44). For example, hardness values of thermal spray WC-Co coatings range from $\sim 795$ to $1568 \mathrm{HV}$ in comparison with $\sim 750$ to $2250 \mathrm{HV}$ for cemented WC-Co carbides (Fig. 3, Table 2). Similarly, the fracture toughness of thermal sprayed WC-Co varies between $\sim 1.2$ and $25 \mathrm{MPa} \mathrm{m} \mathrm{m}^{1 / 2}$ in comparison with $\sim 8$ and $30 \mathrm{MPa} \mathrm{m} \mathrm{m}^{1 / 2}$ for cemented WC-Co carbides (Fig. 3, Table 2). The elastic modulus of as-sprayed thermal spray WC-Co deposits is around one-third of the bulk material, typically around $\sim 250 \pm 50 \mathrm{GPa}(\operatorname{Ref} 14,15)$
Fig. 1 Spectrum of thermal spray and cold spray processes across particle velocity and flame temperature attainable during coating deposition (Ref 4)

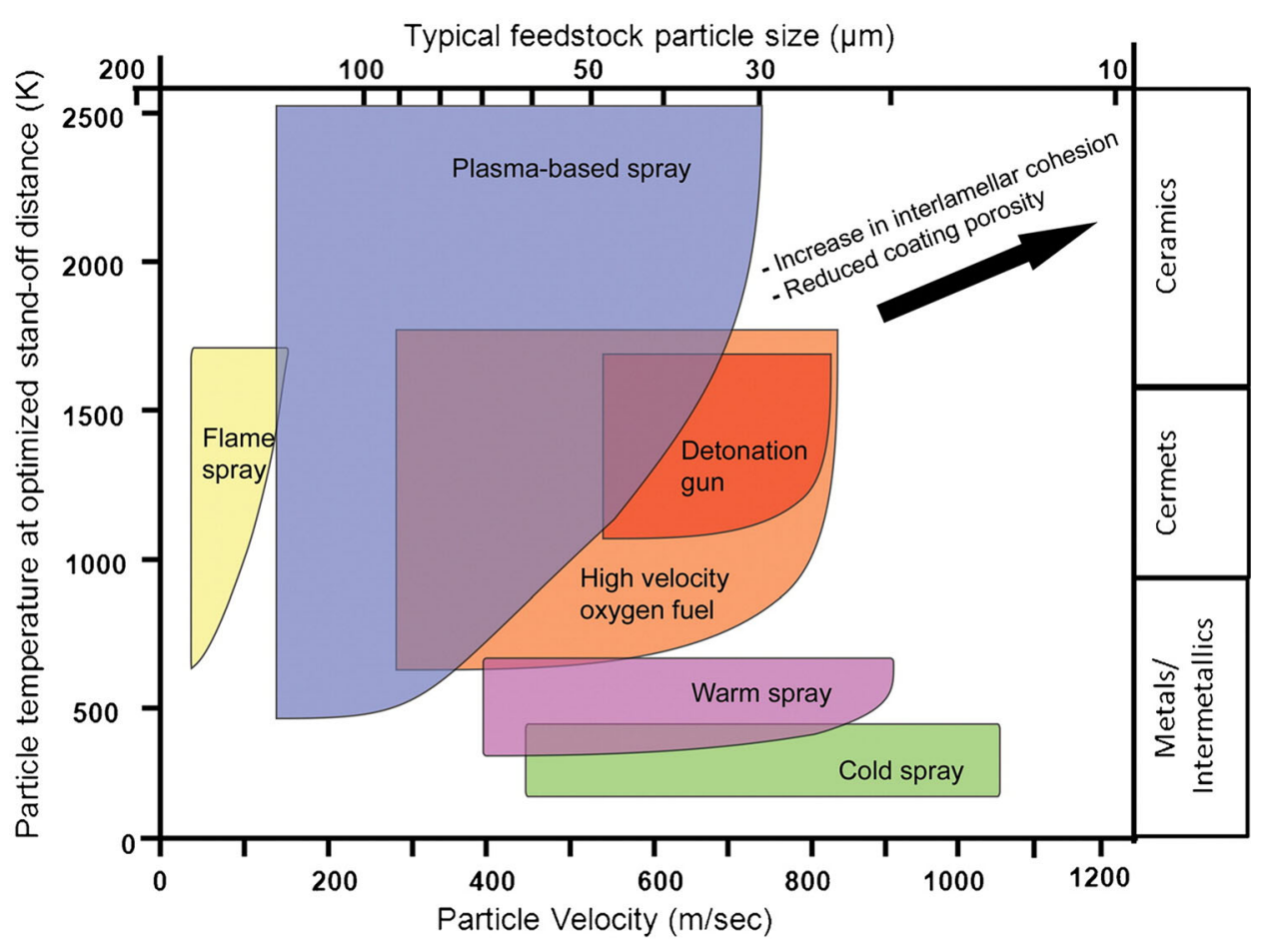




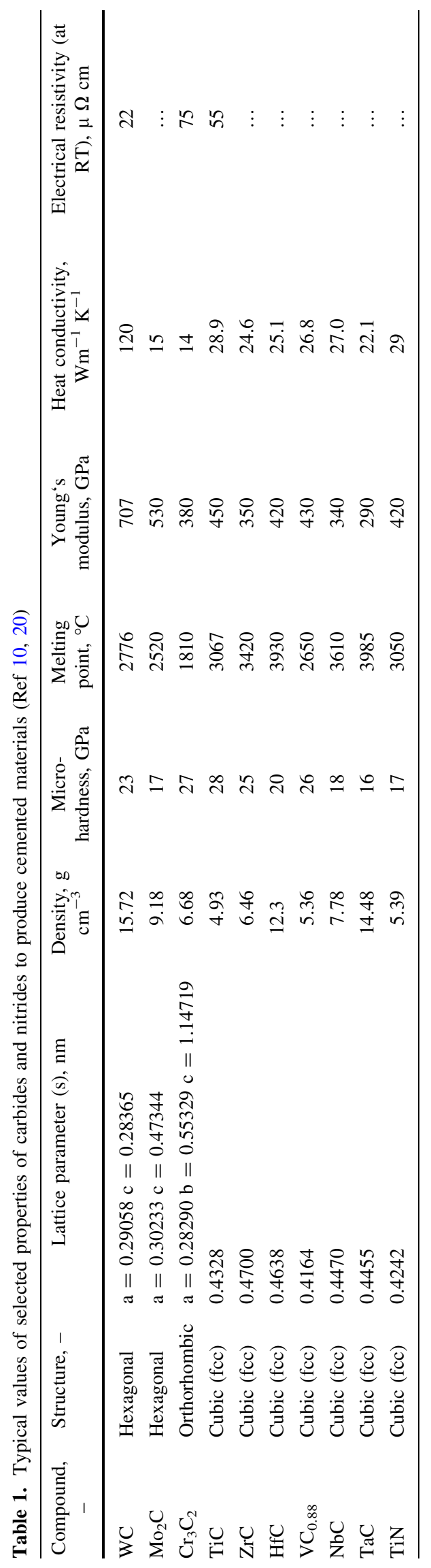

in comparison with $400-650 \mathrm{GPa}$ for cemented carbides (Ref 10).

Cobalt ( 4-17 wt.\%) is generally used with $\mathrm{WC}$ as a metal binder due to its high fracture toughness, good wettability and dry lubricating effects (Ref $3,9,10)$. The cobalt also provides a good combination of hardness and toughness for thermal spray coatings (Ref 37, 41$43,45,46)$. Other variations in binder composition with $\mathrm{Ni}$ and $\mathrm{Cr}$ allow for improved performance under high temperature and corrosive environments, respectively (Ref 47).

The sliding wear performance (Table 2) of WC-Co coatings depends on the coating process and the process parameters that dictate the microstructure and the tribological test conditions leading to differences in the wear mechanisms. Figure 4 summarises the factors that influence the sliding wear performance of these coatings in terms of the structure-property relationship and the underlying wear mechanism. The upper half of the figure shows the parameters influencing the coating microstructure and its mechanical properties, whereas the lower half summarises the tribological parameters influencing coating performance. The outer ring in this figure depicts design factors that need to be selected for a given application. The middle ring summarises the interdependency of these design factors on coating performance and highlights a complex behaviour of microstructure and tribological conditions. The central ring shows the relationship between the structure-property and the sliding wear process.

\section{Organisation of This Review}

Corrosive wear and tribo-corrosion conditions of thermal sprayed carbide coatings have been reviewed (Ref $8,37,45)$ as has the microstructural evolution of cemented carbides (Ref 10). This contribution reviews the structureproperty relationships and wear mechanisms in sliding wear of conventional and nanocomposite suspension sprayed WC-Co coatings and suggests future trends to further improve their sliding wear performance.

This review is arranged in the eight sections. "Introducion" section provides an introduction of the coating processes, whereas "Microstructure of WC-Co Coatings" section concentrates on the evolution of the WC-Co coating microstructure. "Sliding Wear Mechanisms" section relates the complexity of this microstructure to the wear mechanisms and wear rates. Comparison of failure modes of WC-Co coatings with cemented WC-Co carbides is also discussed in "Sliding Wear Mechanisms" section. The dependency of coating microstructure and mechanical properties on the prediction of wear rates is discussed in "Structure-Property Relationship in Sliding Wear" section. The influence of post-treatment on the structureproperty relationship is discussed in this 


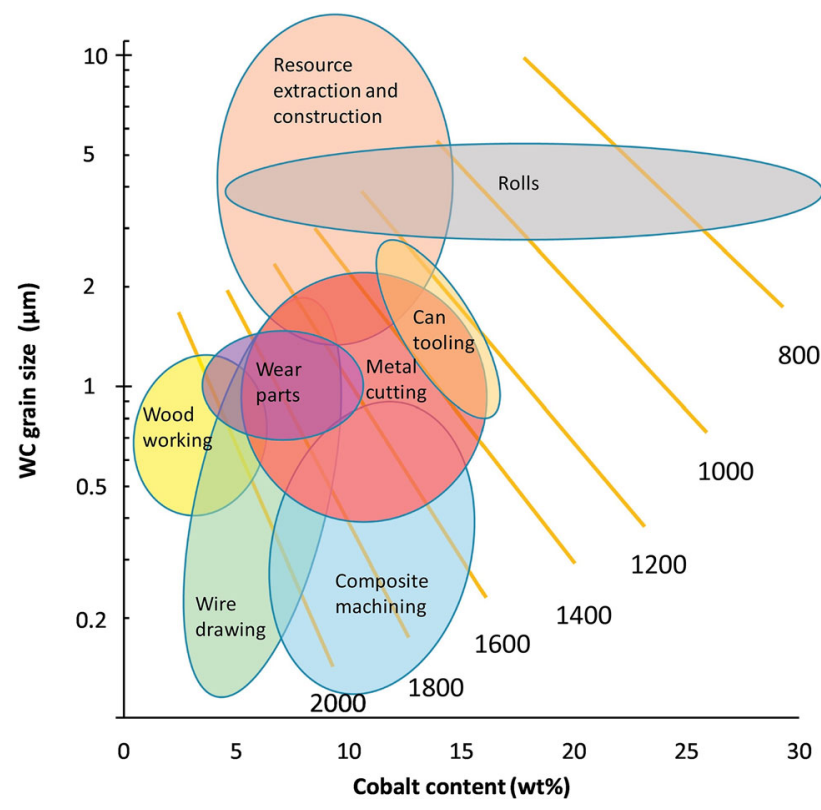

Fig. 2 Combinations of WC grain size and cobalt content in cemented carbides, showing a wide range of applications. The lines indicate values of isohardness (Vickers a.u.) (Ref 10)

section. Semiempirical mathematical relationship interlinking the wear rate with coating and counter body properties are summarised in "Semiempirical Mathematical Relationship in Sliding Wear of WC-Co Coatings" sction. Numerical modelling of wear rates is discussed in "Computational Wear Modelling". Conclusions and future recommendations are included in "Conclusion" and "Microstructural Quality and Sliding" sections, respectively. In this paper, the term wear is specifically applied to sliding wear unless otherwise stated.

\section{Microstructure of WC-Co Coatings}

\section{Distinguishing Features of Thermal Sprayed Microstructures}

The microstructure of WC-Co coatings is significantly different from cemented carbides (Ref 3, 9, 10, 16). Thermal sprayed WC-Co coatings reveal a lamella structure where the bonding mechanism is predominantly mechanical interlocks. Despite some claims of metallurgical bonding in thermal spraying process, for example, using patented technology (Ref 48) and/or using a spray and fuse technique (Ref 49), there is no evidence of metallurgical bonding for WC-Co coatings in the published literature. For the case of cold- or warm-sprayed materials in general, although there is a growing discussion of metallurgical bonding in the deposits due to adiabatic shear instabilities, which causes metallurgical bonding due to explosive cladding (Ref 50), no such metallurgical bonding in cold sprayed WC-Co has been reported (Ref 51).

Thermal spray coating microstructure contains pores and micro-cracks and exhibit anisotropy due to layering of splats during coating deposition (Ref 3-5, 17, 26, 45). Due to this complex microstructure, the mechanical properties such as hardness, modulus and fracture toughness are relatively lower than the cemented carbides (Table 2, Fig. 3). Through-thickness residual stress is caused by differences in the coefficients of thermal expansion of the coating substrate system as well as quenching of lamella particles also influence coating properties (Ref 52-55). The residual stress profile is superimposed on the mechanical and/or thermal service loading of the coated component and need to be considered when evaluating coating performance (Ref 50, 54-59).

Despite relatively lower mechanical strength than the cemented carbides (Tables 1, 2 and Fig. 3), these coatings are frequently used in tribological applications because of their ability to provide a cost-effective and environmentalfriendly solution to the design of components requiring surface engineering. Carbide size, carbon loss leading to complex microstructural phases, and microstructural features such as porosity and carbide distribution, therefore, impact the tribo-mechanical performance (Table 2) (Ref 60-63).

Figure 5 shows the typical $\mathrm{x}$-ray diffraction (XRD) pattern of WC-Co coatings deposited by conventional HVOF (JP5000 and Diamond Jet (DJ)), S-HVOF, VPS and APS coatings (Ref 15, 16, 21, 22). This figure also shows the typical XRD pattern for cemented WC-Co carbides (Ref 8). Figure 6 shows the SEM and TEM images of the deposited coatings (Ref 14-16, 21). This figure shows that in conventional HVOF spraying with liquid fuel HVOF systems such as JP5000, most of the WC phase is retained as blocky carbides from the starting powder (Fig. 6c and d). A comparison of the typical microstructure for cemented WC-Co carbides is shown in Figure 6(i) and (j) $(\operatorname{Ref} 8,10)$.

\section{Impact of Decarburisation of WC During Thermal Spray Processing}

As shown in Fig. 1, particle velocity and temperature in thermal processes vary for different spray systems (Ref 4). The oxygen atmosphere in HVOF systems can, however, promote oxidation reactions (Ref 64). HVOF systems are, therefore, preferred over the air plasma spray systems (APS) due to their ability to deposit coating material at a relatively lower temperature and higher velocity (Ref $4,60,64)$. Nevertheless, decarburisation of $\mathrm{WC}$ leading to $\mathrm{W}_{2} \mathrm{C}, \mathrm{W}$ and eta-phases (' $\eta$-phases') such as $\mathrm{Co}_{3} \mathrm{~W}_{3} \mathrm{C}$, $\mathrm{Co}_{2} \mathrm{~W}_{4} \mathrm{C}\left(\mathrm{M}_{6} \mathrm{C}\right)$ and $\mathrm{Co}_{6} \mathrm{~W}_{6} \mathrm{C}\left(\mathrm{M}_{12} \mathrm{C}\right)$ can occur, depending upon the coating process and the process parameters (Ref 

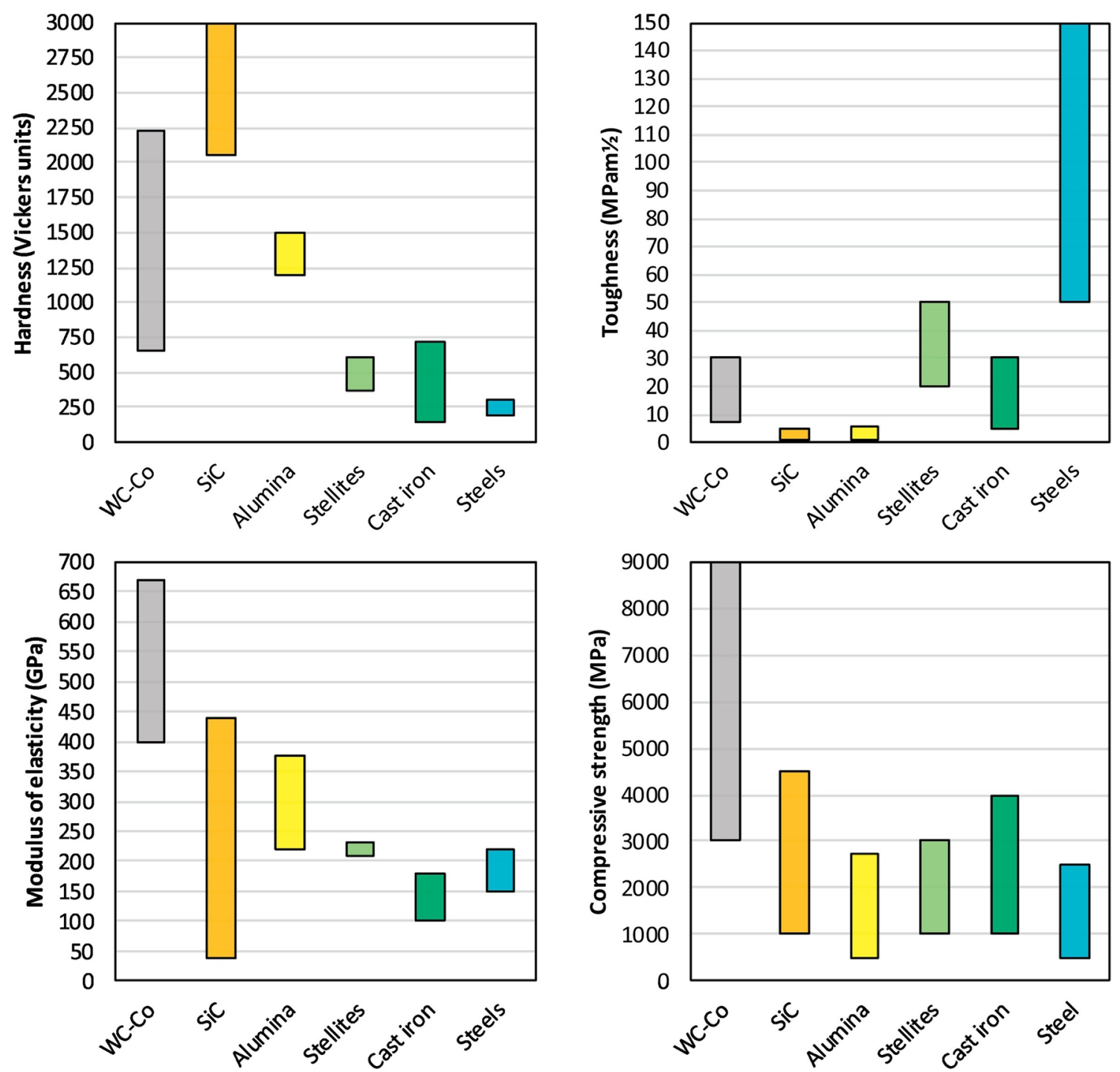

Fig. 3 Typical property ranges of different materials in comparison with cemented carbide (Ref 10)

$14,15,64,65)$. Several studies have linked the formation of eta-phases with three reactions shown in Eq 1 to 3 (Ref 19, 33, 64, 65).

$$
\begin{aligned}
& 2 \mathrm{WC}+\mathrm{O}_{2} \rightarrow \mathrm{W}_{2} \mathrm{C}+\mathrm{CO}_{2} \\
& \mathrm{~W}_{2} \mathrm{C}+1 / 2 \mathrm{O}_{2} \rightarrow \mathrm{W}_{2}(\mathrm{C}, \mathrm{O}) \\
& \mathrm{W}_{2}(\mathrm{C}, \mathrm{O}) \rightarrow 2 \mathrm{~W}+\mathrm{CO}
\end{aligned}
$$

The decarburised $\mathrm{W}_{2} \mathrm{C}$ phase formed from reaction shown in $\mathrm{Eq} 1$ is precipitated along the WC grain boundary, together with a ring of metallic $\mathrm{W}$ between the WC grain and $\mathrm{W}_{2} \mathrm{C}$ (Ref 19) formed by reactions shown in Eq 2 and 3. These reactions take place mainly in $\mathrm{WC}$ grains that interact with oxygen (Eq 1,2, and 3). In addition, WC grains can be degraded in an oxygen-free atmosphere (i.e., those that are in the core of the particles), according to Eq 4 (Ref 33).
$2 \mathrm{WC} \rightarrow \mathrm{W}_{2} \mathrm{C}+\mathrm{C}$

(Eq 4)

Hence $\mathrm{W}_{2} \mathrm{C}$ can be formed in oxygen-rich and oxygenfree atmosphere (Ref 33$)$. Based on the degree of decarburisation, the precipitation of eta-phases has been suggested to take place as follows (Ref 33, 65):

$$
\begin{aligned}
& 4 \mathrm{Co}+4 \mathrm{WC}+\mathrm{O}_{2} \leftrightarrow 2 \mathrm{Co}_{2} \mathrm{~W}_{4} \mathrm{C}+2 \mathrm{CO} \\
& 3 \mathrm{CO}+3 \mathrm{WC}+\mathrm{O}_{2} \leftrightarrow \mathrm{Co}_{3} \mathrm{~W}_{3} \mathrm{C}+2 \mathrm{CO} \\
& 12 \mathrm{Co}+12 \mathrm{WC}+5 \mathrm{O}_{2} \leftrightarrow 2 \mathrm{Co}_{6} \mathrm{~W}_{6} \mathrm{C}+10 \mathrm{CO}
\end{aligned}
$$

Both $\mathrm{W}_{2} \mathrm{C}$ and metallic tungsten are often detected in conventional as-sprayed WC-Co coatings (Ref 22), including the early studies of Verdon et al. (Ref 61) and Stewart et al. (Ref 62). These studies (Ref 61, 62) investigated the formation of WC-Co coatings with HVOF spray processes using both conventional and nanostructured agglomerated and sintered feedstock powders. Stewart 


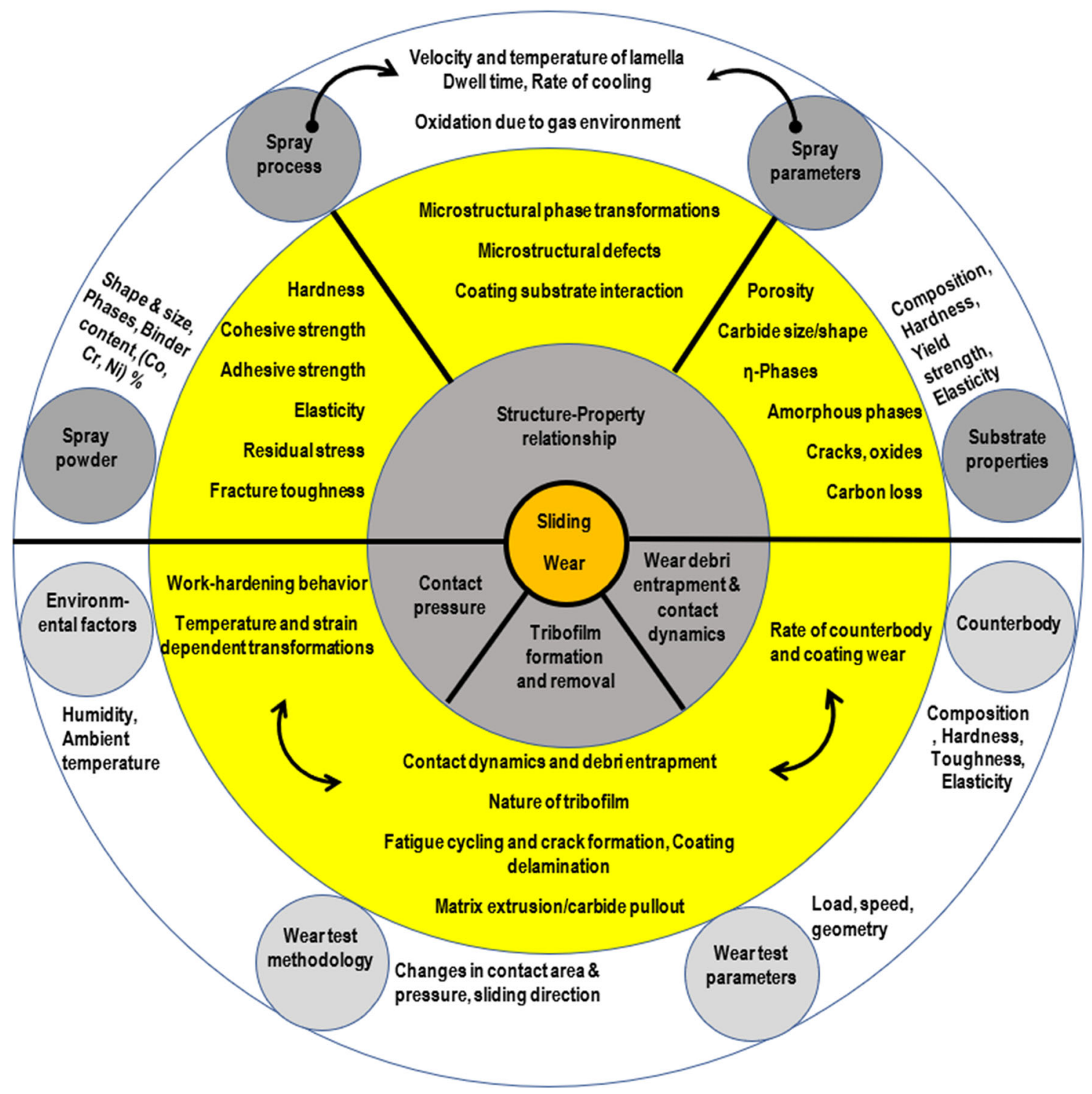

Fig. 4 Factors influencing the dry sliding wear of WC-based thermal spray coatings

et al. (Ref 62) have shown that the formation of metallic tungsten depends on the carbide grain size. Figure 5(b) shows that in conventional HVOF spraying there is limited decarburisation of WC leading to the peak broadening in the 2 -theta range of $35^{\circ}-48^{\circ}$ containing predominantly an amorphous/nanocrystalline phase and the formation of $\mathrm{W}_{2} \mathrm{C}$ and $\mathrm{Co}_{3} \mathrm{~W}_{3} \mathrm{C}$ (Ref 14).

The extent of carbon loss depends on the spray system and conditions, for instance, when conventional coatings are sprayed with excess oxygen in the case of detonation gun spraying (DGS) (Ref 63) or coatings prepared from strongly carbon-deficient powders (Ref 66). The increase in carbon loss also leads to peak broadening in the 2-theta range of $35^{\circ}-48^{\circ}$ (Ref 14,15$)$. In the case of the APS process, the higher particle temperature and lower velocity leads to higher dwell time that results in (i) higher decarburisation due to thermal loading of powder particles and (ii) higher porosity due to lower velocity. These effects are observed in Figure 5(d), where both conventional and nanostructured powders show decarburisation when sprayed with hydrogen or helium (Ref 21). APS processing (Ref 21) with hydrogen leads to relatively higher decarburisation for both conventional and nanostructured coatings, which is caused by a higher enthalpy. APS coatings also show high porosity of up to $\sim 10 \%$ (Ref 21,60$)$.

The lower velocity in some HVOF systems can also lead to porosity, as shown in Figure 6(d), due to either an earlier generation HVOF system or HVOF spraying under nonoptimised spray conditions (Ref 14, 60). Higher velocity in the later generation HVOF spraying not only reduces the 


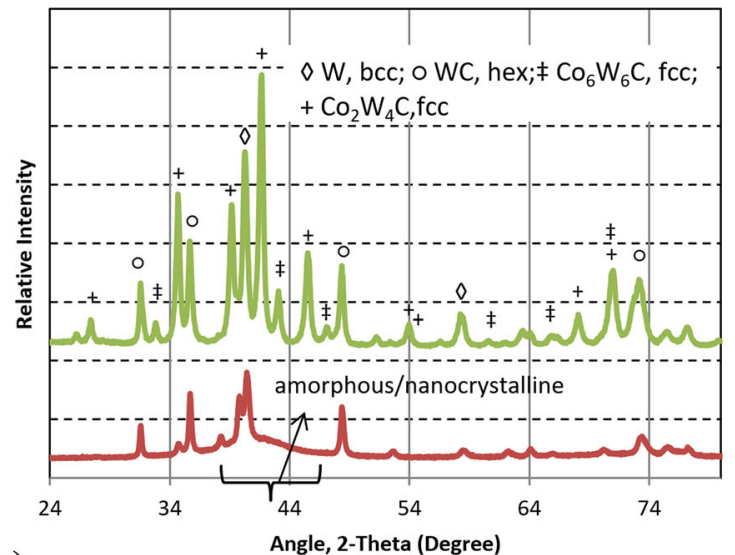

(a)

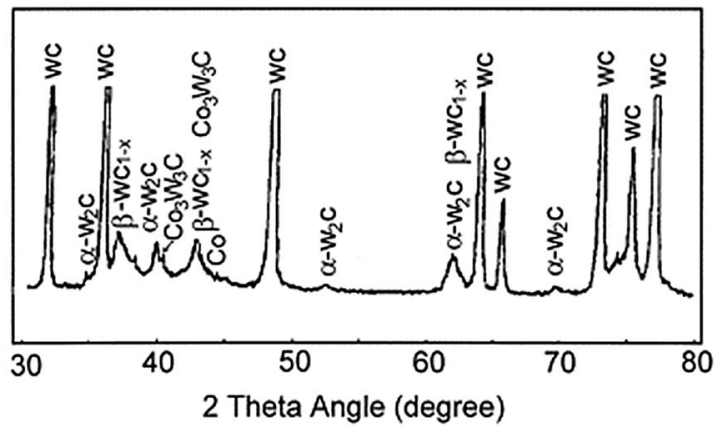

(c)

S-HVOF

(HIPed)

S-HVOF

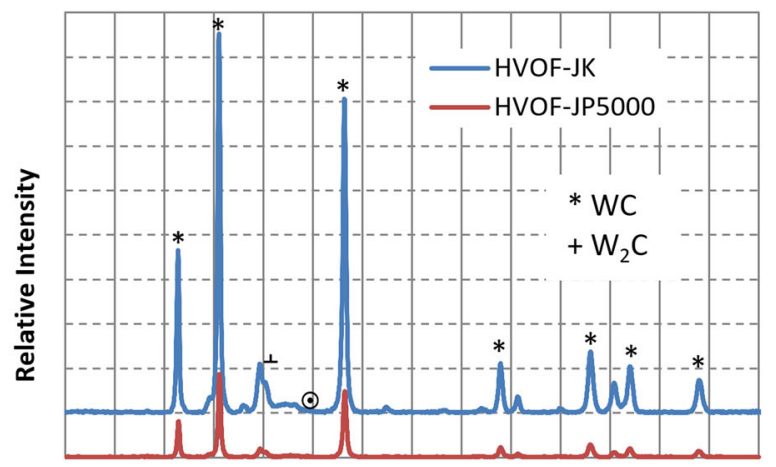

$\begin{array}{lllllllllllllll}20 & 25 & 30 & 35 & 40 & 45 & 50 & 55 & 60 & 65 & 70 & 75 & 80 & 85 & 90\end{array}$ Angle, 2-Theta (Degree)

(b)

(d)

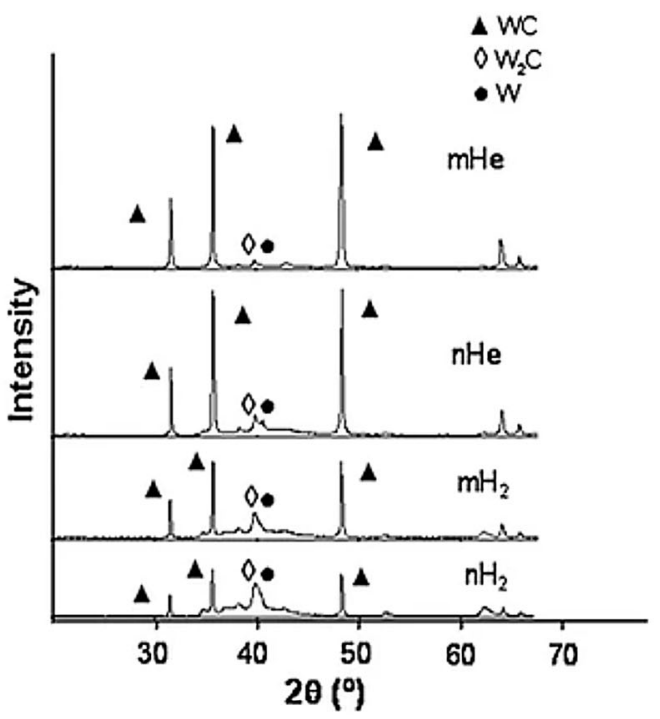

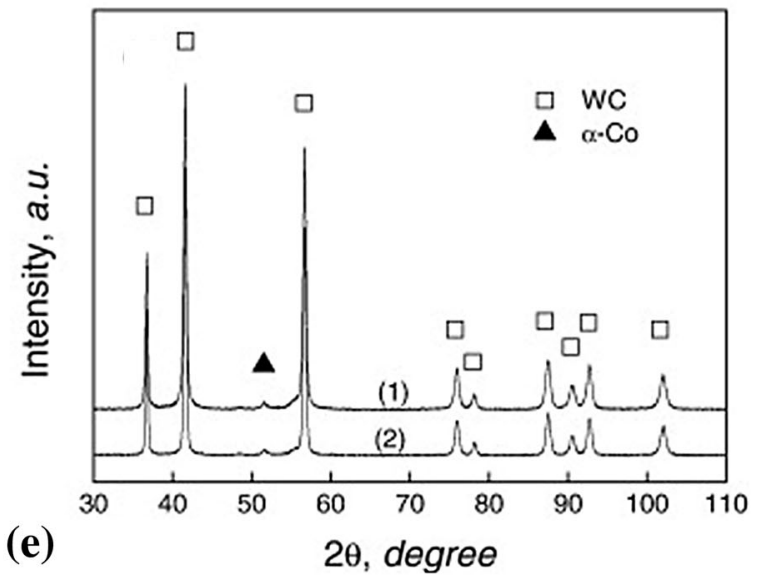

Fig. 5 XRD analysis of (a) S-HVOF and S-HVOF-HIPed (Ref 15), (b) HVOF-JP5000 and HVOF-JK coatings (Ref 16), (c) vacuum plasma-sprayed nanostructured WC-9Co coatings with $35 \mathrm{~nm}$ carbide size (Ref 22), (d) XRD scans for coatings sprayed using conventional powder (15-45 $\mu \mathrm{m}$ size) and hydrogen (mH2), helium (mHe), nanostructured powder $(5-45 \mu \mathrm{m}$ size) and hydrogen $(\mathrm{nH} 2)$, and helium (nHe) spraying (Ref 21), (e) cemented WC-12Co carbide where spectra 1 is for conventional carbide and spectra 2 is for after deep cryogenic treatment (DCT) for improved wear resistance (Ref 8) 
dwell time but also increases the beneficial peening effect that leads to compressive residual stress in the deposit and increases coating density (Ref 52, 53, 56, 57).

VPS coatings should show a lower tendency of decarburisation due to the absence of oxygen in the system. However, as shown in Figure 5c, when nanostructured powders are VPS processed there is formation of eta-phases $\left(\mathrm{M}_{2} \mathrm{C}, \mathrm{M}_{6} \mathrm{C}\right)$ associated with the decarburisation of the WC particles (Ref 22). This suggests that small amounts of oxygen during VPS spraying, in conjunction with the high temperature of the plasma system, can also lead to decarburisation (Eq 1 to 4). Zhu et al. (Ref 22) concluded that the extent of decarburisation was relatively low when compared to studies reported by Stewart et al. that used a HVOF top gun system (Ref 62). However, even with the VPS systems, the decarburisation of HVOF nanostructured coatings cannot be avoided. This stipulates that the higher particle temperature has a more dominant effect on carbon loss in WC-Co coatings instead of the available oxygen content around the powder particles. Some studies (Ref $33,65,67-69$ ) have reported that the carbon loss leads to the formation of $\mathrm{CO}_{2}$ during spraying; however, these reactions require careful interpretation in oxygen-deficient environments such as for the VPS process. The reactions in the W-C-Co phase system have been studied intensely by Matthews et al. (Ref 65).

The production of nanostructured layers is also possible with nanostructured powder feedstock (Ref 32, 34-36, 70). Suspension HVOF (S-HVOF) systems deposit nanostructured coatings using nanopowder suspensions (Ref 14, 16, 20, 71, 72). Nanoparticles cannot be injected directly in HVOF systems; instead, they are suspended in a liquid suspension such as water or ethanol and a dispersant such as polyethyleneimine is added for HVOF spraying (Ref 14-16, 71, 73). A stable suspension of nanoparticles is needed to deposit reproducible coatings (Ref 14). Due to the high surface area-to-volume ratio of the nanosized particles, thermal loading of WC-Co particles in S-HVOF spraying can lead to carbon loss. WC-Co suspensions pose additional challenges; for example, the surface of WC is acidic and that of $\mathrm{Co}(\mathrm{CoO})$ is basic in nature (Ref $14,73,74)$, which influences both the stability and $\mathrm{pH}$ value of the suspension due to Co dissolution. This difference in the acidic and alkaline nature can, however, be avoided by employing a preformed WC-Co composite powder (Ref 14, 16).

Berghaus et al. (Ref 73) studied the development of WC-12Co nanocomposite coatings by suspension spraying using a commercial APS (AXIAL III, Northwest Mettech Corp., Canada) process with an internal injection module that allowed in-flight particle velocities up to $800 \mathrm{~m} / \mathrm{s}$ at particle temperatures up to $\sim 2400{ }^{\circ} \mathrm{C}$. Coatings were prepared mostly from an agglomerated powder (60-250 nm nominal carbide grain size and particle sizes $<20 \mu \mathrm{m}$ ) in a 20 wt. \% ethanol suspension. Coatings with low porosity were produced with a maximum hardness of about 700 HV0.3. It was concluded that the relatively lower coating hardness was a function of both the coating porosity and carbide degradation caused by carbon loss (Ref 73). These coatings showed a pronounced amorphous "hump" in the XRD pattern due to decarburisation (Ref 73).

In summary, thermal loading of WC particles tends to increase carbon loss leading to $\mathrm{M}_{2} \mathrm{C}, \mathrm{M}_{6} \mathrm{C}, \mathrm{M}_{12} \mathrm{C}$ phases along with metallic W (Ref 14, 17, 64). Thermal loading of particles is influenced by the temperature and velocity of the particles that depend on the coating process and the process parameters (Fig. 1), along with the surface area to volume ratio of carbides. In the case of suspension spraying, the carbon loss can be reduced by (i) changing the coating process from APS to HVOF, (ii) optimising the suspension parameters by using water instead of ethanol as suspension media to decrease the process temperatures during spraying, (iii) optimising the concentration of powder particles in the suspension, and (iv) optimising the spray parameters (Ref 14, 16, 73). Heat treatment of WCCo coatings can lead to the transformation of the amorphous phases and also improve the mechanical strength as seen later in "Structure-Property Relationship in Sliding Wear" section (Ref 15).

\section{Eta-Phase Generation}

Studies by Ahmed et al. (Ref 14-16) employed a HVOF system to reduce the thermal loading on particles and increase particle velocity to deposit dense S-HVOF coatings (Fig. 6a and b). The lamella structure in the S-HVOF coatings is finer, Fig. 6. TEM images in Figure 6 (e) and (f) show a uniform distribution of nanosized particles within the S-HVOF microstructure. Figure 5(a) shows that decarburisation still occurs in the S-HVOF spraying as indicated by the hump in the 2-theta range of $35^{\circ}-48^{\circ}$ (Ref 16). The amorphous and the nanocrystalline phases can be crystallised through heat treatment at $920{ }^{\circ} \mathrm{C}$ into $\mathrm{M}_{6} \mathrm{C}$ and $\mathrm{M}_{12} \mathrm{C}$ (Ref 15).

Figure 7 shows the phase composition and amounts of equilibrium phases along the path of carbon loss in the phase diagram (Ref 15). This figure stipulates that as the carbon loss increases during S-HVOF spraying, there is an increase in eta-phases from $\mathrm{M}_{6} \mathrm{C}$ to $\mathrm{M}_{12} \mathrm{C}$ after heat treatment. $\mathrm{M}_{12} \mathrm{C}$ appears twice in this equilibrium diagram, once with the relatively lower carbon loss and then with higher carbon loss. Metallic $\mathrm{W}$ also appears as a stable phase at higher carbon loss as an equilibrium phase (Ref 15). $\mathrm{W}_{2} \mathrm{C}$ is not a stable microstructural phase at this temperature and hence also does not appear in the XRD 

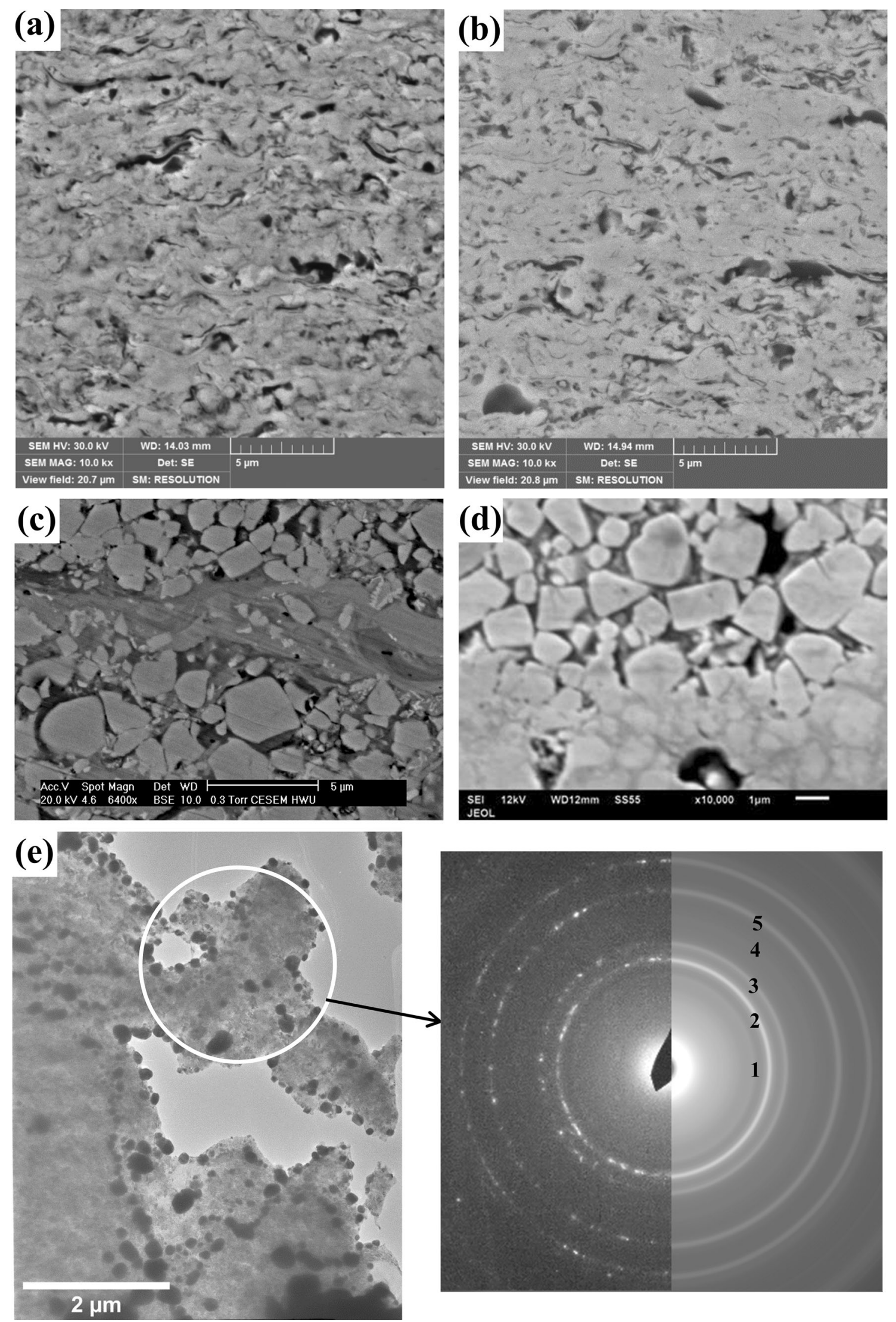
4Fig. 6 SEM observations of the coating microstructure for (a) S-HVOF (Ref 15), (b) S-HVOF-HIP (Ref 15), (c) HVOFJP5000 (Ref 16), (d) HVOF-JK coatings (Ref 14), (e, f) TEM images of S-HVOF coatings (Ref 14); FESEM micrographs showing high magnifications microstructures of dispersions of WC crystals found in (g) conventional APS coating and (h) nanostructured APS WC-12Co coatings (Ref 21), (i) SEM image of platelet WC-Co cemented carbides (Ref 10), (j) SEM image of conventional WC-Co cemented carbides (Ref 8). Experimental d-spacing measured from the TEM different rings and theoretical d-spacing for some possible phases in (Fig. 6e) are shown in Table 3

pattern (Fig. 5a, 7). However, there is crystallisation of amorphous/nanostructured phases and better inter-splat bonding as indicated by the indentation modulus analysis after the heat treatment (Ref 15).

Eta-phases (' $\eta$-phases') can also occur in cemented carbides, and steps are taken to prevent such phase transformation (Ref 10). Garcia et al. (Ref 10) described that gettering of oxygen by inhibitors prevent decarburisation of $\mathrm{WC}$ and the formation of pure $\mathrm{W}$ during the consolidation and densification stages of sintering $\mathrm{WC}-\mathrm{Co}-\mathrm{Cr} / \mathrm{V}$ cemented carbides. The inhibitors are added as carbides and may thus act as a carbon source. Eta-phases, however, are sometimes also intentionally integrated within the cemented carbide microstructure. For example, decarburized cemented carbides containing eta-phase in the microstructure are used to moderate property gradients in cemented carbides (Ref 10).

It is informative to contrast the microstructures of cemented WC-Co carbides with those formed by thermal spray methods. The eta-phases of cemented WC-Co carbides are controlled during the manufacturing process to provide $\mathrm{WC}$ and $\mathrm{Co}$ as the only crystalline phases (Fig. 5e and $6 \mathrm{i}, \mathrm{j}$ ) (Ref 8,10$)$. These cemented carbides are produced using degassing and HIPing (hot isostatic pressing) cycles around $1400-1500{ }^{\circ} \mathrm{C}$. Figure $8(\mathrm{a})$ reveals the microstructural evolution during HIPing of cemented WCCo carbides (Ref 10). Grain growth and densification occur between 800 and $1190{ }^{\circ} \mathrm{C}$. This provides critical understanding concerning the microstructural evolution during the HIPing post-treatment of thermal spray coatings; for example (Ref 15) at a HIPing temperature of $920^{\circ} \mathrm{C}$.

The carbon loss that can occur during thermal spraying restricts grain growth due to existing eta-phases as indicated in Fig. 7 (Ref 15). Additional factors dictate the microstructure for heat-treated thermal spray WC-Co coatings as shown in Figure 8(b) (Ref 75). In this instance, Co diffuses across the coating substrate interface from the coating, whereas $\mathrm{Fe}$ diffuses across this interface from the steel substrate (Ref 75). The mechanism of diffusion is illustrated in Fig. 8(c) and discussed by Stoica (Ref 75). A similar diffusion mechanism of elemental species during
HIP treatment of WC-NiCrBSi coatings is discussed by Stewart (Ref 76). These microstructural changes also influence the hardness, modulus and residual stress profile in heat-treated WC-Co coatings (Ref 75, 76).

During sintering of cemented carbides at temperatures higher than $1190{ }^{\circ} \mathrm{C}$, viscous flow densification, liquid phase sintering and particle rearrangement occurs up to $1400{ }^{\circ} \mathrm{C}$ (Fig. 8a) (Ref 10). Eta-phases can also form during the manufacturing of cemented WC-Co carbides and result in reduced toughness (Ref 10). The control of eta-phases is not a function of temperature in cemented carbides because the temperature is tightly controlled between 1400 and $1500{ }^{\circ} \mathrm{C}$. This is unlike thermal spray coatings where the thermal loading of particles (Fig. 1) plays a dominant role in carbon loss. Instead, the control of eta-phases in cemented WC-Co carbides requires tight control of the carbon content, typically in the range of 0.05 wt.\%. If the carbon content is lower than the ideal ratio [C]/ $[\mathrm{W}]=1$, eta-phases are formed (Ref 10). When the carbon content is higher than this ideal ratio in cemented carbides, free carbon may precipitate as graphite and lower the mechanical properties. Garcia et al. (Ref 10) also indicated that the solubility of $\mathrm{W}$ in liquid Co decreases with increasing carbon activity.

\section{Mitigating Decarburisation During Thermal Spraying}

There are various methods for limiting the decarburisation of WC-Co coatings to improve wear performance. One method is to control the spray parameters, but this requires measurements of particle velocity and temperature and design of experiments that account for carbide sizes, spray particle morphology, fuel/plasma gas chemistry, environmental factors, etc. [see (Ref 43, 44)]. Developments in this area include automated feedback control systems to alter coating process parameters and can further improve the reproducibility of coated components. In suspension spraying, liquid suspensions can reduce the thermal loading of WC particles (Ref 14, 16). Another method of limiting decarburisation is to engineer the powder particles to reduce the thermal loading of carbides through cladding; for example by having the carbides concentrated in the core and the binder/protective coating on the outer shell (Ref 77, 78).

One method used by Jafari et al. milled powder of conventional carbide grain size (CGS) to nano-dimensions, which was then electroplated with nickel (Ref 38). The powder was then spray-dried and agglomerated (Ref 38 ). Three coatings were prepared with the conventional, nanostructured and engineering feedstock for wear testing. The same spray parameters were maintained for all the feedstocks, whereas it is common practise that each 

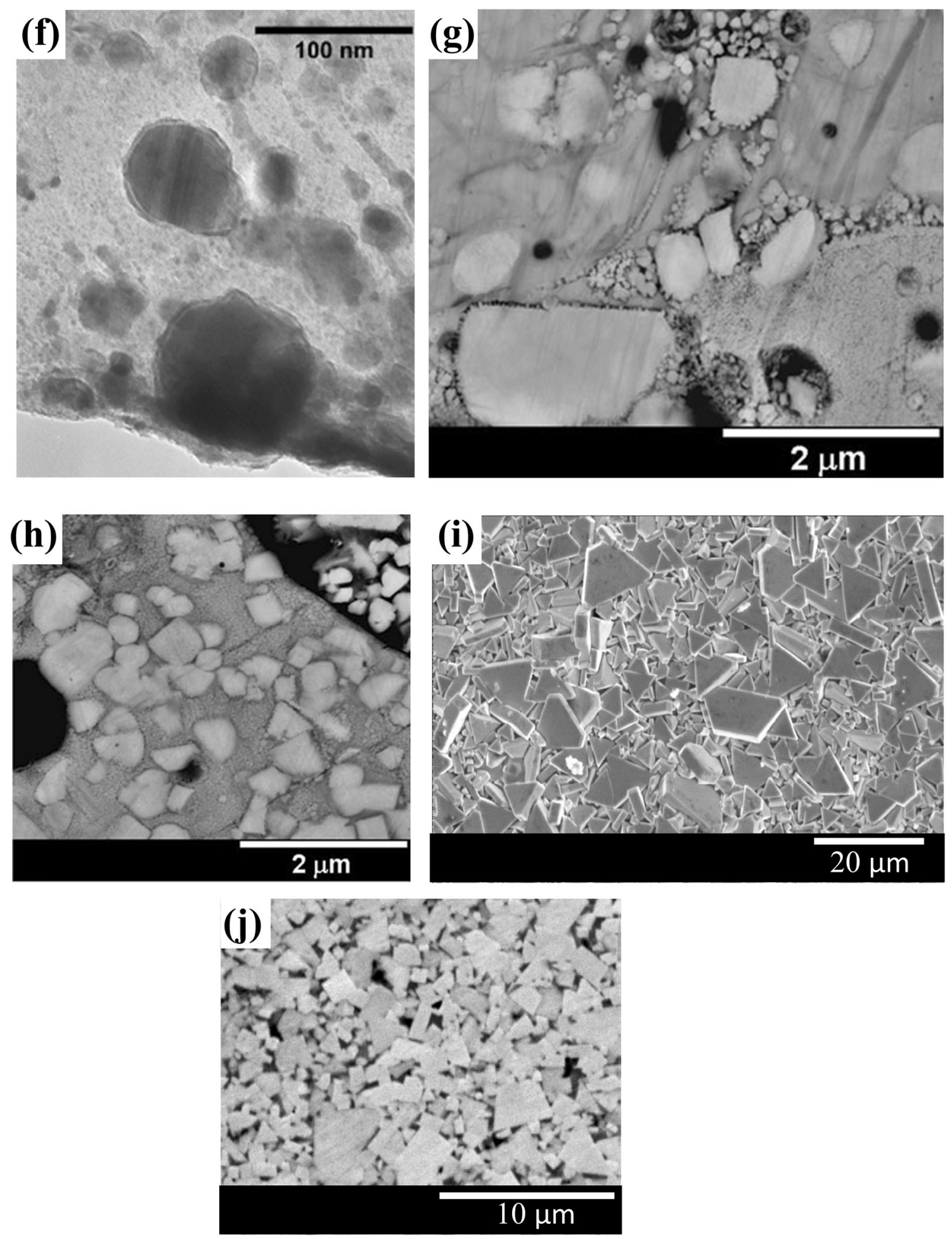

Fig. 6 continued

feedstock would need to be optimised. Nevertheless, the microstructural observations indicated that the conventional coating exhibited some carbide dissolution, whereas the uncoated nanostructured coating revealed extensive decarburisation that led to dissolution into the binder (Ref
38). On the other hand, the nickel-coated nanostructured coating showed no evidence of dissolution into the binder. The best wear performance was achieved for the nickelcoated nanostructured coating, which was followed by the conventional and then the nanostructured coating (Ref 38$)$. 
Fig. 7 (a) Calculated isothermal section of the WCCo-C phase diagram at $1000{ }^{\circ} \mathrm{C}$. Path of decreasing carbon content starting from composition WC-12\%Co. (b) Phase composition and amounts of equilibrium phases along the path of carbon loss at $1000{ }^{\circ} \mathrm{C}(\operatorname{Ref} 15)$

(a)
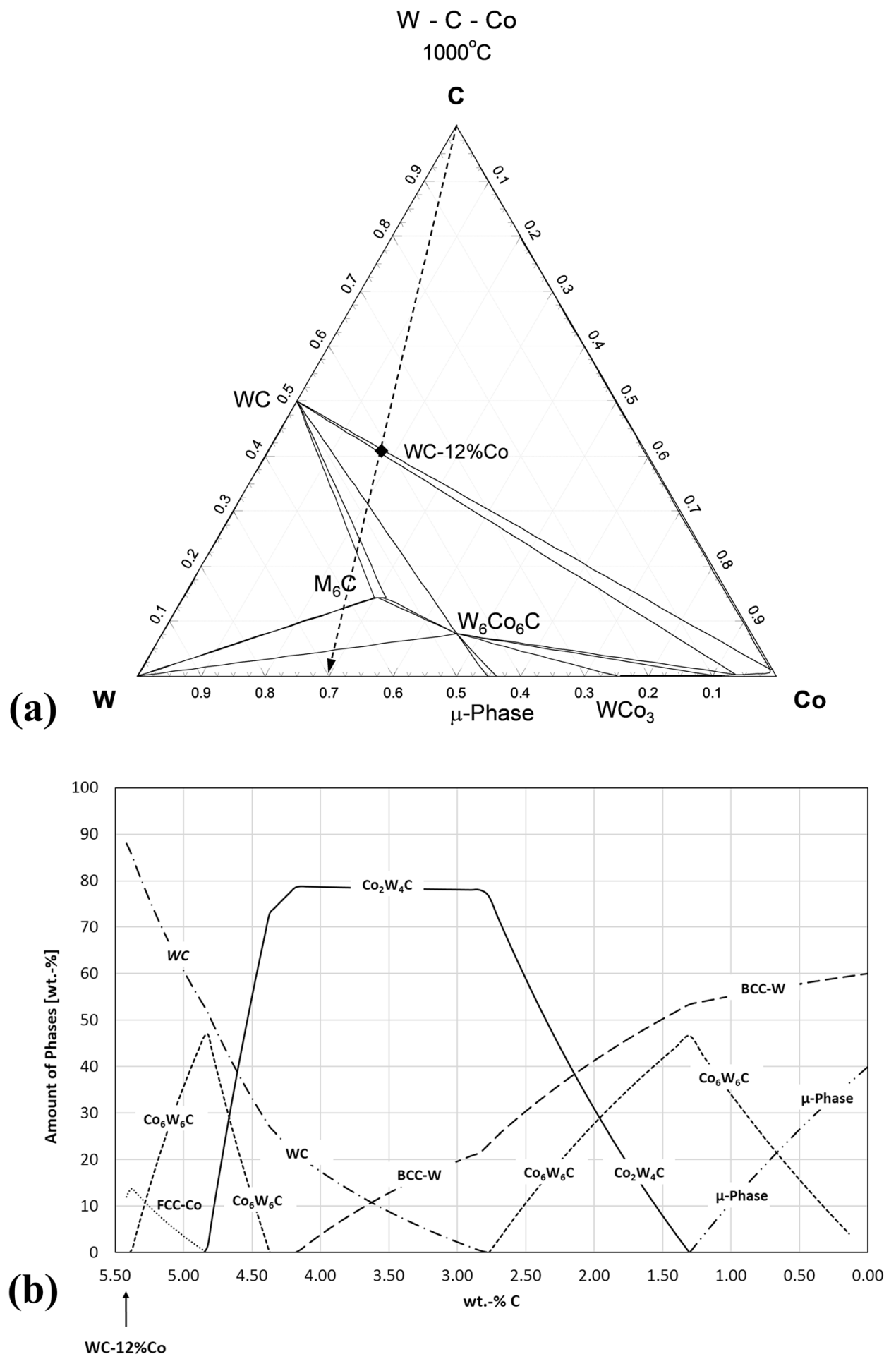

The wear mechanisms of the conventional coating incorporated the formation of tribo-films, subsurface cracking of splats and then delamination. The wear of nickel-coated nanostructured coating was mainly comprised of binder extrusion followed by carbide pull out.
Engineered particles also improve wear as a by-product of enhanced mechanical properties at inter-splat boundaries. Yuan et al. blended submicron WC particles $(\sim 300$ $\mathrm{nm}$ ) with conventional WC-12Co feedstock to coat AISI 304 steel substrate (Ref 79). The wear performance was controlled mainly by the formation of brittle phases, pores 

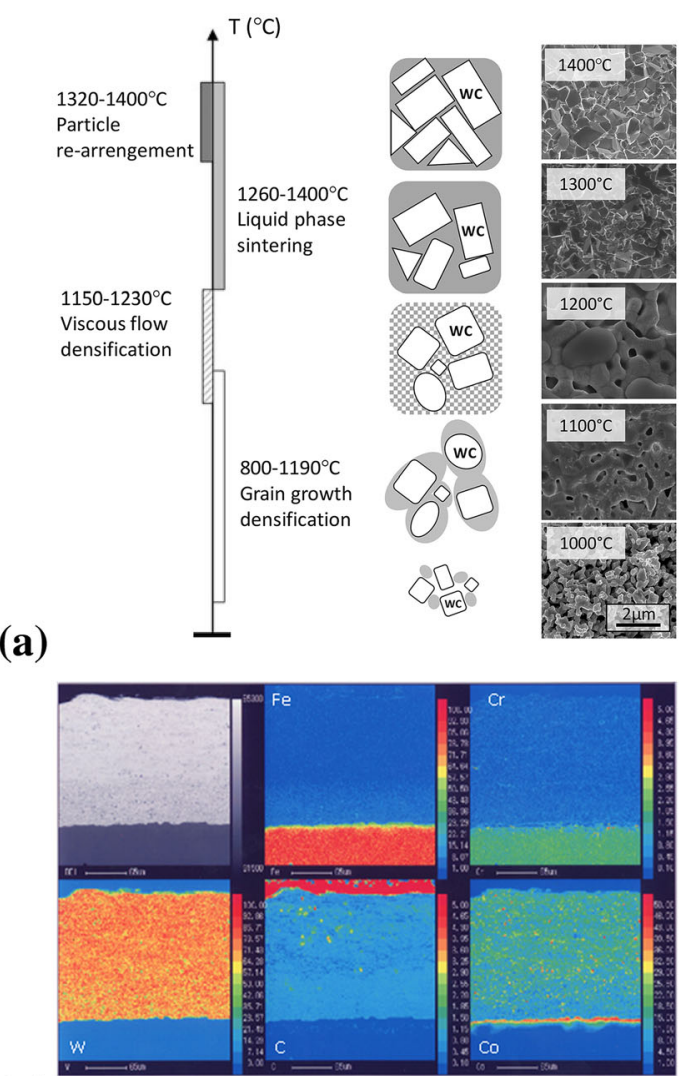

(b)

(c)

Fig. 8 (a) Temperature ranges for densification stages, together with a schematic description of microstructure evolution and corresponding fracture SEM images during sintering of WC-Co cemented carbide (Ref 10), (b) EPMA investigation on the WC-Co coating

and cracks. These microstructural features preferentially originate and propagate along the interfaces between brittle and softer zones in the coating structure. The WC particles reinforced the splat boundaries; therefore, mitigating crack propagation under splats and reducing splat delamination. This reinforcement also increased the sliding wear resistance of the coating (Ref 79).

The cladding of particles to mitigate carbon loss and improve coating strength has improved wear performance when compared to conventionally produced particles (Ref 79). However, the additional particle technology and cost of modifying the particles has restricted widespread use. Several patents have considered the cladding of coating particles to improve the coating microstructure for several applications (Ref 77, 78). These patents exploit techniques such as plating, physical vapour deposition (PVD) and chemical vapour deposition (CVD) to protect the coating particle during thermal spraying. In the case of CVD and PVD coatings, several cladding materials are possible; for example, coating of hydroxyapatite with titanium (Ref 78). Cladding with alloys such as Ti6Al4V using these processes is difficult since the deposition of elemental species
HIPed at $1000{ }^{\circ} \mathrm{C}(\operatorname{Ref} 75)$, (c) Stages of diffusion layer formation at the coating substrate interface for WC-Co coatings on steel substrate during HIPing post-treatment at $1200{ }^{\circ} \mathrm{C}(\operatorname{Ref} 75)$

cannot be controlled precisely to form the specific alloy through CVD and PVD processes.

Another approach to mitigate carbon loss in WC-Co coatings was proposed by Matthews et al. (Ref 65). A combination of powder design, spray parameters and subsequent heat treatment of coatings was employed to minimise the carbon loss in WC-Co coatings. This approach is based on the tendency for carbides to dissolve in-flight and for precipitation of submicron carbide particles on subsequent heat treatment (Ref 65$)$. Similar concepts have been applied to $\mathrm{Cr}_{3} \mathrm{C}_{2}-\mathrm{NiCr}$ coatings to take advantage of the tendency for $\mathrm{Cr}_{3} \mathrm{C}_{2}$ carbides to dissolve into the molten $\mathrm{NiCr}$ binder and maximise carbide dissolution (Ref 80 ). Post-coating heat treatment is then employed to precipitate the dissolved elements out of solid solution to re-form the initial carbide particles. The time and temperature is used to control the extent of grain growth to form unique microstructures that range from high concentrations of nanostructured particles, through to complex interconnected carbide networks (Ref 65). 
(a)

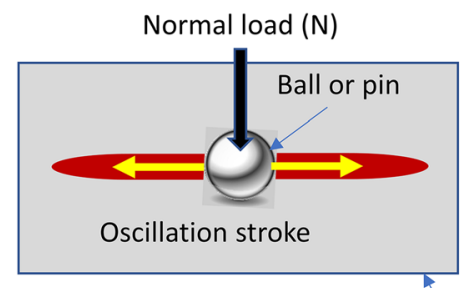

Normal load (N)

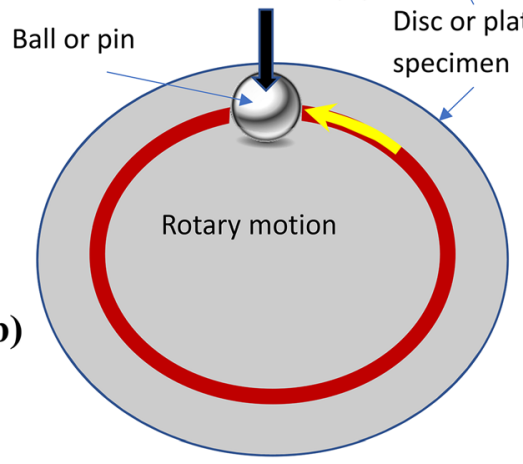

Normal load (N)

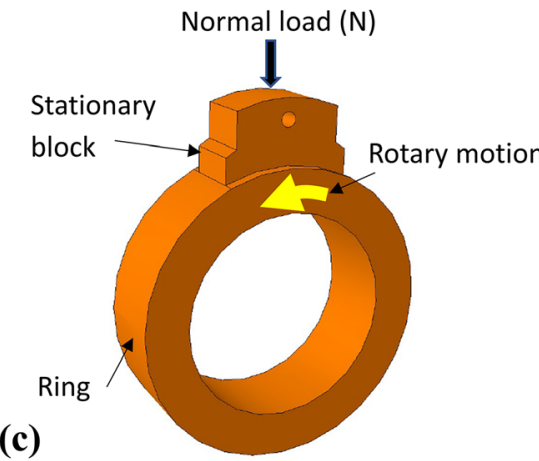

ASTM G 77

Block-on-Ring Test

Fig. 9 Schematic of ASTM test methods for sliding wear, (a) ASTM G133 (Ref 81), (b) ASTM G99 (Ref 82), (c) ASTM G77 (Ref 83)

\section{Sliding Wear Mechanisms}

The complex interdependencies of wear mechanisms must be understood to predict the sliding wear performance of coatings (Fig. 4). The cost of coating development can be significantly reduced using standard tests that evaluate the failure modes and sliding wear rate of coatings. There are three principal tests that assess sliding wear, i.e., ASTM G133 (ball-on-flat) (Ref 81), ASTM G99 (pin-on-disc) (Ref 82) and ASTM G77 (block-on-ring) (Ref 83), which are used either independently or in combination to evaluate the coating performance. As shown in Figure 9, the ASTM G133 (Ref 81) and ASTM G99 (Ref 82) tests use a ball or a pin with a normal force and the difference between the two tests lies in the sliding direction, which is reciprocating for ASTM G133 (Ref 81) and unidirectional motion for ASTM G99 (Ref 82). In ASTM G77, the ring slides against the block specimen with a normal force applied to the test couple (Ref 83). Wear volume is measured in all of these tests, either by the mass loss or surface topography that is used to calculate the wear rate, i.e., wear rate $=$ wear volume / (normal load $\times$ total sliding distance) typically in the units of $\mathrm{mm}^{3} / \mathrm{N} \mathrm{m}(\operatorname{Ref} 81-83)$. In situ and post-test evaluations help identify wear mechanisms. Table 2 summaries the sliding wear test evaluations for the coating and counter body properties along with the sliding wear test method and wear rates. Some of the commonly used counter body materials in these investigations include stainless steel, WC-Co, $\mathrm{Si}_{3} \mathrm{~N}_{4}$ and $\mathrm{Al}_{2} \mathrm{O}_{3}$ (Table 2).

Several studies have proposed wear mechanisms in sliding wear of coated surfaces (Ref 16, 37, 39-41, 79, 84). The wear mechanism of WC-Co coatings depends not only on the coating microstructure but also on the properties of the counter body and the tribological test conditions of load and velocity during sliding wear (Fig. 4). In terms of coating microstructure, the size and distribution of carbides, degree of carburisation leading to eta-phases and mechanical strength of the coating material are the most important factors affecting sliding wear (Ref 16, 37, 39$41,79,84)$. The counter body can also significantly alter the wear mechanism based on its tribo-mechanical and tribo-chemical properties (Ref 14-16, 21, 41). Similarly, the changes in the contact pressure, contact geometry and wear debris in the contact region during sliding wear alter the wear mechanism (Table 2). The wear mechanisms in the sliding wear of WC-Co coatings can be broadly classified as (i) abrasive wear or macro-mechanical wear, (ii) fracture and fatigue and (iii) tribo-chemical. Figure 10 summarises some of the main factors contributing to the sliding wear of WC-Co coatings (Ref 16, 37, 79, 85). SEM observations indicating the underpinning wear mechanism are also shown in Fig. 10.

\section{Abrasive or Macro-mechanical Wear}

Abrasive wear during sliding contact in WC-Co coatings starts as a two-body wear mechanism due to asperity contact (Ref $35,37,62,75,86,87)$. The contact pressure is highest at this stage of the sliding wear process (Ref 87 ). For a given coating material, this process depends on the hardness, fracture toughness and tribological conditions of the test couples (Table 2). In the case of a ball-on-flat test conducted following the ASTM G133 (Ref 81) (procedure A), with a ball radius of $4.76 \mathrm{~mm}$ and a normal load of $25 \mathrm{~N}$, the maximum contact pressure varies as $1.39,1.47$ and 1.79 GPa for ball materials of stainless steel, $\mathrm{Si}_{3} \mathrm{~N}_{4}$ and cemented WC-Co, respectively (Ref 87, 88). The tensile stress at the edge of the contact region can be estimated as $0.2 \mathrm{GPa}$ (Ref 88). The Hertzian contact radius varies between 80 and $90 \mu \mathrm{m}$, which is significantly higher than the carbide size in WC-Co coatings (Fig. 6) or cemented WC-Co carbides, thereby indicating that the contact 

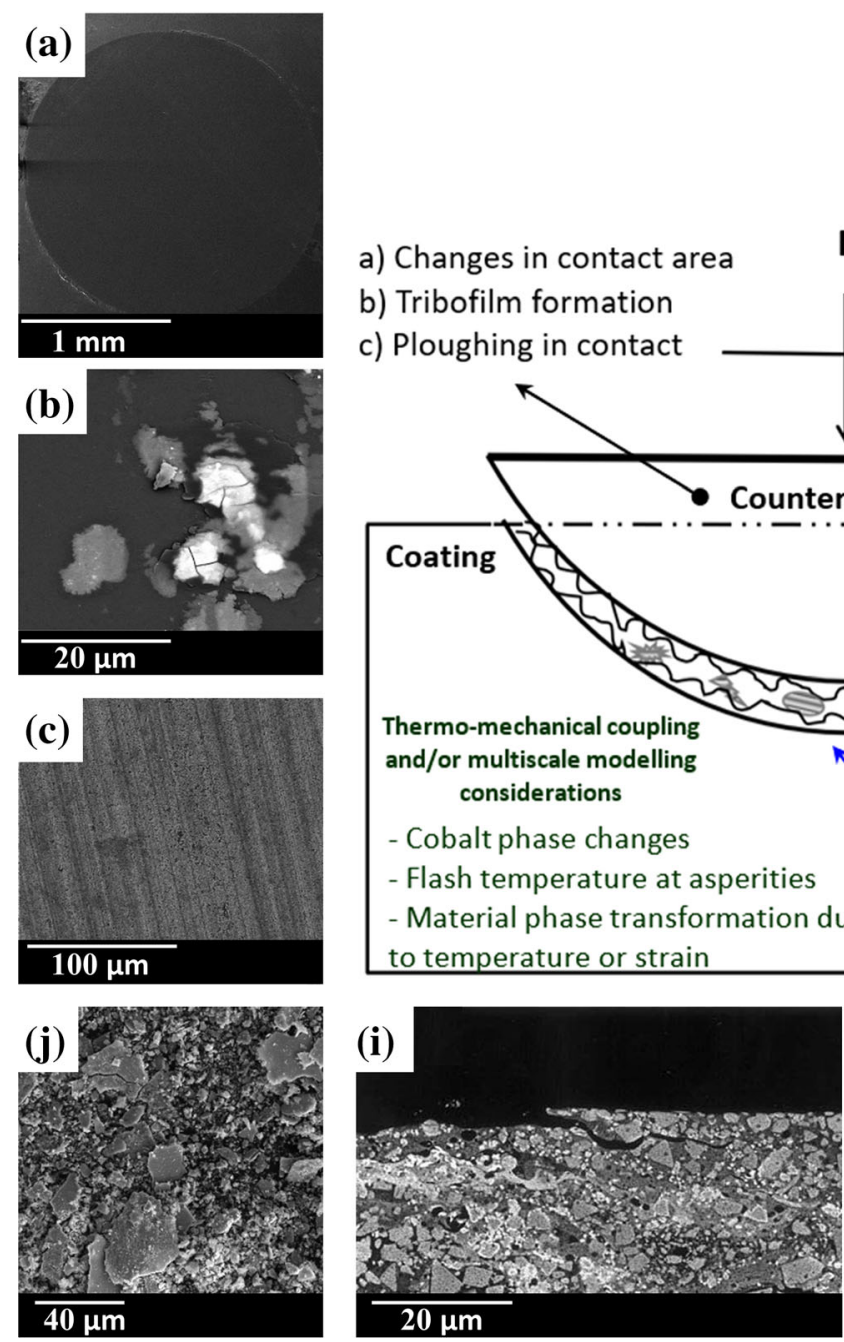

Fig. 10 Factors influencing the sliding wear of WC cermet coatings and counter bodies (Ref 37); SEM images of (a) worn surface of counterbody Si3N4 ball (Ref 16), (b) tribo-film on counterbody Si3N4 ball (Ref 16), (c) worn surface of counterbody steel ball, (d) carbide pullout in HVOF WC-Co coating, (e) transgranular carbide fracture in WC-Co coating (Ref 79), (f) matrix extrusion (Ref 16), (g) tribo-film

pressure is shared between the carbides and the matrix. The surface asperities interact within the contact region. Thus, there can be preferential wear of the matrix (Fig. 10f) that can expose carbides (Ref 16, 40). The extent of this matrix erosion depends on the surface roughness, hardness and toughness of the counter body.

For a given surface roughness, a harder counter body can increase matrix erosion because the harder surface asperity of the counter body and/or entrapped wear debris within the contact region can plough through the softer matrix (Ref 16, 40, 79). The carbides dislodge due to matrix erosion as the sliding wear process continues, hence leading to three-body abrasion of the test couple (Ref 14, 37, 40, 79). This is schematically represented in Figure 11(a), where matrix erosion leads to the removal of

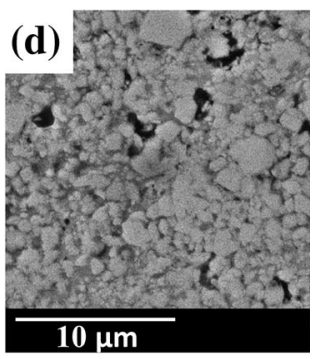

\section{Sliding Velocity}
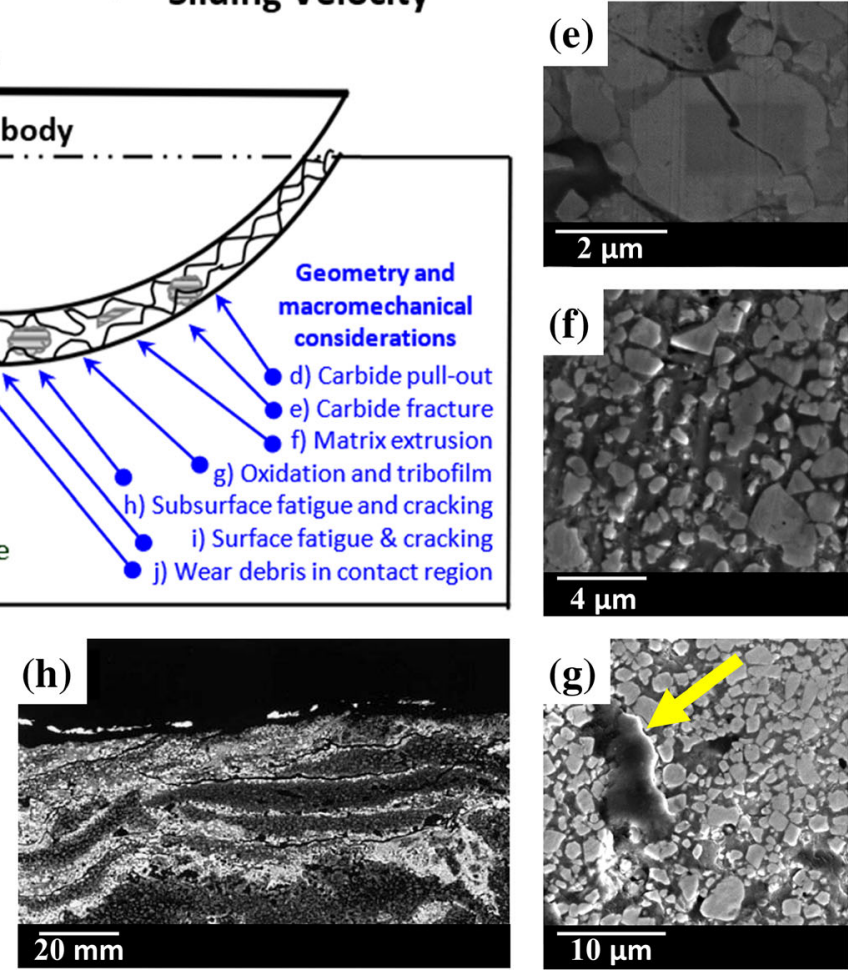

on wear track (arrow indicates tribo-film location) (Ref 14), (h) subsurface cracking shown through cross section of the wear track (sliding direction from left to right) (Ref 37), (i) intergranular surface cracking within the wear track shown via cross section of the wear track (sliding direction from left to right) (Ref 37), (j) wear debris from wear tests (Ref 14)

carbides (Ref 75). As the wear process continues, the conformity of the contact region increases leading to an increase in the apparent area of contact (Fig. 10a), which reduces the contact pressure (Ref 14, 16, 87). However, the wear debris within the contact region (Fig. 10j) increases the contact pressure as the real area of contact is now dictated by three-body abrasion of the (i) coating material, (ii) counter body and (iii) wear debris (Ref 14-16, 75, 87). The wear debris can roll and slide within the contact region, leading to a change in friction and wear behaviour. The debris is composed of both the coating and counter body material. Even for a relatively lower hardness counter body such as steel sliding against a WC-Co coating, the preferential wear of the metal matrix and carbide pull out is accelerated by the presence of detached carbides in the 


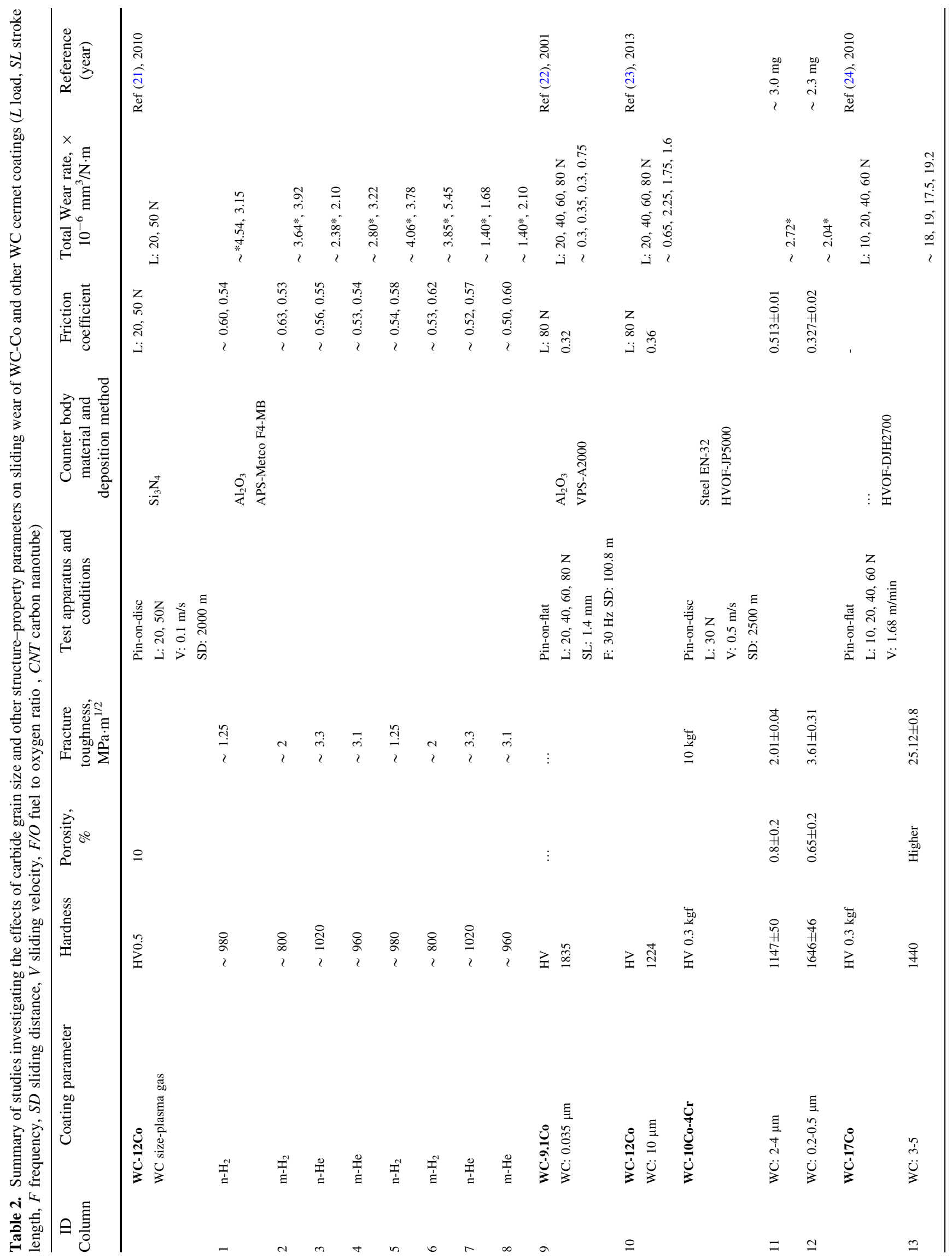




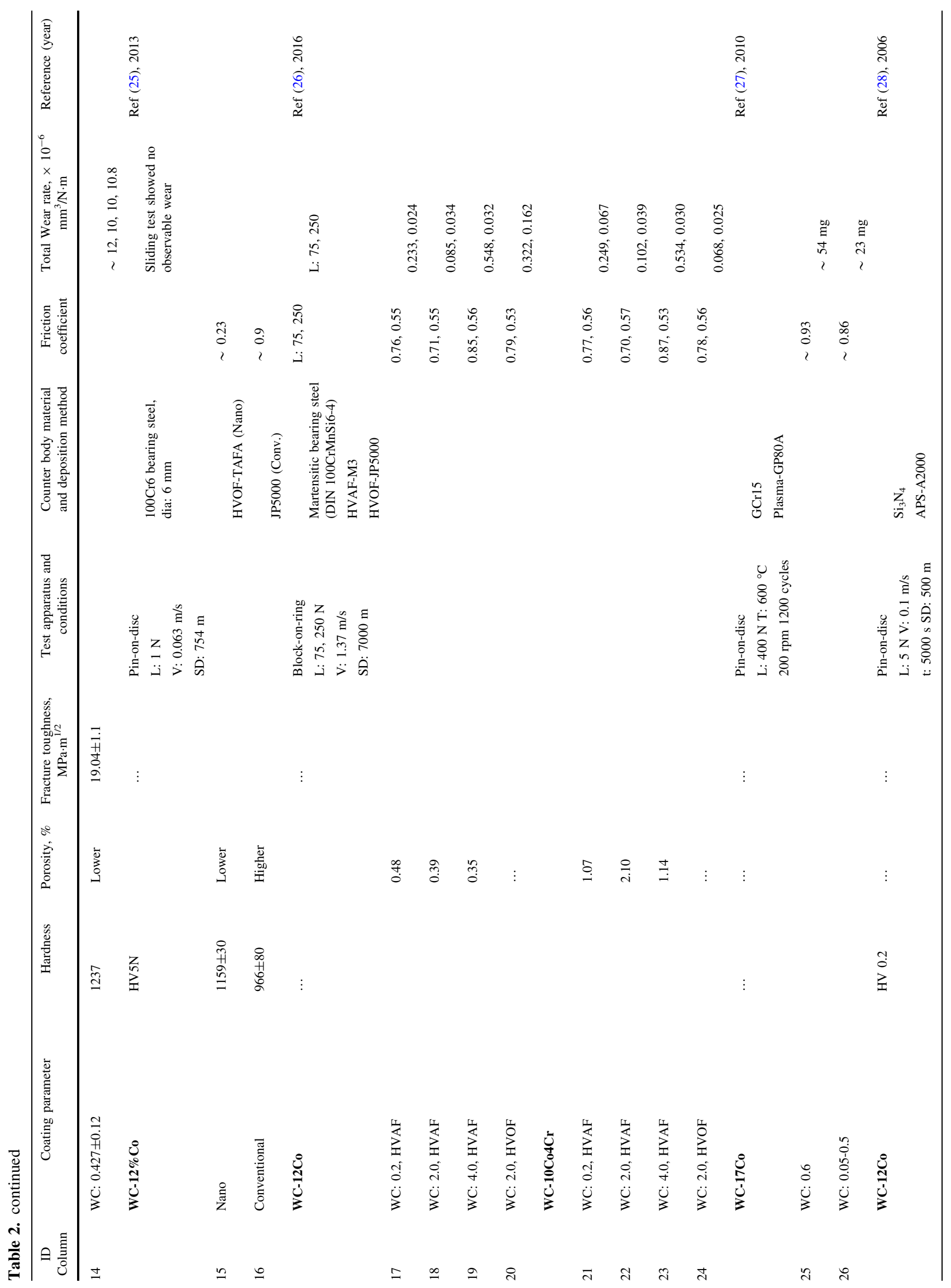




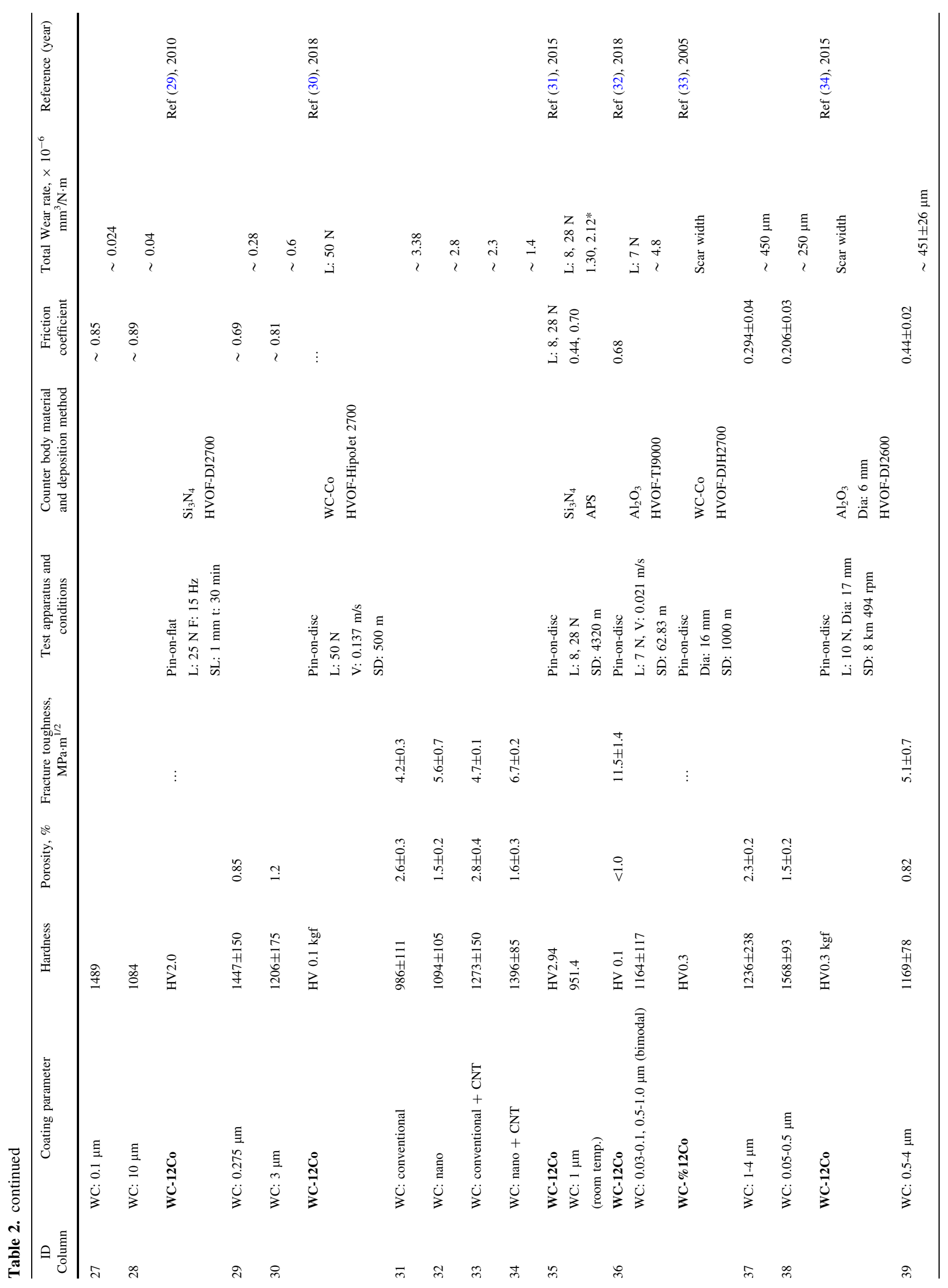




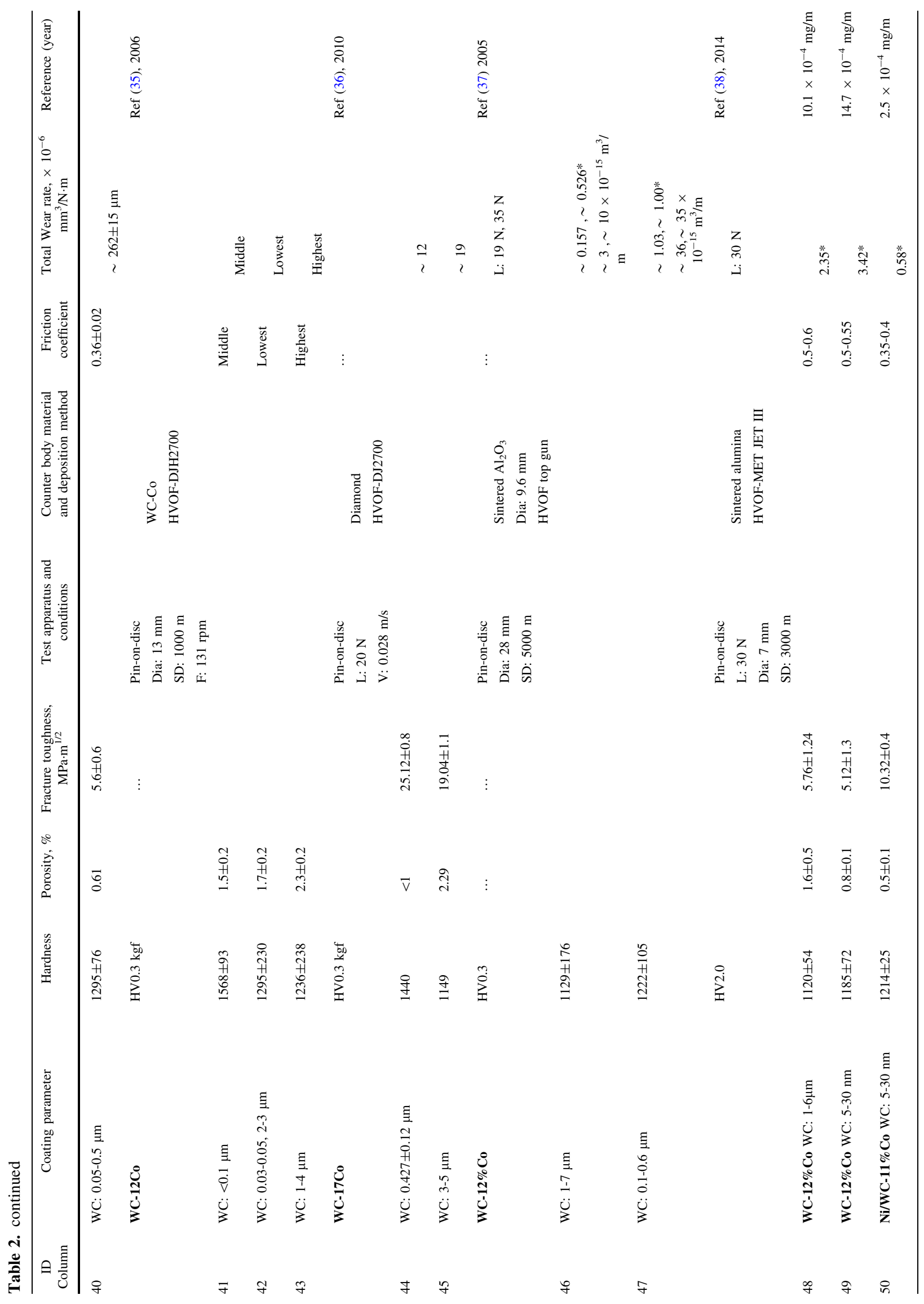




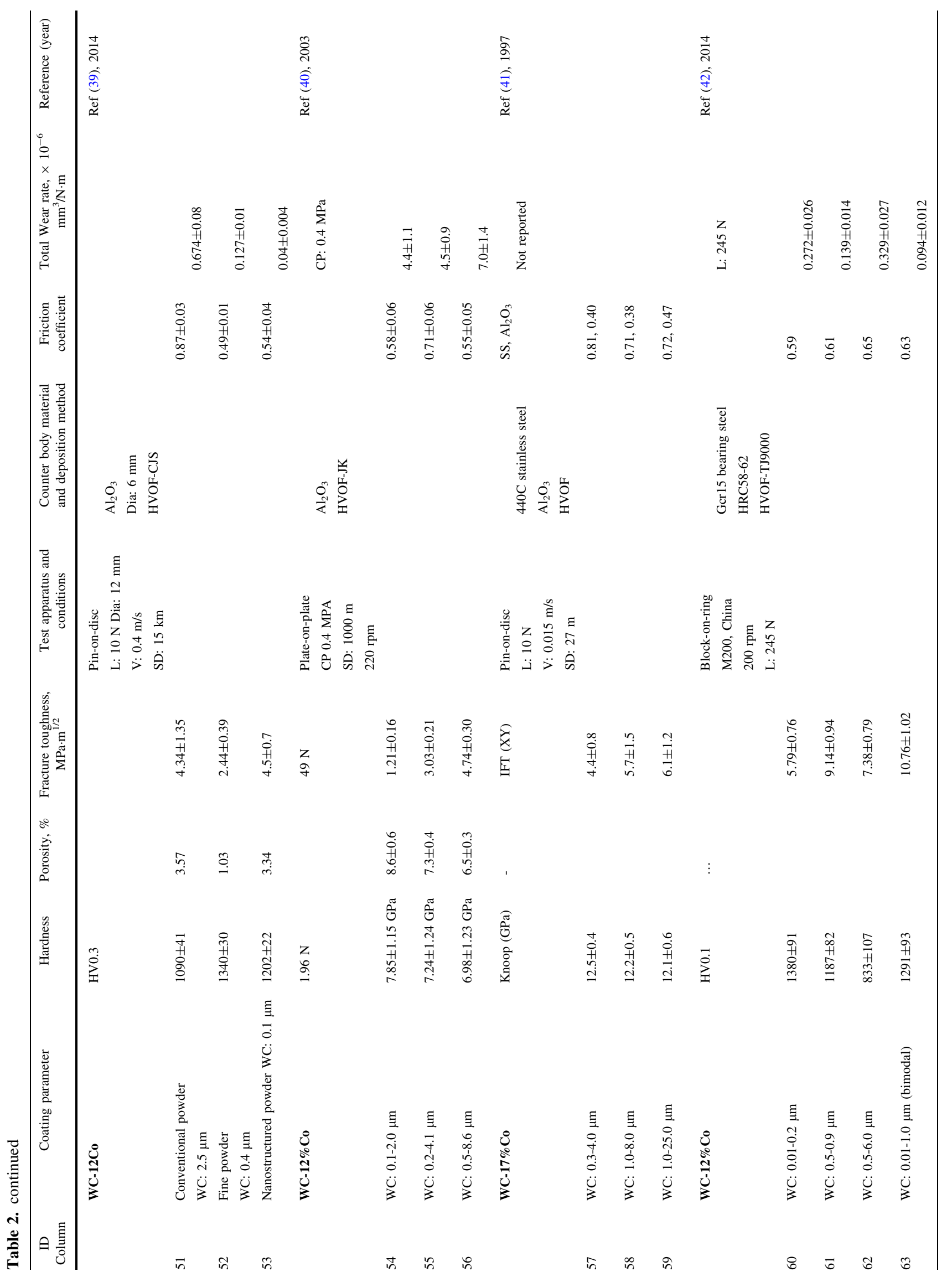




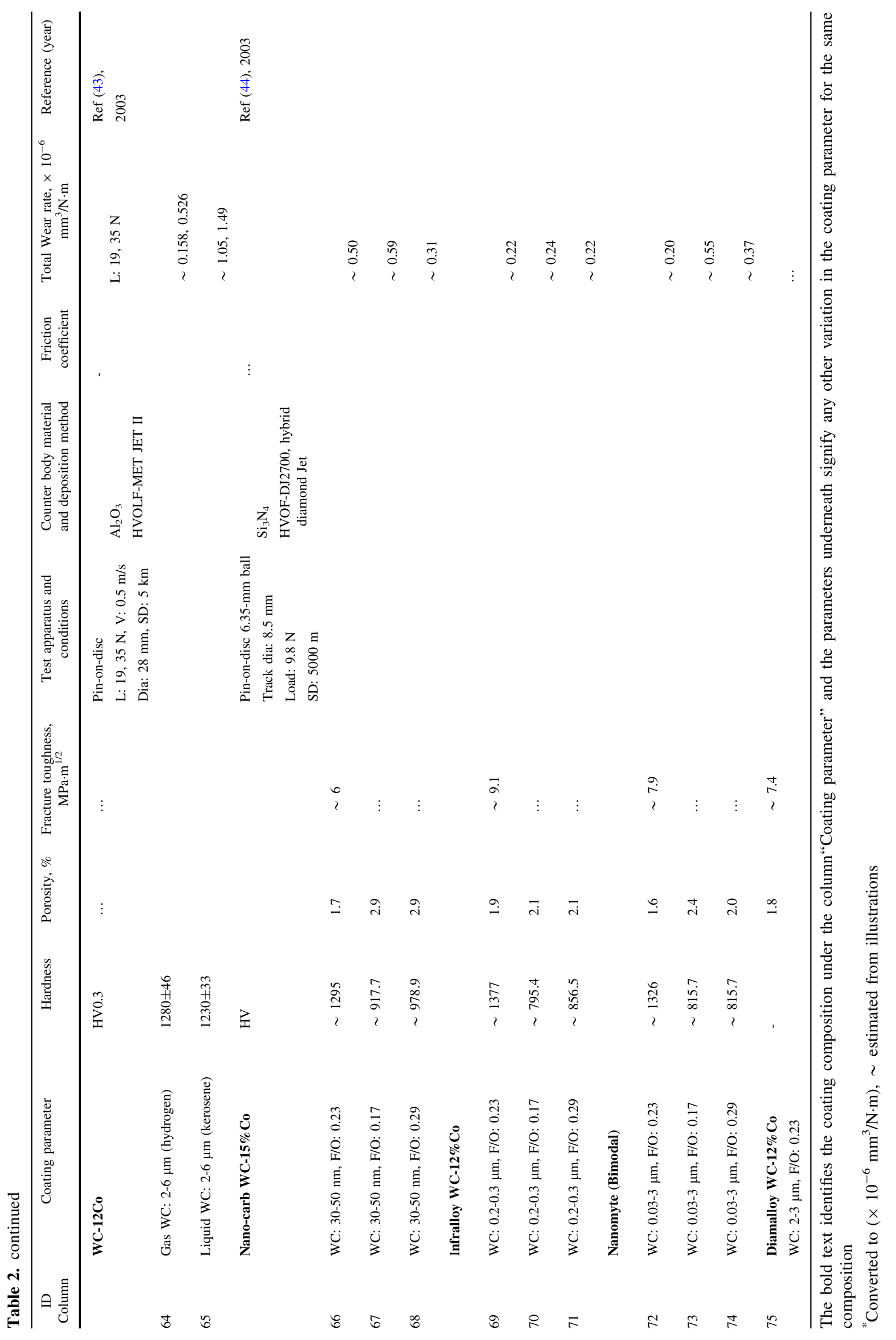


Table 3. Experimental d-spacing measured from the different rings and theoretical d-spacing for some possible phases for the TEM image shown in Fig. 6(e). In brackets are the hkl values. The intensities of the x-ray reflections are also summarised in the table.

\begin{tabular}{|c|c|c|c|c|c|c|c|c|}
\hline \multirow[t]{2}{*}{ Ring number } & \multirow[t]{2}{*}{$d_{\exp }(\mathrm{A})$} & \multicolumn{7}{|c|}{$d_{\mathrm{th}}(\mathrm{A})$} \\
\hline & & $\begin{array}{c}\text { WC } \\
\text { (Hex.) }\end{array}$ & $\begin{array}{l}\mathrm{W}_{2} \mathrm{C} \\
\text { (Hex.) }\end{array}$ & $\begin{array}{c}\text { W } \\
\text { (Cubic) }\end{array}$ & $\begin{array}{c}\mathrm{Co}_{3} \mathrm{~W}_{3} \mathrm{C} \\
\text { (Cubic) }\end{array}$ & $\begin{array}{c}\mathrm{Co}_{6} \mathrm{~W}_{6} \mathrm{C} \\
\text { (Cubic) }\end{array}$ & $\begin{array}{c}\mathrm{Co}_{3} \mathrm{~W}_{9} \mathrm{C}_{4} \\
\text { (Hex.) }\end{array}$ & $\begin{array}{c}\text { Co } \\
\text { (Hex.) }\end{array}$ \\
\hline \multirow[t]{2}{*}{1} & 2.2 & $\ldots$ & $2.3(-1-11)$ & $2.2(011)$ & $2.1(511)$ & $2.1(511)$ & $2.2(301)$ & $2.2(010)$ \\
\hline & & & Int100 & Int100 & Int100 & Int100 & Int100 & Int 100 \\
\hline \multirow[t]{2}{*}{2} & 1.9 (Strong) & $1.9(101)$ & $\cdots$ & $\ldots$ & $1.9(440)$ & $1.9(440)$ & $1.9(302)$ & $1.9(002)$ \\
\hline & & Int83 & & & Int40 & Int35 & Int 10 & Int25 \\
\hline \multirow[t]{2}{*}{3} & 1.7 & $\ldots$ & $1.7(-1-12)$ & $1.6(002)$ & $1.7(620)$ & $\cdots$ & $1.7(400)$ & $\cdots$ \\
\hline & & & Int15 & Int 17 & Int2 & & Int11 & \\
\hline \multirow[t]{2}{*}{4} & 1.4 (Weak) & $1.4(002)$ & $1.5(300)$ & & $1.4(731)$ & $1.4(731)$ & $1.4(205)$ & $1.5(012)$ \\
\hline & & Int5 & Int16 & & Int12 & Int 15 & Int54 & Int13 \\
\hline \multirow[t]{2}{*}{5} & 1.1 & $1.2(201)$ & $1.1(-2-22)$ & $1.1(022)$ & $1.1(755)$ & $\cdots$ & $1.1(325)$ & $1.2(013)$ \\
\hline & & Int11 & Int3 & Int12 & Int13 & & Int8 & Int 16 \\
\hline
\end{tabular}

wear debris from the coating material (Ref 14, 16, 21, 41, 89). This behaviour can lead to fracture within the coating material as shown schematically in Figure 11(b) and (c) (Ref 75). The influence of nanocomposite particles on fracture behaviour shown in Figure 11(c) is discussed later in "Fracture and Fatigue" section.

The properties of matrix are important in the wear process. Although no cobalt peak is observed in the XRD patterns of WC-Co coatings (Fig. 5), its structure can be observed through the TEM observations, Fig. 6(e) and (f) and Table 3, where the presence of HCP Co can be observed (Ref 15). Cobalt undergoes FCC to HCP transformation under strain (Ref 90-95), which can influence matrix erosion. Such transformations play an important role in the mechanical properties and wear mechanism of Co-based Stellite ${ }^{\mathrm{TM}}$ alloys (Fig. 3). However, as the weight percentage of $\mathrm{Co}$ in WC-Co coatings is relatively low, there has been no reported observation of a strain induced FCC to HCP transformation in the WC-Co coatings during sliding contact. The presence of tungsten in the cobalt matrix due to carbide dissolution and formation of etaphases due to carbon loss can, however, alter its properties, especially hardness and fracture toughness (Ref 30, 36, 38, 42, 44).

The binder mean free path decreases as the carbide size decreases, which decreases the extent of preferential matrix erosion (Ref 41). Nanocomposite coatings are expected to have better resistance to abrasive wear processes due to reduction in carbide size, since smaller carbides resist fracture, and also leads to a reduction in the binder mean free path that reduces matrix erosion (Ref 25, 30, 36). However, the carbon loss and formation of eta-phases during thermal spraying can make the matrix relatively brittle, which can increase matrix erosion. Usmani et al. (Ref 41) indicated that the average diameter of WC grains $\left(D_{\mathrm{WC}}\right)$ and the mean free path of the binder $(L)$ can be related as:

$$
\begin{aligned}
& D_{\mathrm{WC}}=\frac{4}{\pi} \frac{N_{L}}{N_{s}} \\
& L=\frac{1-f}{N_{L}}
\end{aligned}
$$

where $N_{L}$ is the number of non-contiguous grains intersected on a metallographic plane by a line of unit length, $N_{S}$ is the number of non-contiguous grains per unit area, and $f$ is the volume fraction of the dispersed phase. They indicated that the binder mean free path $(L)$ is nonlinearly related to the fine $(\mathrm{WC}$ size $=1.2 \mu \mathrm{m})$, medium $(\mathrm{WC}$ size $=$ $3.8 \mu \mathrm{m}$ ) and coarse (WC size $=7.9 \mu \mathrm{m}$ ) carbide size distributions (Figure 12a). Later studies by Yang et al. (Ref 40) investigated a relatively small mean WC size of $0.82 \pm 0.12 \mu \mathrm{m}$ (fine), $1.42 \pm 0.19 \mu \mathrm{m}$ (medium) and $2.81 \pm 0.25 \mu \mathrm{m}$ (coarse) and indicated a linear relationship of $L=0.37 D_{W C}$ with reasonable reliability $\left(\mathrm{R}^{2}\right.$ of trend line $=0.993$ ) between the carbide size and matrix mean free path. The decrease in the binder mean free path can reduce matrix extrusion and improve toughness as the crack has to change direction, thereby absorbing more energy in the process for intergranular fracture within the binder or at the binder-carbide interface (Ref 79).

One aspect of three-body abrasion is the increase in the wear rate of the coating materials caused by the relatively higher wear of the counter body (Ref 14-16, 21, 89). Therefore, the higher fraction of wear debris in the contact region increases the coating wear rate. Guilemany et al. 

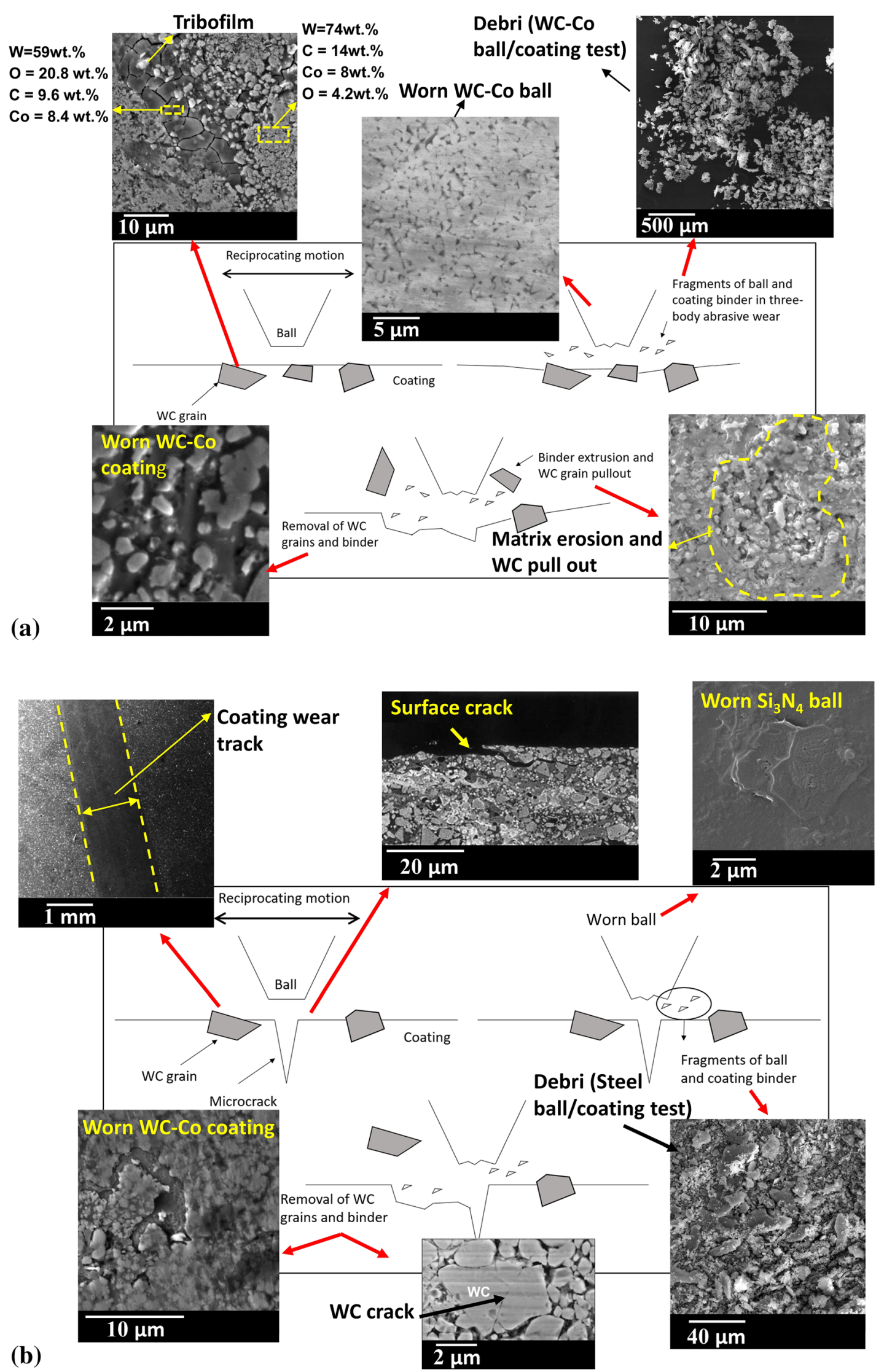
4Fig. 11 (a) Schematic of the process of matrix extrusion and carbide pullout following three-body abrasive wear (Ref 14-16, 75) (EDS analysis of wear track is also shown in the figure), (b) schematic of the influence of the coating microcracking on the coating and ball wear (Ref 14, 16, 37, 39, 75), (c) (i) mechanism of inter-splat crack propagation blocked by nano WC particles $(\sim 300 \mathrm{~nm})$ inhibiting propagation of the cracks originated during the sliding wear test [Redrawn from (Ref 79)], SEM cross section image of coating after wear test of (ii) coating without submicron-sized particles, (iii) coating with submicron-sized particles (Ref 79)

(Ref 89) observed that the wear rate of WC-Co coatings increased in sliding contact with a lower hardness counter body such as steel and $\mathrm{Si}_{3} \mathrm{~N}_{4}$. They indicated that this was due to the higher volume of the material lost by the ball (counter body) when compared to harder counter face material such as $\mathrm{Al}_{2} \mathrm{O}_{3}$. A similar trend was noted in the case of S-HVOF coatings where the coating suffered a higher wear rate when sliding against the relatively softer counter body (steel and $\mathrm{Si}_{3} \mathrm{~N}_{4}$ ) when compared to a cemented WC-Co ball (Ref 15, 16). As the wear rate increases for the relatively softer counter body, the wear rate of the WC-Co coating also increases due to three-body abrasion. This results in deeper wear tracks due to debris entrapment within the contact region that destabilises the tribo-film by altering the surface chemistry and dynamics of the interacting asperities (Ref 15, 16, 40, 75, 79, 89).

In summary, apart from the coating characteristics such as its hardness, carbide size and strength, the hardness and surface chemistry of the counter body also plays an important role in the sliding wear of WC-Co coatings due to its effect on the three-body wear and stability of the tribo-film (Ref 15, 16, 40, 75, 79, 89).

\section{Fracture and Fatigue}

The compressive strength of WC is $\sim 1.4 \mathrm{GPa}$ and its tensile strength $0.3 \mathrm{GPa}$ (Ref 96). As discussed above, a typical contact pressure and the tensile stress of 1.41.8 GPa and 0.2 GPa, respectively, exist during the ASTM G133 (Ref 81) (Procedure A) sliding wear test (Ref 87, 88).
This stress can, therefore, reach the strength of $\mathrm{WC}$ at asperity interactions, which can lead to fracture of carbides within the contact region. However, as the load is shared between several carbides and the matrix, the stress within the carbide only reaches these values if the carbide size increases, leading to carbide fracture as shown in Fig. 10(e) and (i) (Ref 37, 75, 79). In the case of finer carbides or nanocomposite S-HVOF coatings, the carbide fracture is not observed as the stress on the individual carbides reduces due to the increase in the number of carbides within the contact region. Repeated sliding within the contact region, however, leads to fatigue crack initiation and propagation as shown in Fig. 10(i), which can lead to coating delamination (Ref 37, 75). The critical crack length for fast fracture in WC-Co is larger than the carbide size in WC-Co coatings; hence, crack propagation occurs through the metal matrix binder or along boundary regions with brittle phases for coating delamination (Ref 75, 79).

As the carbide size decreases, the binder mean free path also decreases (Figure 12a) which can reduce the probability of fatigue crack initiation and propagation during sliding wear (Ref 40, 41). However, this behaviour is not always observed in the fracture toughness measurements as shown in Figure 12(b) (Ref 40,41). The microstructure of the binder and type of carbides therefore play a more dominant role in this process. As the carbon loss increases within the WC-Co coating, the coating becomes more brittle due to the formation of $\mathrm{M}_{6} \mathrm{C}$ and $\mathrm{M}_{12} \mathrm{C}$ carbides, increasing coating wear ( $\operatorname{Ref} 15,16)$. Fracture toughness of the WC-Co coatings thus plays an important role in resisting coating fracture and delamination. The literature adapts different approaches to calculate the fracture toughness of thermal spray coatings (Ref 4). One approach for measuring fracture toughness of WC-Co coatings uses the radial crack length and has been adopted by Yang et al. (Ref 40) and Usmani et al. (Ref 41), i.e.,

$$
K_{I C}=\frac{0.113 H \sqrt{D}}{\left(1+\frac{C_{L}}{2 D}\right)^{3 / 2}}
$$



(c)

(i)

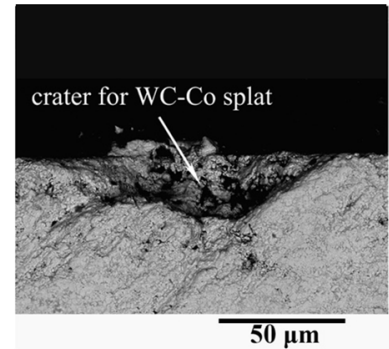

(ii)

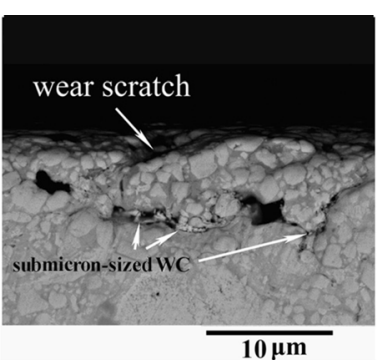

(iii)

Fig. 11 continued 

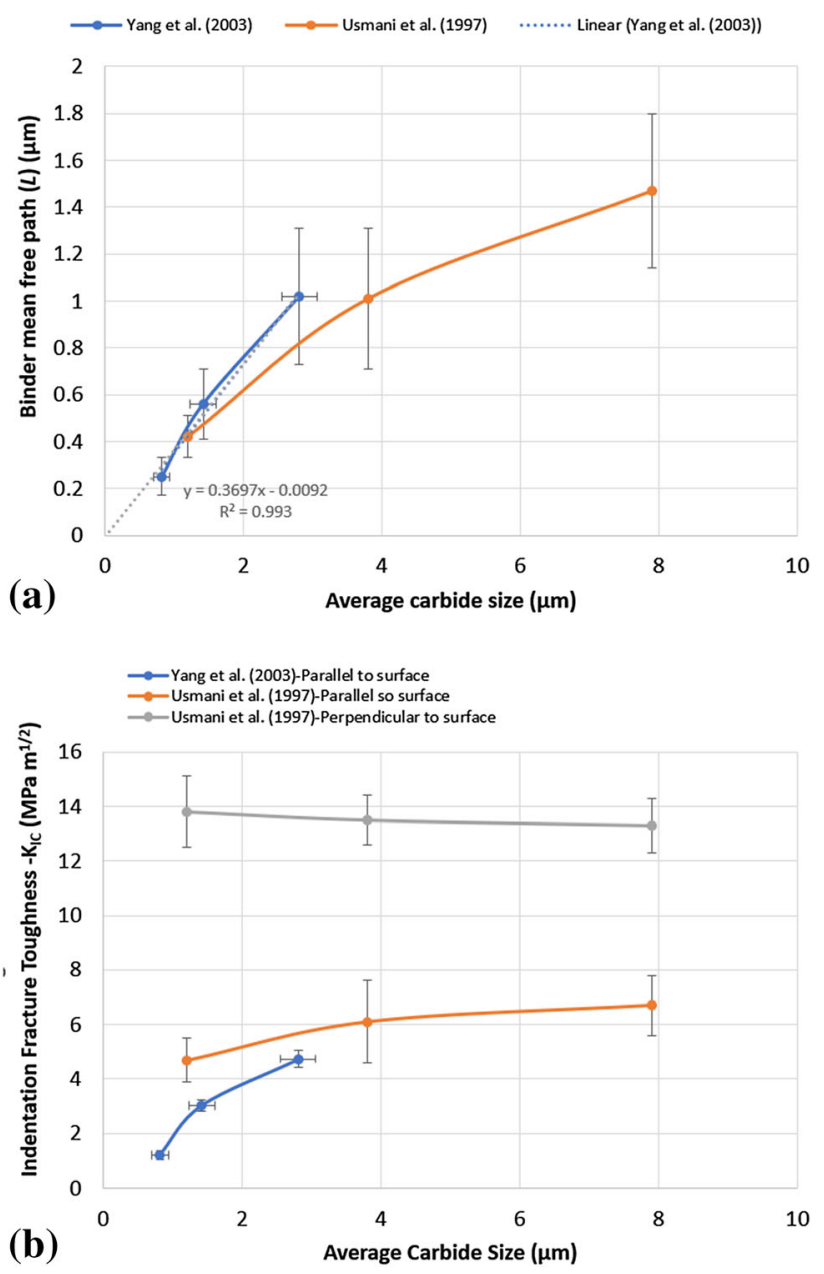

Fig. 12 Influence of average carbide grain size on (a) the binder mean free path, (b) indentation fracture toughness $\mathrm{K}_{\mathrm{IC}}$ of WC-Co coatings (Ref 40, 41)

where $H$ is the Vickers micro-hardness, $D$ is the diagonal of Vickers indentation $(\mu \mathrm{m}), C_{L}$ is the total crack length $(\mu \mathrm{m})$ emanating from the four corners of the Vickers indentation.

Faisal et al. (Ref 97) applied acoustic emission (AE) and crack length investigations to measure the fracture toughness of WC-Co coatings. They used the relationship (Ref 97):

$K_{I C}=K_{L}\left(\frac{P}{a \sqrt{L}}\right)$

where $a$ is the average indent half-diagonal size, $P$ is the indentation load, and $K_{L}$ is an empirical constant that can be determined for any given indenter/specimen/indentation system combination. The AE technique can quantify the fracture toughness of WC-Co coatings in cases where the approach of measuring radial cracks from indents fails to measure $\mathrm{K}_{\mathrm{IC}}$ values (Eq 11). Typical $\mathrm{K}_{\mathrm{IC}}$ values in HVOF WC-12Co coatings range from 4.6 to $7.4 \mathrm{MPa} \mathrm{m}^{1 / 2}$ (Ref 97). Yang et al. (Ref 40) and Usmani et al. (Ref 41) used a conventional radial crack length approach (Eq 10) and determined $\mathrm{K}_{\mathrm{IC}}$ values between 1.2 and $8.0 \mathrm{MPa} \mathrm{m}{ }^{1 / 2}$ when measurements were taken parallel to the coating surface.

Usmani et al. (Ref 41) also measured values perpendicular to the coating surface and indicated that the coatings are relatively tough and resist crack propagation when indented perpendicular to the coating surface. Their work is summarised in Figure 12(b) and shows a coating anisotropy of $\sim$ 0.34-0.5 based on $\mathrm{K}_{\mathrm{IC}}$ values measured parallel and perpendicular to the coating surface ( $\operatorname{Ref} 40,41)$. The value of anisotropy is, however, sensitive to the measurement technique, for example the fracture toughness value measured on the coating surface can be influenced by the substrate which supports the coating during the indentation fracture, whereas the cross section measurements are not influenced by the substrate properties. Several studies have discussed the influence of complexity of lamella structure on the anisotropy (hardness, elastic modulus and fracture toughness) of thermal spray coatings (Ref 3-5, 20) . Faisal et al. (Ref 97) also showed that the measured $\mathrm{K}_{\mathrm{IC}}$ values are also sensitive to the measurement technique since not all WC-Co coatings present classical radial cracks emanating from the indent edges for fracture toughness measurements. Fracture toughness of WC-Co coatings is, therefore, not an easily measurable quantity and literature on the sliding wear of WC-Co coatings that include $\mathrm{K}_{\mathrm{IC}}$ values is sparse (Table 2). The fracture behaviour of WCCo coatings during sliding wear is mostly intergranular as the evidence of carbide fracture is only observed for relatively large carbide size coatings (Fig. 10e) (Ref 37, 79). Ma et al. (Ref 42) indicated that the indentation fracture toughness values for coatings with carbide size ranges of $0.5 \sim 0.9 \mu \mathrm{m}$ and $0.5 \sim 6.0 \mu \mathrm{m}$, were $9.14 \pm 0.94 \mathrm{MPa} \mathrm{m}^{1 /}$ 2 and $7.38 \pm 0.79 \mathrm{MPa} \mathrm{m}^{1 / 2}$, respectively, which is in broad agreement with the values shown in Fig. 12(b) (Ref 40, 41).

Subsurface and surface fracture of WC-Co coating is the most accepted theory of material removal during delamination [e.g.(Ref 37, 40, 41)]. Figure 10(h) and (i) shows the subsurface crack propagation as indicated by Shipway et al. (Ref 37). These cracks are shown to initiate and propagate at the carbide matrix interface, which agrees with earlier studies by Yang et al. (Ref 40). Yuan et al. (Ref 79) and Usmani et al. (Ref 41) have provided experimental evidence that the crack propagation in WC-Co coatings follows the inter-splat boundary. Shipway et al. (Ref 37), however, has not specifically concluded the inter-splat boundary as the preferred crack propagation path, whereas Yang et al. (Ref 40) suggested that there was no evidence of splat delamination and binder/carbide interface fracture in their studies. 
Shipway et al. (Ref 37) suggested that the cracks run predominantly in the brittle regions of the coating where there has been the most extensive decomposition. These highly decomposed regions result in large-scale material loss and thus high rates of wear. However, Yuan et al. (Ref 79) postulated that splat interfaces were the weakest zone in thermal spray coatings. They provided experimental evidence that once a crack is initiated, then the fracture path follows a trajectory of minimum strain energy density.

For the WC-Co coatings, the propagation of wear-induced crack in the coating can be explained by the possible flaws between splats, such as poorly bonded area, micropores and micro-cracks at splat interfaces (Ref 79). This reasoning is consistent with the investigation of Usmani et al. (Ref 41), where these authors indicated that most cracks originate from pores or the carbide-matrix interface. Noting that most of the carbide decomposition occurs at the carbide matrix boundary leading to the formation of etaphases, the mechanism of crack propagation due to stress concentrations within the coating microstructure is consistent in all of these investigations (Ref 37, 40, 41, 79).

The view of Yuan et al. (Ref 79) was that the microcracks at splat boundaries influence significantly both the sliding and abrasive wear rate of WC-Co coatings (Ref 79). This is schematically represented is Figure 11(c) where the crack propagation is through the inter-splat boundary (Ref 79) and incorporation of nanoparticles thus arrests the crack. This inter-splat crack propagation is consistent with the work of Usmani et al. (Ref 41), where it was hypothesised that crack propagation for smaller carbides is through the inter-splat boundary (i.e., intergranular), whereas for larger carbides the cracks propagate through the carbide (i.e., transgranular). Yuan et al. (Ref 79) thus concluded that submicron-sized WC particles with an even distribution at splat interfaces could cause deflection or impede cracks. This improvement in the fracture behaviour from transgranular to intergranular by reducing the carbide size to nanocomposite is consistent with the approach of S-HVOF coatings (Ref 14-16) for improving sliding wear performance. However, the carbon loss needs to be carefully controlled before a significant improvement in the sliding wear performance of nanocomposite coatings under a range of sliding wear conditions can be observed (Ref 14$16,22,25,30,44)$.

The fracture and fatigue behaviour of thermal sprayed WC-Co coatings can also be determined through rolling contact fatigue (RCF) investigations (Ref 88). In RCF, the maximum shear stress occurs in subsurface and, hence, crack initiation and propagation are always subsurface. Asperity contact is possible under certain lubrication conditions, which leads to surface initiation and propagation of cracks (Ref 68, 69, 88, 98). Figure 13(a) shows the shear stress distribution under pure rolling and pure sliding conditions (Ref 88). The finite element analysis (FEA) in pure rolling contact is shown in Figure 13(b) and defines the subsurface location of the maximum shear stress (Ref 76). Figure 13(c) shows that the subsurface shear stress reaches the surface due to frictional effects in sliding wear, and hence, crack initiation and propagation in sliding contact occurs near the surface (Ref 85).

Ahmed et al. provided a back-to-back analysis of wear mechanisms for WC-Co coatings under RCF and sliding wear (Ref 98). This investigation indicated that as the mechanical properties of the WC Co improved after heat treatment, then the RCF and sliding wear performance also increases. The improved behaviour was attributed to improved inter-splat bonding after the heat treatment (Ref 98). Generally, as the fracture toughness of the coating increases, then the sliding wear and RCF attributes also increase. Higher metallic Co binder content contributes to higher ductility and fracture toughness of the WC-Co coatings and also results in less cracking during rolling contact test (Ref 79). However, no direct mathematical relationship between the RCF and sliding wear performance has been reported.

\section{Tribo-Chemical Behaviour}

The oxidation of elemental species within the test couples leads to the formation of tribo-films, Fig. 10(g) [see (Ref $14,89)]$. In some cases, the tribo-film is also formed by the transfer of material in its original or oxidised form, for example there is evidence of $\mathrm{Fe}$ in the oxidised film forming during the sliding wear of WC-Co coatings against steel (Ref 14, 16). Oxidation occurs due to the flash temperature during asperity interaction in sliding contact (Ref 87). In the case of WC-Co coatings in sliding contacts, regardless of the counter body material, tribo-films of $\mathrm{WO}_{3}$ and $\mathrm{CoO}$ caused by the isothermal oxidation of WC-Co are frequently reported (Ref 16, 40, 43, 89). This oxidised tribo-film covers the surface of the wear track and also fills the delaminated areas and pores within the coating (Fig. 10 and 11). In addition to these oxides, when sliding wear tests are conducted at higher temperatures $\left(\sim 200-300{ }^{\circ} \mathrm{C}\right)$, an additional oxide of $\mathrm{WCoO}_{4}$ has been reported (Ref 99). A tribo-film reduces the friction and wear of the test couples by providing a low shear strength film during sliding contact. The oxide $\mathrm{WO}_{3}$, in particular, has been reported to exhibit good lubricating properties (Ref 89 ). Counter body materials in sliding wear such as $\mathrm{Si}_{3} \mathrm{~N}_{4}$ and steel also indicate tribological reactions leading to the formation of a tribo-film (Ref 100).

The formation and removal of the tribo-film during sliding wear of WC-Co coatings is a continuous process where the film thickness grows until it becomes unstable and is then removed due to sliding action to make way 

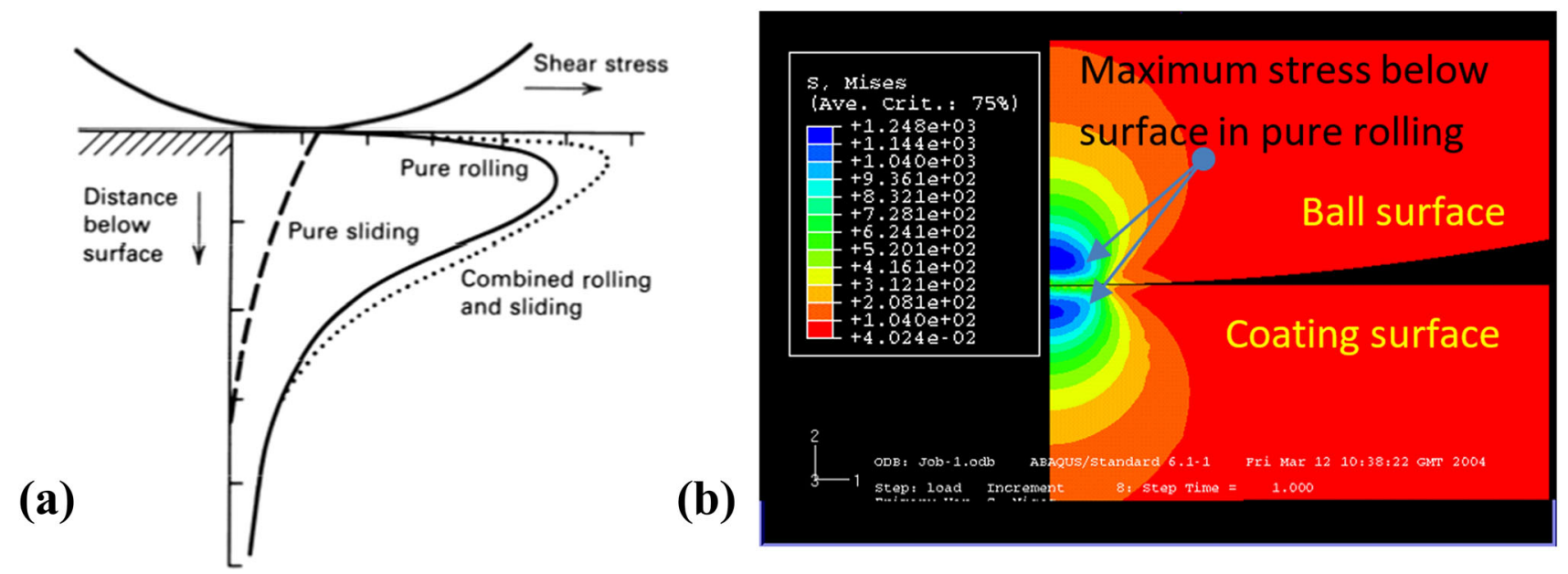

(b)

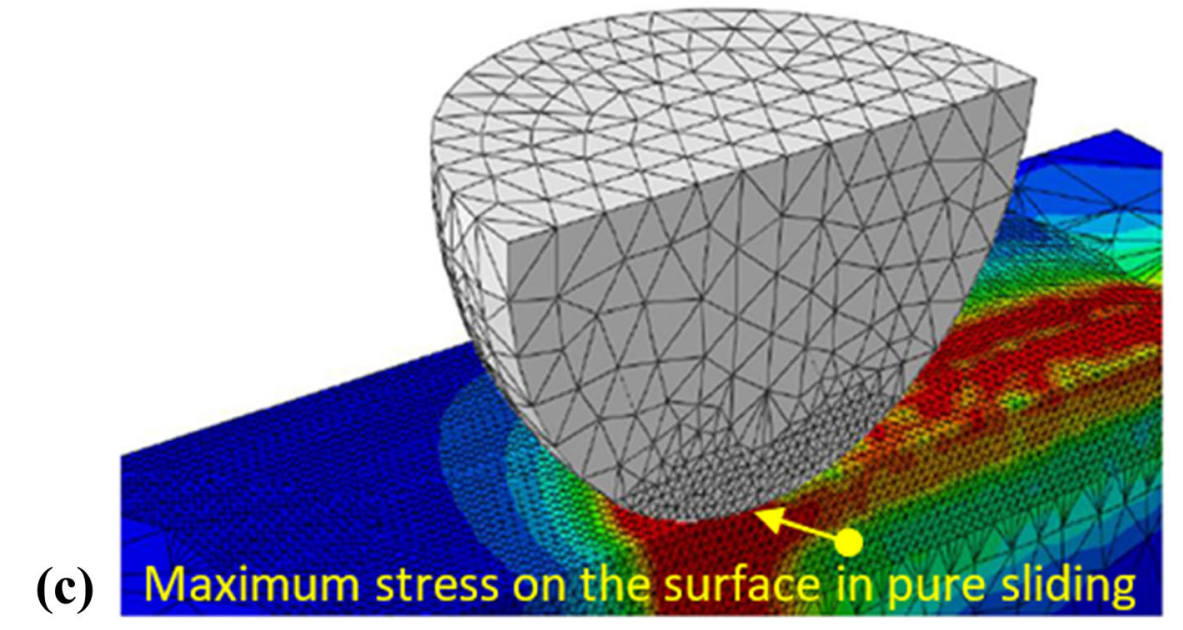

Fig. 13 A comparison of stress distribution in rolling and sliding contacts, (a) shear stress for pure rolling, rolling sliding and pure sliding below the surface (Ref 88), (b) finite element model showing

for new tribo-film formation (Ref 15, 75). Engqvist et al. (Ref 101) conducted a comprehensive investigation on the mechanism of tribo-film formation in cemented carbides during dry sliding contact. The observed surface reactions corresponded to the predicted chemical equilibrium calculations (Ref 101). The WC debris is rapidly cemented together with the Co binder phase to resemble a nanocrystalline WC-Co composite. An uneven but sharp transition to the unaffected carbides appeared underneath the tribo-film (Ref 101). The calculated surface temperatures and the low degree of oxidation suggest that the surface temperatures generally stayed below $600{ }^{\circ} \mathrm{C}$ during sliding contact (Ref 101).

Another observation from this study indicated that most of the Co was unoxidised because oxidation of Co requires an excess of Co at the surface (Ref 101). The relatively lower amount of $\mathrm{Co}$ in the case of WC-Co coatings indicate that the tribo-film is predominantly $\mathrm{WO}_{\mathrm{X}}$ instead of $\mathrm{CoO}$ (Ref 101). This result can be further verified by considering maximum stress distribution subsurface, (c) finite element model showing maximum stress reaching the surface in pure sliding (Ref 85)

the formation of tribo-film when WC coatings are deposited with NiCrBSi as the binder instead of Co (Ref 102). When these WC-10\%WC-NiCrBSi coatings are tested in sliding wear against the steel and $\mathrm{Si}_{3} \mathrm{~N}_{4}$ balls, Co is absent in the tribological system. However, the tribo-film still forms on the surface of the wear track (Ref 102) and indicates that the tribo-film is more likely caused by oxidised $\mathrm{W}$ within the carbide phase. The investigation of Stoyanov et al. (Ref 11) provided further support where the sliding of $\mathrm{WC}$ against $\mathrm{W}$ concluded the formation of $\mathrm{WO}_{\mathrm{X}}$ as a tribo-film.

\section{Influence of Counter Body on the Tribo-Film}

The W-rich tribo-film generally covers the surface of the wear track when sliding wear tests on WC-Co coatings are conducted against hard metals such as WC-Co and $\mathrm{Al}_{2} \mathrm{O}_{3}$ (Ref $15,75,101)$. In conventional WC-Co coatings, for tests against steel and $\mathrm{Si}_{3} \mathrm{~N}_{4}$ surfaces, the oxidised layer is 
easily removed (Ref 89). Nevertheless, its presence can be observed during the debris analysis and the presence of oxygen on the surface of wear tracks. In the case of S-HVOF WC-Co coatings sliding against steel, studies have indicated that there is significant tribo-film formation against WC-Co and steel ball counter bodies (Ref 15). For contact against steel balls, there is also evidence of the presence of higher concentrations of $\mathrm{Fe}$ in the oxidised state (Ref 16). However, in the case of $\mathrm{Si}_{3} \mathrm{~N}_{4}$ as the counter body, both conventional and S-HVOF WC-Co coatings indicate the absence of tribo-film on the surface of the wear track (Ref 14-16, 75). The absence of this film on the surface of the wear track does not mean that the film is not formed; instead, it is quickly removed during the sliding wear process against $\mathrm{Si}_{3} \mathrm{~N}_{4}$ counter body.

The tribo-chemical reactions occurring during the sliding wear of $\mathrm{Si}_{3} \mathrm{~N}_{4}$ were reviewed by Dante et al. (Ref 100). They indicated that in air or humid conditions, hydroxylated silicon oxide is the main product of tribo-chemical wear, which flattens the surface and thereby decreases stresses on asperities that reduces the wear rate and friction level. Boundary lubrication with n-alcohols is also characterized by tribo-chemical wear, which leads to the formation of silicon alkoxides and polysiloxanes (Ref 100). Their work describes that during the tribo-chemical reaction, $\mathrm{Si}_{3} \mathrm{~N}_{4}$ can react both with i) atmospheric molecules (e.g. $\mathrm{O}_{2}$ and $\mathrm{H}_{2} \mathrm{O}$ ), and also the ii) adsorbed molecules (alcohols, hydrocarbons, lubricants, etc.), through the breaking of bond between silicon and nitrogen (Ref 100). These tribo-chemical reactions in $\mathrm{Si}_{3} \mathrm{~N}_{4}$ are also advantageous in ball manufacture as a material removal process during the finishing operation (Ref 103). However, in the case of WC-Co coatings sliding against $\mathrm{Si}_{3} \mathrm{~N}_{4}$ balls, the stability of the protective $\mathrm{WO}_{3}$ tribo-film is compromised, which increases the wear rate against both conventional and the S-HVOF WC-Co coatings (Ref 15). In the investigation of WC-10\%WC-NiCrBSi coatings sliding against $\mathrm{Si}_{3} \mathrm{~N}_{4}$ balls, tests were conducted at a relatively low load of $12 \mathrm{~N}$ instead of $25 \mathrm{~N}$ used in the ASTM G133 (Ref 81) (procedure A) (Ref 102). The authors indicated that relatively small quantities of tribo-film were present on the surface of WC-Co wear track. This observation shows better stability of the $\mathrm{WO}_{\mathrm{x}}$ tribo-film for wear tests against $\mathrm{Si}_{3} \mathrm{~N}_{4}$ balls at lower loads. In summary, the stability of W-rich tribo-film is compromised when WC-Co and WC$\mathrm{NiCrBSi}$ coatings are tested against $\mathrm{Si}_{3} \mathrm{~N}_{4}$ counterbody.

\section{Influence of Decarburisation on the Tribo-Film}

The formation of a W-rich tribo-film in WC-Co coatings is not influenced by the microstructural phase of tungsten, which can consist of eta-phases, WC or W (Ref 14$16,43,89)$. In the case of decarburisation of WC-Co coatings during coating deposition, leading to eta-phases, there is still formation of a W-rich tribo-film during sliding wear (Ref 14-16, 78, 89). Hence, it is not the phase of tungsten but instead its presence on the surface of the wear track that helps $\mathrm{WO}_{\mathrm{x}}$ tribo-film formation. This understanding is consistent with other engineering alloys such as Co-based Stellite ${ }^{\mathrm{TM}}$ alloys that contain tungsten (Ref 104). In the case of Stellite ${ }^{\mathrm{TM}} 6$ alloy that contains almost $4.6 \mathrm{wt} . \%$ tungsten and $1.09 \mathrm{wt} . \%$ carbon, most of the tungsten forms part of the metal matrix instead of WC. Whereas for Stellite ${ }^{\mathrm{TM}} 20$ that contains almost $16.3 \mathrm{wt} . \%$ tungsten and $2.35 \mathrm{wt} . \%$ carbon, most of the tungsten forms WC (Ref 91-95). However, regardless of the type of W-phase in both alloys, sliding wear tests performed under ASTM G133 (Ref 81) (procedure A) indicate a strong presence of a W-rich $\left(\mathrm{WO}_{\mathrm{x}}\right)$ tribo-film against several counter body materials (Ref 91-95). This observation concerning the nature of the tribo-film further confirms that decarburisation in the WC-Co coatings leading to etaphases or $\mathrm{W}$ has no significant effect on the formation of a protective W-rich tribo-film (Ref 14-16, 43, 89).

In summary, the tribo-film can significantly influence the sliding wear and friction of WC-Co coatings (Ref 14$16,43,89)$. The formation and removal of the beneficial $\mathrm{WO}_{\mathrm{x}}$ tribo-film in sliding wear of WC-Co coatings is influenced significantly by the surface chemistry of the counter body and the test load (Ref 100,101$)$. It is, however, not influenced by the microstructural phase of tungsten within the coating material. The wear debris within the contact region also influences considerably the stability of the tribo-film (Ref 14-16, 75).

\section{Comparison of Failure Modes of WC-Co Coatings with Cemented WC-Co Carbides}

Although the microstructure of cemented WC-Co carbides is different from WC-Co coatings (Fig. 5 and 6), there are similarities in their wear mechanisms (Ref 6, 7,9). The sliding wear mechanism in cemented WC-Co carbides is categorised into six steps as (i) polishing of grains due to micro-abrasion, (ii) wear debris formation due to microabrasion, (iii) adhesion of wear debris to form agglomerates, (iv) removal of binder, (v) grain cracking and/or grain fragmentation, and (vi) grain pull out (Ref 7). These mechanisms are consistent with the investigation of Pirso et al. (Ref 6) that indicated (i) preferential removal of the carbide binder, followed by (ii) fracture of intergranular boundaries, and (iii) fragmentation of carbide grains.

Binder removal in cemented carbides has been reported to increase with the contact load, where the softer Co binder is preferentially removed from the top layer of WC grains (Ref 7). Pirso et al. (Ref 6) linked the preferential binder removal to binder extrusion, which increases as the 
content of binder increases in the cemented carbide. The weakest structural elements are either carbide-binder or carbide-carbide boundaries (Ref 6); which, due to fatigue under repeated sliding, lead to detachment of carbide grains. The wear debris resulting from this process causes the extraction of binder between carbide grains (Ref 6). Binder removal also leads to cracking and/or pullout of cemented carbides (Ref 6, 7). Another factor influencing the role of the binder in sliding wear was reported by Saito et al. (Ref 9); where the increase in carbide mean free path led to increased plastic deformation and, thus, increased sliding wear rate.

The above-mentioned six wear mechanisms in cemented WC-Co are also observed in the case of WC-Co coatings (Fig. 10) but not necessarily in the same order of these steps (Fig. 10 and 11). For example, in the case of thermal sprayed WC-Co coatings, synergism among these mechanisms can occur, and the dictating wear mechanisms may change over time. The wear can start with loosely bonded carbides, which can then influence both three-body abrasion and stability of the tribo-film due to carbide pullout (Ref 75). Alternatively, the wear can start with carbide fracture or subsurface delamination of the coating material (Fig. 10 and 11). Similarly, subsurface fracture or delamination is not a wear mechanism observed in cemented WC-Co carbides, which can be attributed to the strength of material due to sintering manufacturing route (Ref 10), whereas microstructural defects lead to subsurface delamination of thermal sprayed coatings that accelerate the sliding wear process (Fig. 10).

Although tribo-film formation is not indicated within the wear mechanism of WC-Co cemented carbides by Bonny et al. (Ref 7), the presence of elemental W, Co, C and $\mathrm{O}$ within the wear track was observed, that is consistent with the formation of a tribo-film in thermal sprayed WC-Co coatings (Fig. 10) (Ref 101). Stoyanov et al. (Ref 11) considered the sliding wear of WC against $\mathrm{W}$ and also discussed that the wear particles revealed the crystalline structure of $\mathrm{W}, \mathrm{WC}, \mathrm{W}_{2} \mathrm{C}, \mathrm{WO}_{\mathrm{x}}$ and Co. They also conducted a molecular dynamics simulation of the test couples. It was concluded that for rough-on-rough tribocouples, the WC asperities ploughed through the W asperities. The exposed carbon layer of the WC gradually mixes with the disordered $\mathrm{W}$ atoms, which accommodates the sliding motion. Hence, the beneficial effects of the tribo-film, which can include $\mathrm{W}$ in both the elemental and oxidised form, reduces the wear and friction of sliding test couples for cemented WC-Co carbides and thermal sprayed WC-Co coatings (Ref 11). The role of a beneficial $\mathrm{WO}_{\mathrm{x}}$ tribo-film is very similar in the sliding wear of WC-Co coatings and cemented WC-Co carbides (Ref 2, 69, 11, 14-16, 43, 89, 101).
Table 2 summarises thermal sprayed WC-Co coatings that were tested against counter body materials including $\mathrm{Si}_{3} \mathrm{~N}_{4}$, WC-Co, $\mathrm{Al}_{2} \mathrm{O}_{3}$ and steel. Amongst these counter bodies, steel has a significantly lower hardness than WCCo. An investigation by Saito et al. (Ref 9) for cemented WC-Co carbides considered the changes in wear mechanism for test couples comprised of $0.45 \mathrm{wt} \%$ carbon steel. The authors concluded that the wear of cemented carbide in this case was controlled by the transfer of counter body (steel) material on to WC-Co during sliding wear (Ref 9). This is consistent with the observation in thermal sprayed WC-Co coatings tested against steel balls (Ref 14-16, 75). This investigation revealed that removal of the binder phase can play a dominant role during the wear of cemented WC-Co carbides (Ref 9). Despite this difference in the sliding wear mechanism due to the steel counter body, the authors concluded that the wear rate for $\mathrm{WC}$ $16 \mathrm{wt} \%$ Co varied between $0.1 \times 10^{-6}$ and $0.65 \times 10^{-6} \mathrm{~mm}^{3} / \mathrm{Nm}$ for the carbide grain size range of 0.6-6 $\mu \mathrm{m}$ (Ref 9). Although the wear rate in their investigation was proportional to the Vickers hardness, which is consistent with other investigations (Ref 6,7), it was discussed that the hardness and carbide mean free path cannot completely clarify the wear mechanism. This was observed when the manufacturing route of cemented carbides was adjusted to a tighter impurity composition and mean carbide sizes from those specifications of commercially available (Ref 9) feedstocks. The authors highlighted that changes in feedstock manufacture need to be considered to understand the wear mechanism since these influence the microstructure of cemented carbides and affect properties such as fracture toughness. They also concluded that the wear rate should consider the shape and size distribution of WC grains (Ref 9).

The investigation by Saito et al. (Ref 9) concerned cemented WC-Co carbides and related wear mechanisms to the microstructure. These considerations are as equally important concerning the wear rate and wear mechanism of thermal sprayed WC-Co coatings due to their complex coating microstructure, as discussed in "Structure-Property Relationship in Sliding Wear" and "Semiempirical Mathematical Relationship in Sliding Wear of WC-Co Coatings" sctions.

\section{Structure-Property Relationship in Sliding Wear}

This section develops wear performance relationships between the sliding wear test parameters and material properties of the test couples. These include design parameters such as normal loads, sliding distance, sliding velocity for service loading and material properties such as hardness, elastic modulus and fracture toughness of the test 
couples (Fig. 4). This objective requires a rigorous assessment of the literature, where there are often gaps in the provision of explicit materials characterisation data. Care has been exercised to select high pedigree data for analysis, and in some cases, values have been estimated from graphs or converted from wear volume loss to wear rate. These estimated and converted data are identified in the analysis shown in the relevant figures.

Tillmann et al. summarised that wear performance of thermal sprayed coatings depends on (Ref 39):

1. The features of the coating microstructure that include the phases present, the extent of decarburisation, the mean free path of the binder, porosity, inter-splat bond strength, cracks and impurities.

2. The bulk properties of the coating itself, e.g., hardness, fracture toughness and elasticity.

3. The wear test parameters such as test type, material couple and test conditions.

4. Tribological incidents in the wear environment, e.g., three-body abrasion, tribo-film, binder and carbide interactions.

The following sections analyse these design and performance parameters to develop structure-property relationships.

\section{Influence of Carbide Grain Size (CGS) on Hardness and Sliding Wear Resistance}

The usual methods of manufacturing feedstocks for thermal spray coatings are by agglomeration and fuse/sintering processes. Commercial powders are manufactured with different carbide grain size (CGS) and binder composition that influence the wear rate (Table 2). In cemented WC-6 wt.\%Co carbides, the resistance to abrasive wear depends upon CGS and can be approximated by the relationship $K_{I C}{ }^{3 / 8} H^{1 / 2} / D_{w c}$, where $K_{I C}$ is the fracture toughness, $H$ is the hardness, and $D_{w c}$ average WC grain size diameter (Ref 41). Although this relationship does not hold for thermal sprayed WC-Co coatings, it does show the dependency of wear rate on CGS. A reduction in CGS is expected to reduce the binder mean free path (Fig. 12a) that forces the crack propagation behaviour from transgranular to intergranular (Fig. 10 and 11), hence encouraging cracks to propagate through the tougher binder and thereby increasing the toughness of the material. As discussed in "Sliding Wear Mechanisms" section, a reduction in the binder mean free path also reduces preferential matrix erosion during sliding wear (Ref 40, 41). Reduction in CGS is also expected to reduce the variation in hardness due to evenly distributed carbides within the microstructure, as described by Shipway et al. (Ref 37, 105).
Conventional WC-Co coatings exhibit a CGS of roughly 2-7 $\mu \mathrm{m}$ (Table 2). Several investigations have considered reducing the CGS to sub-micrometer-sized and nanosized carbides for wear-resistant applications (Ref $14,22,25,38,42)$. However, there is a compromise since investigations on WC-12Co coatings showed that finer carbides are associated with a lower thermal load capacity, which leads to decarburisation and dissolution of WC into the binder that increases binder brittleness (Ref 14$16,35,65,73)$. The increase of thermal loading on smaller CGS affects the carbides on the surface of the powder particles, thereby affecting the inter-splat features. The resulting brittle phases become a path for crack propagation around and under the splats that leads to splat delamination (Ref 37). These earlier studies, therefore, reported that the wear performance of reduced CGS coatings was inferior to conventional coatings (Ref 37). An important retrospect comment, however, is that the spray parameters were not optimised in these studies for the reduced CGS and optimum performance would not be expected for these coatings that were manufactured using the same spray parameters.

Further studies showed that the reduction in CGS produced more wear-resistant WC-Co coatings, especially where nanosized carbides are used in HVOF (Ref $33,39,40,42)$ and APS coatings (Ref 21, 22). Ma et al. (Ref 42) observed that coatings with nanosized carbides demonstrated better sliding wear performance when the normal load was low (50 N-block-on-ring configuration). However, at higher normal load $(250 \mathrm{~N}$, block-on-ring configuration) the wear performance decreased. It was concluded that (i) an increase in the contact pressure had an adverse response on the inter-splat boundary and the amorphous phases and (ii) the sliding wear resistance using the block-on-ring test was directly proportional to the product of the hardness and fracture toughness (Ref 42). Tillman et al. (Ref 39) observed that smaller carbides dissolve into the binder more easily, thus allowing for better bonding with the binder material that resisted carbide pullout. The coating with micrometer-sized carbides exhibited cracks propagating through the carbides in both the sliding (ball-on-flat) and the rolling Taber test.

Schwetzke et al. (Ref 106) indicated that as long as the carbon loss was below $60 \mathrm{wt} . \%$ then the hardness and sliding wear resistance of HVOF WC-Co coatings was not affected significantly. In plasma-sprayed coatings, the plasma spray torch and gas mixture heavily influence the microstructure and properties of the coating. Zhu et al. (Ref 22) produced coatings using VPS, which limited the decarburisation due to the high temperatures inherent in such plasma spray technologies (Fig. 5). The nanostructured VPS coating performed significantly better than the conventional counterpart at loads of $20-80 \mathrm{~N}$ when using 
the ball-on-flat methodology against an alumina ball (Ref 22). The improved wear resistance of the nanostructured coating was attributed to its higher hardness and toughness. This allowed the nanostructured coating to perform well compared to the conventional coating. Sanchez et al. (Ref 21) studied the wear performance of coatings produced using Ar- $\mathrm{H}_{2}$ and Ar-He. The $\mathrm{H}_{2}$ gas mixture provides a higher enthalpy and produced a coating with higher decarburisation and more amorphous phase that resulted in relatively poor sliding wear performance (Ref 21$)$.

Ahmed et al. (Ref 14) produced a nanostructured coating using S-HVOF where the total wear rate of the test couples was better than a conventional coating. When comparing the influence of the counterbody on the total wear rate, S-HVOF coatings performed relatively better when tested against a WC-Co ball (Ref 16, 107). The S-HVOF coatings exhibited a higher hardness but also a higher carbon loss, as inferred by the presence of $\mathrm{W}$ that was detected by XRD of the S-HVOF coating, Fig. 5 (Ref $14,15,107)$. Another study investigated S-HVOF coatings using another nanostructured feedstock, where similar behaviour of improved total wear rate of test couples was observed in both as-sprayed and HIPed coatings sliding against WC-Co ball (Ref 16). This improved performance after HIPing is consistent with earlier investigations in conventional WC-Co coatings (Ref 75, 98, 102, 108). Hence as the coating process and process parameters are optimised, nanostructured coatings indicate an improvement in the wear performance under specific tribological conditions (Ref 14-16, 21, 22, 33, 39, 40, 42).

A further point is that the S-HVOF process has the capability of manufacturing thin coatings that are unachievable by conventional thermal spray technologies. Similarly, improved sliding wear performance of nanostructured coatings depends on an even distribution of nanosized particles (Ref 79), which is not a limitation in the S-HVOF coatings as all WC particles are nanosized (Ref 14-16, 73). There is, accordingly, an optimisation trade-off concerning the design specifications for these nanocomposite coatings.

Figure 14(a) summarises the relationship between CGS and Vickers hardness and indicates that the reduction in carbide size can lead to increased hardness (Ref 2123, 25, 28-31, 33, 34, 38-40, 43, 44, 105). There are several outlier data points that are attributed to non-optimised spray parameters or eta-phase-transformations (Ref 21, 22). Increased retention of WC in coatings tends to produce coatings with higher hardness. Although the hardness of $\mathrm{W}_{2} \mathrm{C}$ is higher $\left(\mathrm{HV}=3000 \mathrm{kgf} / \mathrm{mm}^{2}\right)$ than $\mathrm{WC}(\mathrm{HV}=$ $\left.2400 \mathrm{kgf} / \mathrm{mm}^{2}\right)(\operatorname{Ref} 41)$, the greater proportion of retained WC still produces a coating with higher average hardness and lower wear rate. This is consistent with the findings of Ang et al. (Ref 60) where HVOF coatings produced a higher normalised hardness ( $\simeq 8-16 \mathrm{GPa})$ in comparison of APS ( $\simeq 6-12 \mathrm{GPa})$ and cold-sprayed ( $\simeq 7-12 \mathrm{GPa})$ WC-Co coatings. The materials science reasoning is that decarburisation of $\mathrm{WC}$ not only produces $\mathrm{W}_{2} \mathrm{C}$ but also $\mathrm{W}$ (Fig. 5 and 6), which significantly reduces hardness (Ref 41). In addition, the eta-phases of $\mathrm{M}_{6} \mathrm{C}$ and $\mathrm{M}_{12} \mathrm{C}$ reduce fracture toughness; thereby reducing wear performance. Figure 14(b) indicates that, although the CGS has no direct correlation to the sliding wear performance, the wear performance is related to the extent of decarburisation. The paucity of data in some publications restricted their use in Fig. 14; but these investigations related to the influence of CGS have been included in Table 2 .

In summary, the wear performance tends to improve when CGS is reduced, if decarburisation and other mechanical properties are controlled, which demands optimised spray parameters when depositing WC-12Co coatings. Furthermore, HIPing can increase the hardness and elastic modulus and influence the wear performance (Ref 15, 75, 98, 102, 108) in conventional and S-HVOF coatings (Table 2).

\section{Influence of Binder Composition, Content and Test Temperature On Sliding Wear Performance}

The binder composition plays an important role in WC cermet coatings by allowing the coating to perform under high temperature and corrosive environments (Ref 19, 23, 109, 110). Common compositions for WC cermet coatings are $\mathrm{WC}-12 \mathrm{Co}$, WC-17Co, WC-10Co-4Cr and WC-12Ni (Ref 3, 5, 19, 20, 26) (note that all compositions are in wt.\%). Figure 15(a) (Ref 26, 109, 110) depicts the influence of composition on the corrosion resistance. Figure 15(b) (Ref 111-113) shows the mechanical properties of the binder materials commonly used in WC cermet coatings. Cobalt demonstrates a good combination of hardness and toughness as a binder material (Ref 10, 46). It also has good wetting properties among the WC-Co constituents (Ref 10). Cobalt exhibits a hexagonal crystal structure, which provides Co with dry lubrication properties similar to graphite, which is unlike the cubic crystal structures of $\mathrm{Cr}$ and $\mathrm{Ni}$ (Ref 114). Cobalt is able to also undergo a beneficial FCC to HCP transformation under strain (Ref 91-95). Buckley et al. (Ref 114) investigated the phase transformation of Co and concluded that the HCP form of cobalt exhibited much lower friction and better wear characteristics than the FCC form.

Increasing the binder content from the $\mathrm{WC}-12 \mathrm{Co}$ to WC-17Co permits improved sliding wear performance under tribological conditions of elevated temperature (Ref 115) and lower load (Ref 115, 116). This improvement in wear performance is attributed to the stability of the tribofilm. The films form in large areas of the wear track when 
Fig. 14 (a) The Vickers hardness and (b) wear rate of WC-12Co coatings with average CGS in $\mu \mathrm{m}$ (red: high WC retention and low amorphous presence, black: increased presence of $\mathrm{W}$,

$\sim$ value estimated from graphs, $\mathrm{mm}^{3} / \mathrm{Nm}$ ) $*$ value converted to $\times 10^{-6}$
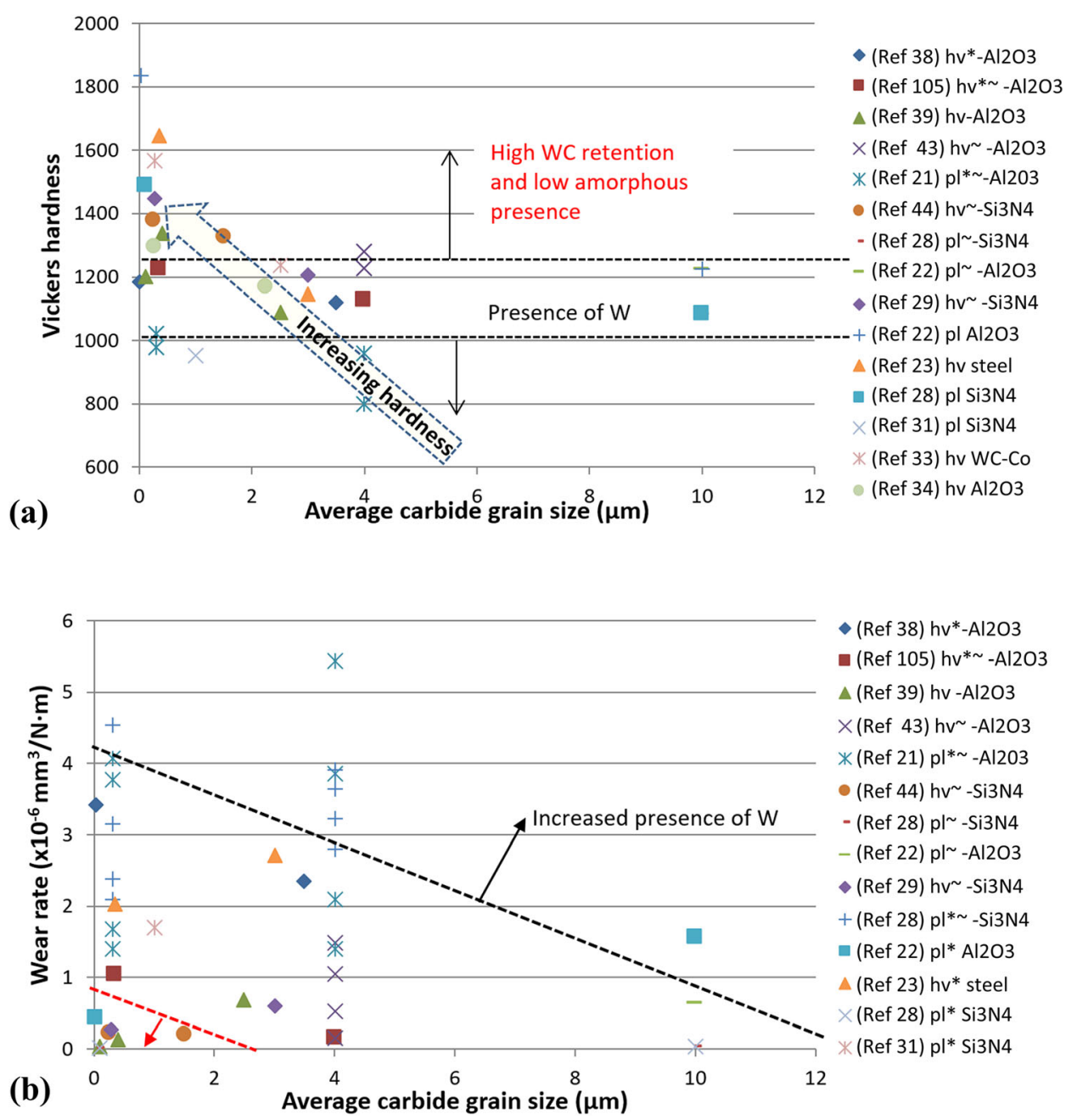

higher binder content is available, especially at high temperatures and low load conditions (Ref 115, 116). The corrosion resistance of WC-17Co coatings has been observed to be lower than WC-12Co (Ref 109) since the increased binder content is conducive for corrosion mechanisms.

The addition of $\mathrm{Cr}$ to the Co binder allows for a harder binder (Ref 117). The composition of WC-10Co-4Cr was investigated by Berger et al. (Ref 117). The influence of this binder composition on the sliding wear performance was inconclusive because the CGS between these two coatings was inconsistent (Ref 117). Xie et al. found that the addition of $\mathrm{Cr}$ does not improve sliding wear resistance despite the increase in coating hardness (Ref 116). Lyphout et al. (Ref 26), however, showed that coatings of WC10Co-4Cr demonstrated higher corrosion resistance compared to WC-12Co coatings when the CGS's are equal. Nanocomposite S-HVOF WC-Co coatings have also been investigated for their corrosion performance and compared with conventional HVOF coatings (Ref 118). The authors concluded that, based on the potentiodynamic polarisation results, coatings produced by S-HVOF technique show lower corrosion resistance compared with the coatings produced by HVOF-JK (HVOF JetKote) and HVOF-JP (HVOF JP5000) techniques (Ref 118). This was attributed to strong carbon loss during spraying leading to the presence of metallic tungsten and the presence of a higher amount of amorphous/nanocrystalline constituents compared with conventional coatings (Ref 118).

Berger et al. (Ref 117) compared WC-12Co coatings with WC cermet coatings where Co was substituted with $\mathrm{Ni}$. The Ni binder coatings resulted in relatively lower hardness and wear resistance. Ward et al. (Ref 119) observed that the sliding wear performance of WC- $12 \mathrm{Ni}$ coatings was lower by an order of magnitude when compared to WC-10Co-4Cr coating. They postulated that the extra binder content and formation of chromium carbide were contributing factors in improved wear performance 
Fig. 15 (a) Corrosion resistance of WC cermet coatings (Ref $23,109,110)$, (b) typical values of mechanical properties for common binder materials (Ref 111-113), (c) wear rates of all of the tested coatings, measured after ball-on-disc testing at room temperature, at 400 and $700{ }^{\circ} \mathrm{C}$ against sintered $\mathrm{Al}_{2} \mathrm{O}_{3}$ spheres (Ref 128), (d) estimated room and high-temperature sliding wear rates of WC-12Co, WC-17Co, WC-10Co-4Cr, $\mathrm{Cr}_{3} \mathrm{C}_{2}-25 \mathrm{NiCr}$ coatings deposited by HVOF, HVAF, APS, LPPS, coatings in air and argon environments (Ref $31,115,116,121,128)$. The top image is the wear rate in log scale, and the bottom image is the magnified version in normal scale
Low corrosion resistance

High corrosion resistance

\begin{tabular}{|l|l|l|l|}
\hline WC-17Co & WC-12Co & WC-10Co-4Cr & WC-12Ni \\
\hline
\end{tabular}

(a)

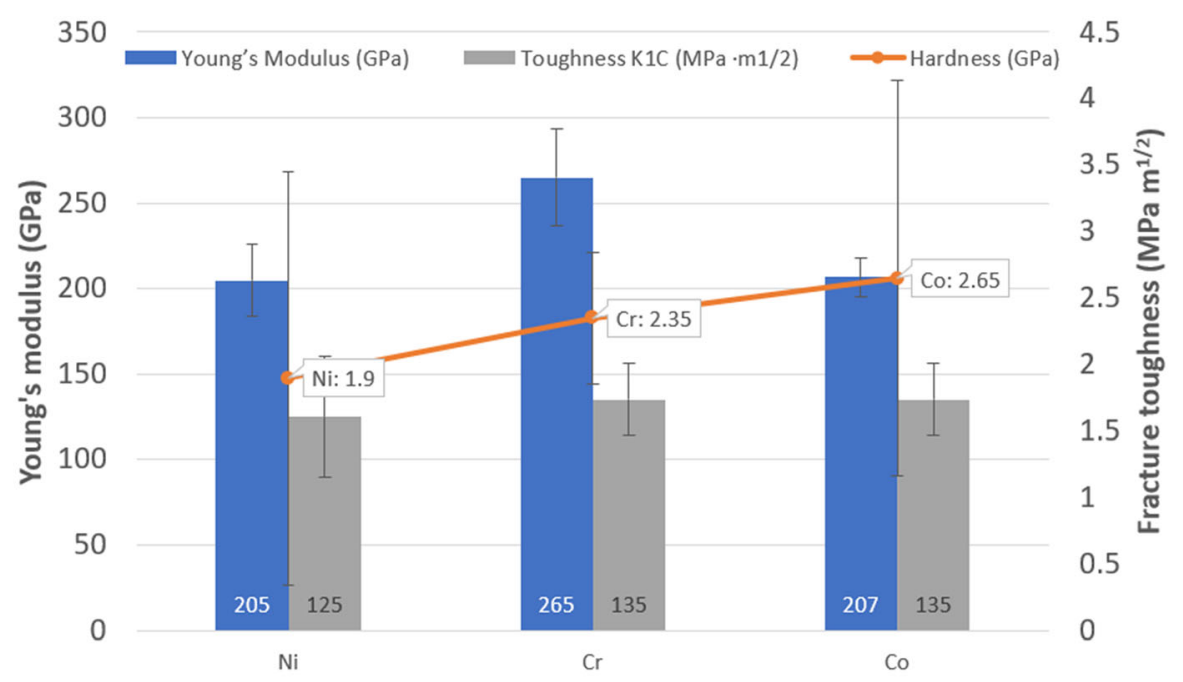

(b)

(c)

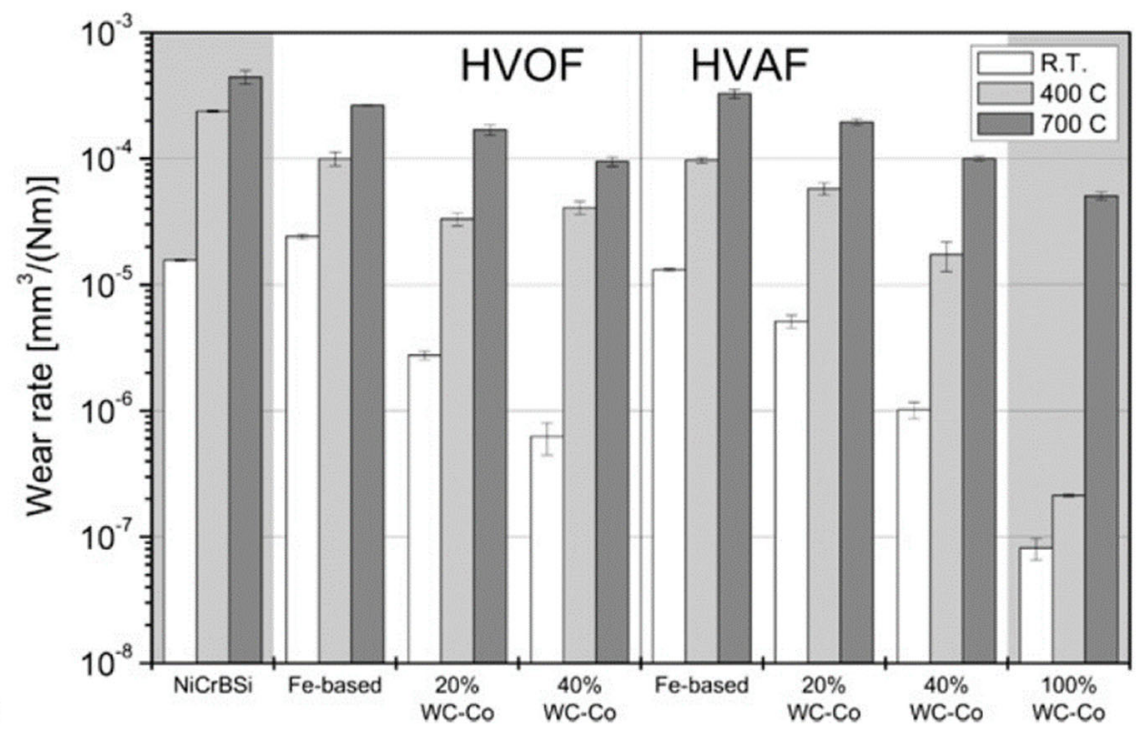

(Ref 119). The corrosion resistance of WC-Ni coatings is significantly higher than $\mathrm{WC}-10 \mathrm{Co}-4 \mathrm{Cr}$ coatings, as observed in a study by Ward et al. (Ref 110).

Table 4 (Ref 32,108, 116, 117, 120-127) presents the wear performance of WC cermet coatings with respect to binder composition. The cermet coating composed of WC$\mathrm{NiCrBSi}$ is not well-documented in terms of its sliding wear in comparison to WC-12Co coatings (Table 4). The $\mathrm{NiCrBSi}$ alloy has attractive properties as a binder material that is attributed to (i) the wettability of $\mathrm{Ni}$, (ii) an increase in the resistance to oxidation and corrosion by $\mathrm{Cr}$, and (iii) a reduced melting temperature conferred by boron and silicon (Ref 122). Coatings of WC-NiCrBSi, when compared to WC-12Co coatings, demonstrate more consistent performance in high-temperature environments, as observed by Bolelli et al. (Ref 128). These authors also reported that the sliding wear performance of a $\mathrm{WC}-12 \mathrm{Co}$ blend was better than a WC-NiCrBSi coating. 
Fig. 15 continued
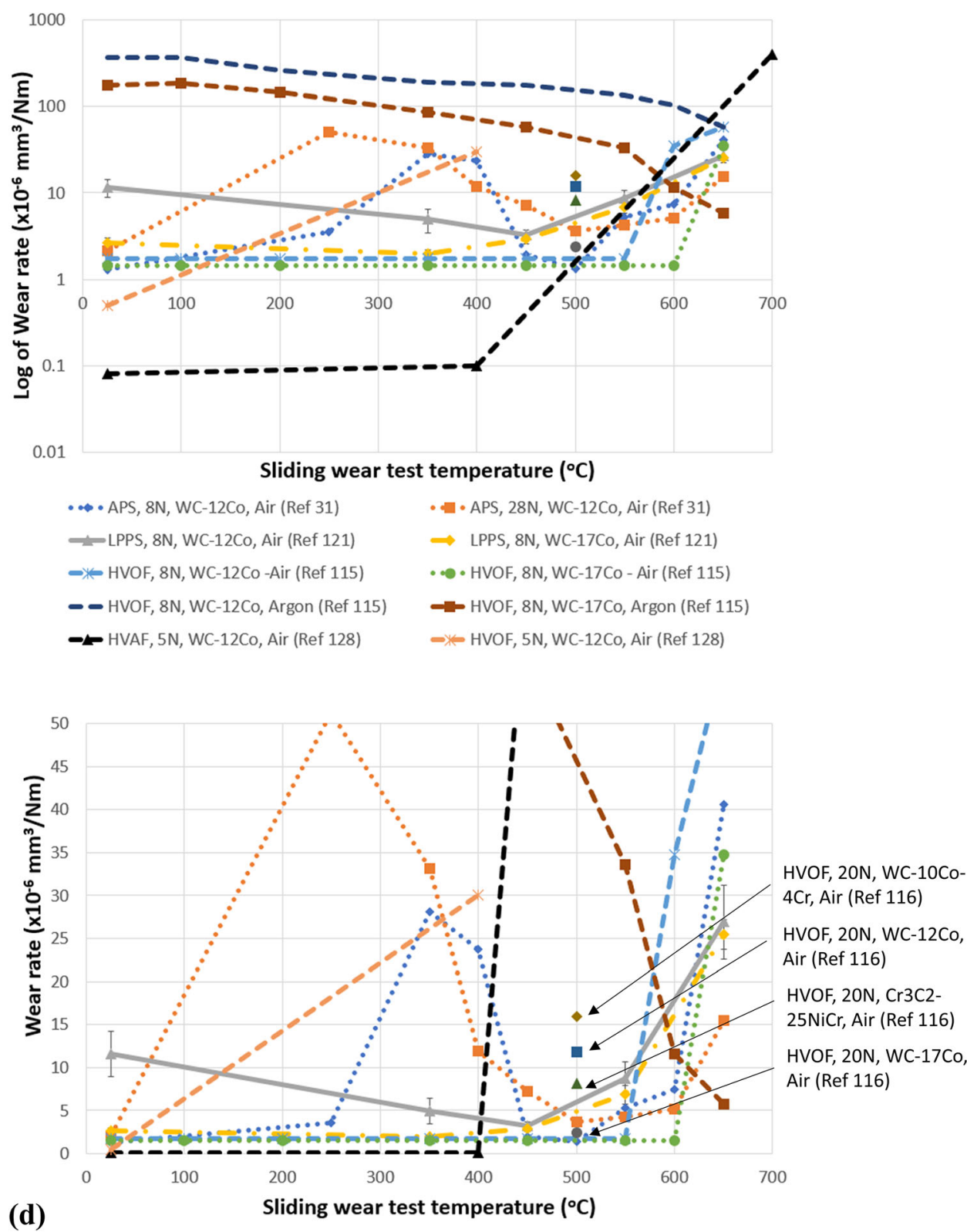

Figure 15(c) compares the sliding wear resistance of $\mathrm{FeCrNiSiBC}+$ WC-Co composite coatings with NiCrBSi coatings using HVOF and HVAF spraying (Ref 128). This investigation was conducted from room temperature to $700{ }^{\circ} \mathrm{C}$. The Vickers micro-hardness values of these coatings were similar despite the difference in microstructures between these HVOF and HVAF coatings. The reinforcing effect of WC-Co decreases the wear rate of composite coatings $\left(\approx 1 \times 10^{-6} \mathrm{~mm}^{3} / \mathrm{Nm}\right)$ by more than an order of magnitude, compared to unreinforced ones $(\approx 1$ $\left.2 \times 10^{-5} \mathrm{~mm}^{3} / \mathrm{Nm}\right)$. The increase in test temperature led to an increase in the wear rate, which arose from the oxidation of WC-Co. Variations of the NiCrBSi alloy composition with the addition of WC have been investigated in other sliding wear investigations (Ref 56, 102, 108).

WC-12Co, under sliding wear conditions, is considered as an ideal coating material amongst commercially available WC cermet coatings (Tables 2 and 4). Table 4 and Fig. 15 specify that adjustments in binder composition are justified when the environmental factors are changed to high temperatures or corrosive environments.

Figure 15(d) shows an analysis of the variation in sliding wear rates for APS, HVOF, HVAF, LPPS coatings over $25-650{ }^{\circ} \mathrm{C}(\operatorname{Ref} 31,115,116,121,128)$. The data in this analysis are presented in the log scale to visualise the large variations in sliding wear rate with temperature and argon 


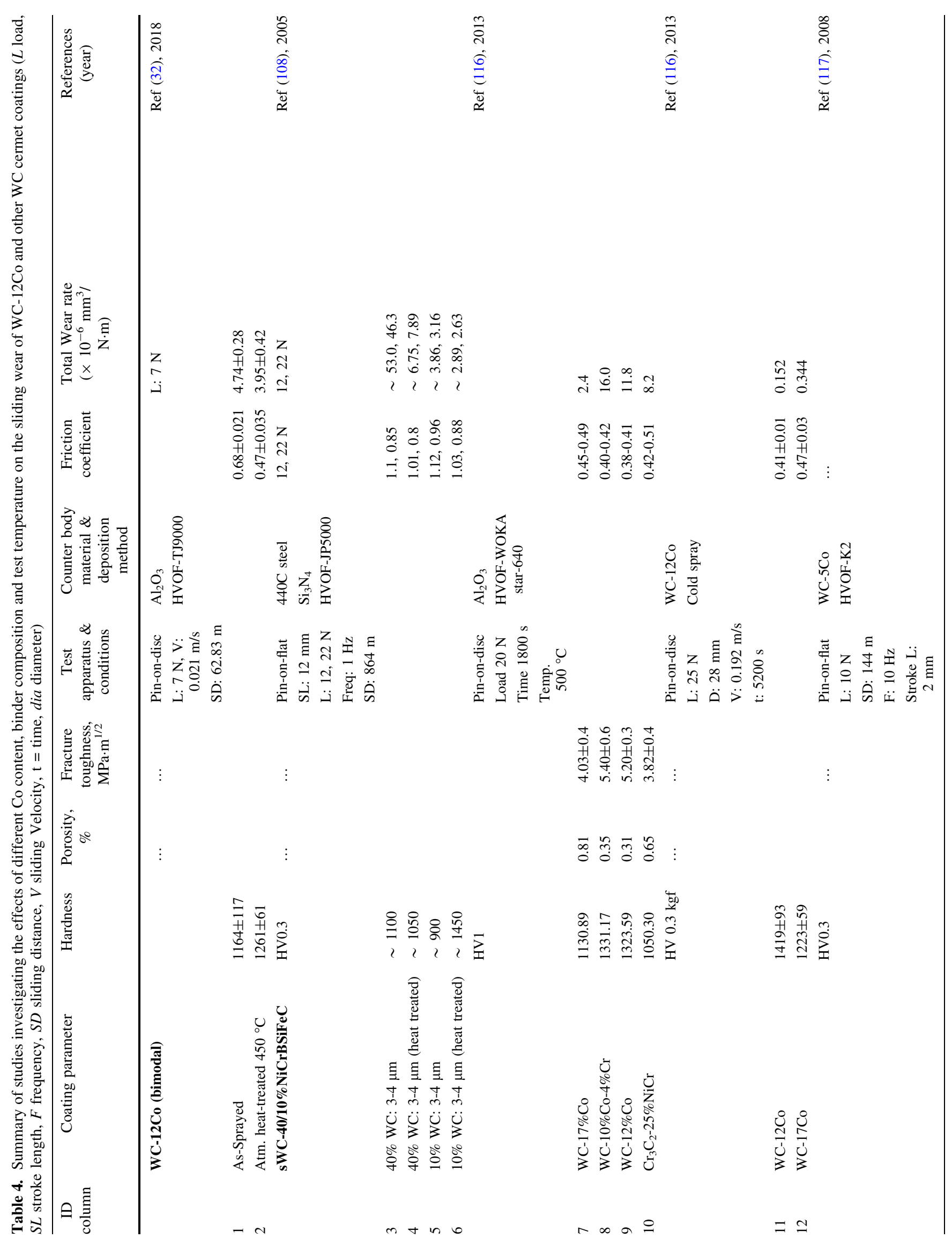




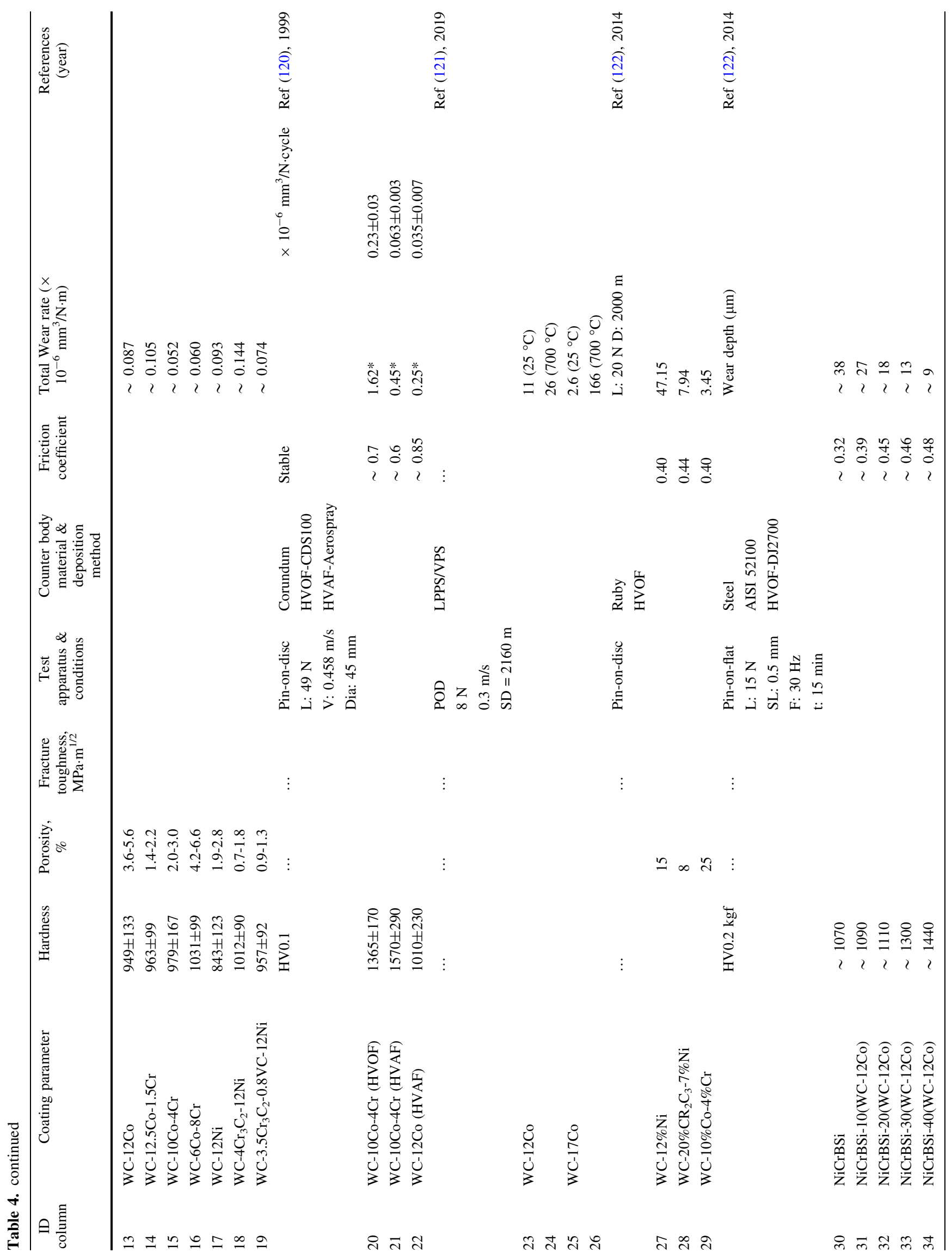




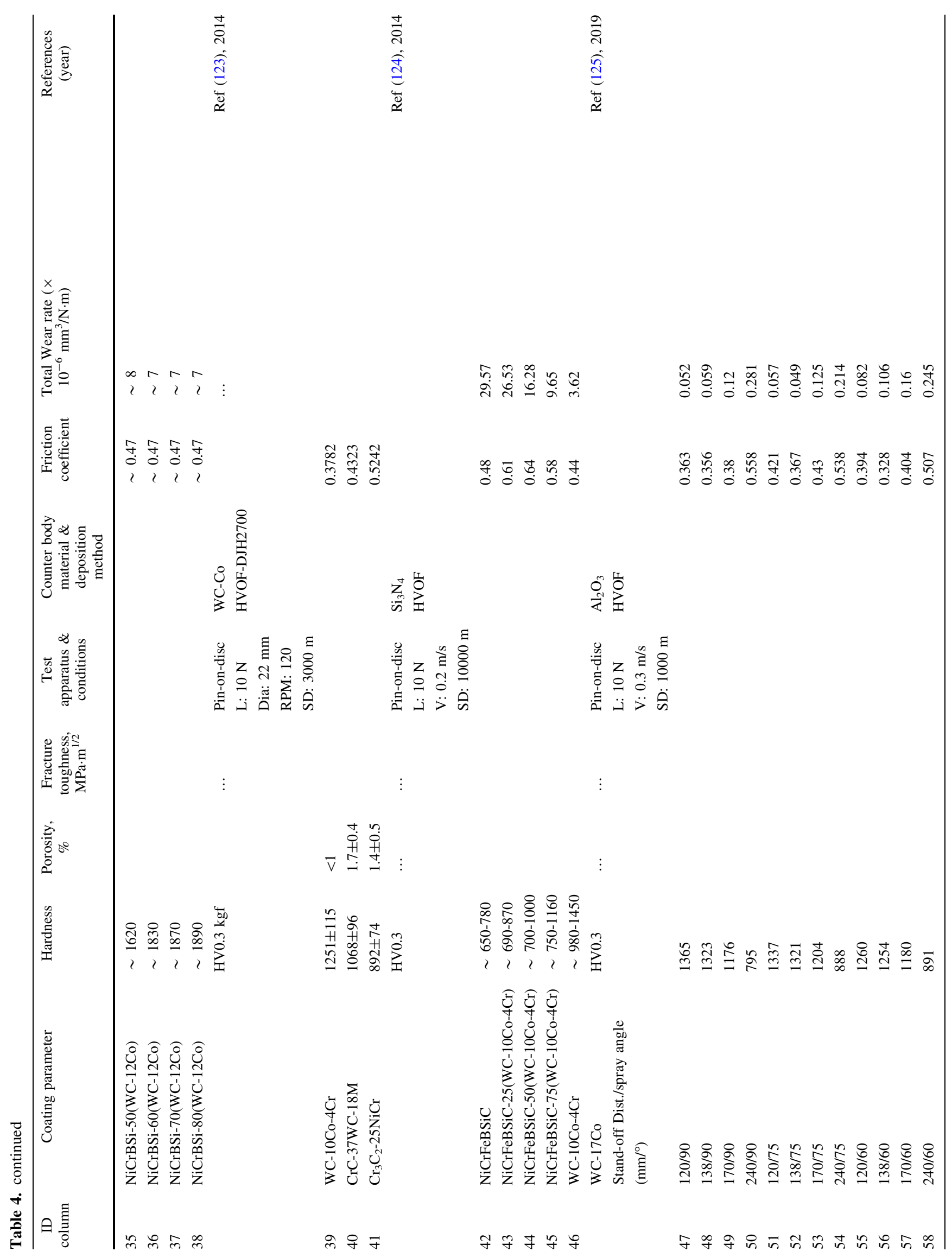




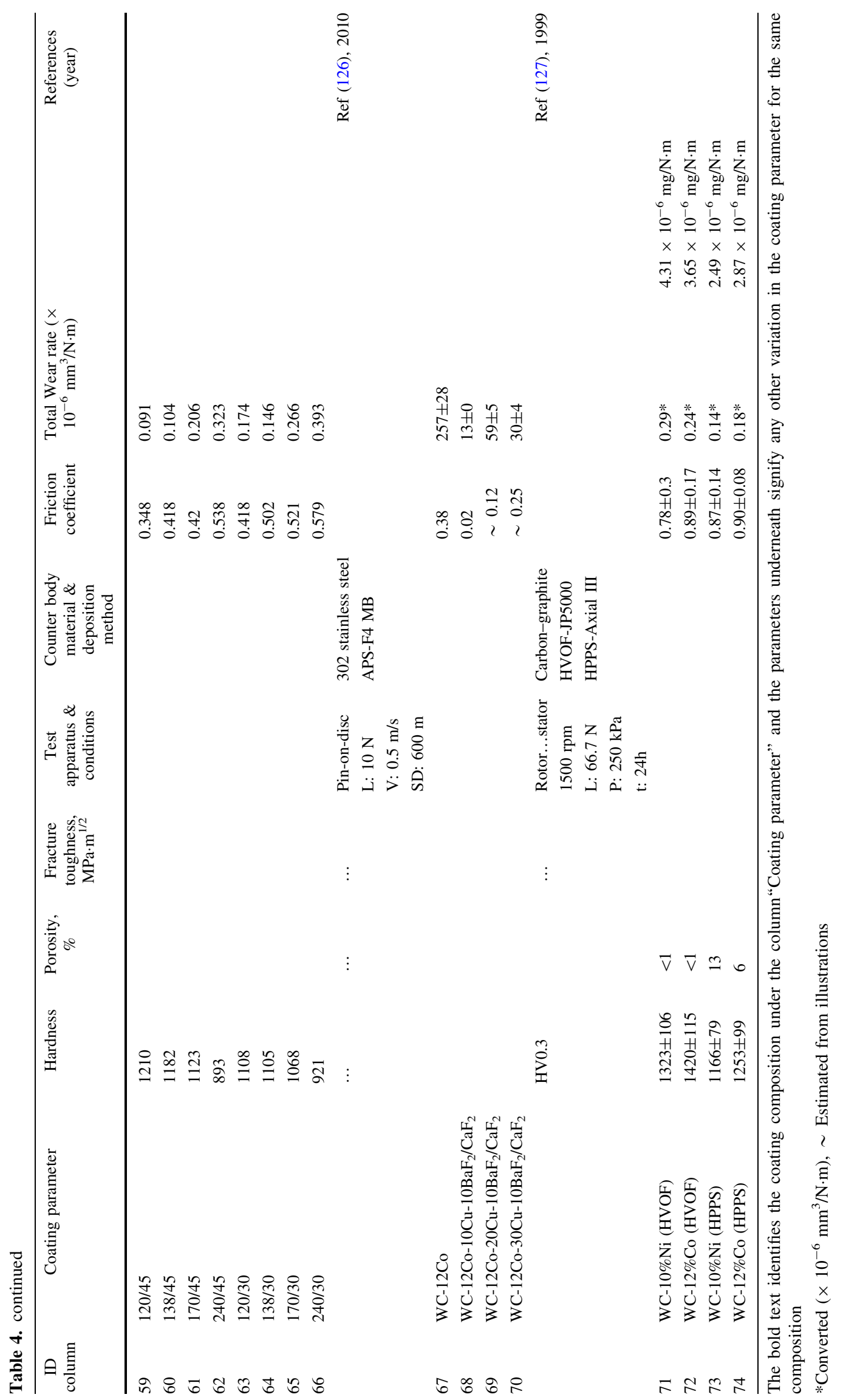


environment. The lower part of the figure shows a comparison of wear rate up to $\sim 50 \times 10^{-6} \mathrm{~mm}^{3} / \mathrm{Nm}$ to highlight the wear rate differences in oxygen environment up to a temperature of $600{ }^{\circ} \mathrm{C}$. A comparison of Fig.15(d) with Fig. 14(b) shows that the wear rate for higher temperature tests can increase by orders of magnitude $\left(\sim 0.1-400 \times 10^{-6} \mathrm{~mm}^{3} / \mathrm{Nm}\right)$ in comparison with room temperature tests $\left(\sim 0.1-6 \times 10^{-6} \mathrm{~mm}^{3} / \mathrm{Nm}\right)$. A further inspection of the data shows that in most cases the wear rate over the temperature range of $25-650{ }^{\circ} \mathrm{C}$ is below $50 \times 10^{-6} \mathrm{~mm}^{3} / \mathrm{Nm}$, as the higher wear rates, shown in Fig. 15(d), are related to the Argon environment tests or tests above $650{ }^{\circ} \mathrm{C}$. Both coating quality and test load influences the wear rate, for example for tests in the temperature range of $25-550{ }^{\circ} \mathrm{C}$ conducted in air, APS coatings show the highest wear rate. For the APS coating, the wear rate also increases with the increase in test load. The wear rate in all cases of tests conducted in air above $550{ }^{\circ} \mathrm{C}$ shows an increase in the wear rate. The tests conducted in the argon environment show an inverse trend where the very high wear rates $\left(\sim 170-370 \times 10^{-6} \mathrm{~mm}^{3} / \mathrm{Nm}\right)$ at room temperature decrease to lower values $(\sim 0.57-57$ $\left.\times 10^{-6} \mathrm{~mm}^{3} / \mathrm{Nm}\right)$ at $650{ }^{\circ} \mathrm{C}$.

In the case of APS coatings tested at loads of 8 and $28 \mathrm{~N}$ using $\mathrm{Si}_{3} \mathrm{~N}_{4}$ balls, the wear rate increases up to $\sim 250{ }^{\circ} \mathrm{C}$, where significant coating delamination was observed. A subsequent temperature increase led to a decrease in the wear rate (Ref 31). The performance comparison of WC12Co and WC-17Co coatings was also provided by Geng et al. (Ref 121) using a low plasma spray process. They indicated that the higher binder content in WC-17Co coatings helped decrease the wear rate at $550{ }^{\circ} \mathrm{C}$. The wear rates in this investigation were slightly higher than those reported by Bolelli et al. (Ref 128) in the lower temperature range. However, at higher temperatures, the wear rates reported by Geng et al. (Ref 121) were lower. Bolelli et al. (Ref 128) also indicated a significant decrease in the wear rate at $700{ }^{\circ} \mathrm{C}$ when changing the coating process from HVOF to HVAF. In an argon environment, Geng et al. (Ref 115 ) indicated that the volume loss of WC-Co coatings is significantly higher than that in air for sliding wear tests conducted in the range of $\sim 25-600{ }^{\circ} \mathrm{C}$. They concluded that the WC-Co coatings should not be used for applications in oxygen-deficient environments.

Two factors play an important role as the temperature increases from room temperature up to $\sim 600{ }^{\circ} \mathrm{C}$. The first factor is the temperature-dependent changes in the mechanical properties of the coatings. As the temperature increases, the elastic modulus and hardness decreases, whereas fracture toughness is expected to show an increase due to thermal softening. However, due to microstructural phase changes leading to eta-phases at a higher temperature, the toughness also decreases as indicated by Geng et al. (Ref 115). These temperature-dependent variations in the mechanical strength are well documented for cemented WC-Co carbides (Ref 129, 130); however, they are more complex in WC-Co coatings due to their microstructure (Ref 115). In particular, the changes in the cracking and delamination behaviour of WC-Co coatings at higher temperatures depend on the coating microstructure and, thus, the coating process and parameters. This was discussed by Geng et al. (Ref 31) where APS coatings showed significant delamination at $\sim 250{ }^{\circ} \mathrm{C}$. Other studies using HVOF, HVAF and LPPS coating processes did not show such an aggressive delamination behaviour until a much higher temperature of $\sim 650{ }^{\circ} \mathrm{C}$, as shown in Fig. 15(d) (Ref 31, 115, 116, 121, 128).

The second factor depends on the tribological test conditions and surface chemistry of the coating material. Geng et al. (Ref 115) investigated the microstructural phase changes in HVOF-sprayed WC-Co coatings using XRD performed under air and argon environments. They indicated that in air, WC peaks remain dominant in the microstructure up to $600{ }^{\circ} \mathrm{C}$; whereas $\mathrm{WO}_{3}$ and $\mathrm{CoWO}_{4}$ peaks are also observed above $\sim 450{ }^{\circ} \mathrm{C}$. As discussed earlier in "Tribo-Chemical Behaviour" section, $\mathrm{WO}_{3}$ and $\mathrm{CoWO}_{4}$ are important tribo-films that reduce the sliding friction and wear behaviour of WC-Co coatings. There were no significant changes below $550{ }^{\circ} \mathrm{C}$ for the XRD measurements carried out in an oxygen-deficient, argon environment, whereas $\mathrm{M}_{12} \mathrm{C}\left(\mathrm{Co}_{6} \mathrm{~W}_{6} \mathrm{C}\right)$ forms at $600{ }^{\circ} \mathrm{C}$ (Ref 115). Some oxygen is present even in a presumed argon environment, so the formation of some $\mathrm{CoWO}_{4}$ at $650{ }^{\circ} \mathrm{C}$ was reported.

Note that even for sliding wear tests conducted at room temperature, the flash temperature caused by the asperity interaction still exceeds $\sim 500{ }^{\circ} \mathrm{C}$, leading to the formation of a beneficial tribo-film $\mathrm{WO}_{3}$ (Ref $16,40,43,89,101)$. Hence the role of oxidation leading to the formation of tribo-film at higher temperature sliding wear tests is both beneficial and counterproductive. It is beneficial for protective tribo-film formation and stability, but counterproductive due to detrimental phase changes that lead to loss of carbides due to oxidation and reduced mechanical strength. In some respects, the WC-Co coating becomes sacrificial at higher temperatures due to material loss through oxidation during the formation of the protective oxide film. Other wear mechanisms of preferential matrix erosion and cracking are also observed at higher temperature sliding wear tests; however, the wear mechanism is dominated by the formation and stability of the oxidised tribo-film.

Structure-property relationship and tribological test conditions dictate the performance during high-temperature sliding wear tests. The test load and temperature influences the stability of the tribo-film. This effect was 
indicated by Geng et al. (Ref 31) where back-to-back tests conducted at 8 and $28 \mathrm{~N}$ load using $\mathrm{Si}_{3} \mathrm{~N}_{4}$ counter body ball material revealed a significantly lower friction coefficient and sliding wear rate due to the stability of the tribofilm at the lower load (Fig. 15d). The figure shows that a change in binder Co content from 12 to $17 \mathrm{wt} . \%$ increases the wear resistance due to the relatively lower oxidation of $\mathrm{WC}$ and beneficial influence of Co in improving both the mechanical strength and formation of $\mathrm{CoWO}_{4}$ tribo-film at higher temperatures. This outcome is consistent with the investigation of Xie et al. (Ref 116) where the sliding wear rate at $500{ }^{\circ} \mathrm{C}$ was lowest for WC-17Co by $\sim 50 \%$, followed by $\mathrm{Cr}_{3} \mathrm{C}_{2}-25 \mathrm{NiCr}$, WC-12Co, WC- $10 \mathrm{Co}-4 \mathrm{Cr}$, respectively (Fig. 15d).

\section{Influence of Spray Parameters on Sliding Wear Performance}

HVOF and APS processes are the most commonly used methods for the deposition of WC-Co coatings (Table 2). APS coatings are inferior due to their higher porosity, low adhesion strength and adverse phase reactions to those produced using HVOF (Table 2). Hence, there are less recent studies of WC-Co deposition by APS processes. HVOF systems use liquid or gas fuels and plasma systems use plasma gases, both of which need to be optimised to keep the feedstock from overheating in-flight and decomposing into eta-phases.

Qiao et al. (Ref 44) studied the effect of changing the fuel to oxygen ratio $(\mathrm{F} / \mathrm{O})$ on the wear performance of coatings produced with different CGS feedstocks. The fuel ratios were classified as neutral (complete combustion), oxidising (excess oxygen) and reducing (excess propylene) and are indicated in Table 2. In-flight temperature and velocity of the powders were measured using a Technar DPV 2000 system. In the neutral condition, the feedstock powders achieved the highest temperature, $\sim 2200{ }^{\circ} \mathrm{C}$, and the highest velocity, $\sim 700 \mathrm{~m} / \mathrm{s}$. Since the combustion in the reducing and oxidising flame is not complete, powder temperatures $\left(1550-1800{ }^{\circ} \mathrm{C}\right)$ and velocities $(450$ $550 \mathrm{~m} / \mathrm{s}$ ) were lower than in the neutral flame. The neutral ratio produced the highest temperatures and also exhibited more decarburisation in the deposited coatings, followed by the oxidising ratio in most cases. The importance of the in-flight temperatures was highlighted in this study since the coatings with high degrees of decarburisation (neutral ratio) performed better in sliding wear than their counterparts. The lower temperatures affect the melting of particles in-flight and, therefore, weakening the adhesion strength of the coating which affected the wear performance. The dominating wear mechanism for coatings formed from the neutral ratio was binder extrusion followed by carbide pull out with a small degree of three-body abrasion. The carbides were well-embedded in the binder with low porosity. On the other hand, the coatings produced under reducing or oxidising ratios were dominated mainly by three-body abrasion since the porosity was higher and bonding between splats was weak, which lead to carbide pull out (Ref 44).

Sudaprasert et al. (Ref 43) compared coatings produced by kerosene and hydrogen fuel using the same feedstock. Results were similar to those of Qiao et al. (Ref 44), where the coating with a higher degree of decarburisation (hydrogen fuel) exhibited better wear performance than its counterpart. The reason was the incomplete melting of the particle that affected the adhesion of the embedded carbide in the binder. Qiao et al. (Ref 44) and Sudaprasert et al. (Ref 43) emphasised the necessity of carbide dissolution into the binder to improve wear performance, but there is a critical point beyond which the wear performance falls, which is highlighted by Wang et al. (Ref 131). In their investigation, propylene was used as fuel and was incrementally increased while keeping the oxygen input constant. Carbide dissolution kept increasing with increasing propylene and signified decarburisation (Ref 131). Table 5 (Ref 131) shows the changes in bulk mechanical properties of the coating and the wear track width for changing fuel/ oxygen ratios. The coating with the highest wear resistance (96/1020 fuel to oxygen ratio) showed good carbide retention, whereas the coating with the highest degree of decarburisation (136/1020 fuel to oxygen ratio) displayed brittle fracture in the worn surface. The brittle fracture of the coating would contribute strongly to three-body abrasion (Ref 131).

The preferred wear mechanism for WC-Co-based coatings was binder extrusion followed by carbide pull out with small degrees of three-body abrasion (Ref 131). The coating wear rate becomes significantly higher when threebody abrasion becomes the main wear mechanism. Improvement of the sliding wear resistance carbide bonding is achieved by the partial dissolution of the carbide into the binder. Girolamo et al. investigated different compositions of gases to produce WC-12Co wear-resistant coatings (Ref 132). Table 6 summarises the parameter and bulk mechanical properties and their findings of wear performance (Ref 132, 133). Decarburisation was extensive for the coating produced using Ar-H gases. Decomposition of $\mathrm{WC}$ to $\beta$-WC, which occurs at high temperatures, led to brittle phases and promoted fracture-based wear mechanisms followed by three-body abrasion. The Ar-H-He and Ar-He coatings exhibited heterogeneous microstructures with embedded carbides in both un-dissolved and dissolved states within the binder (Ref 132). The authors reported that wear mechanics for these (Ar-H-He and $\mathrm{Ar}-\mathrm{He})$ coatings was composed mainly of binder extrusion and carbide pull out or fragmentation. The coating produced 
Table 5. Difference in WC12 Co coating properties, wear and decarburisation with varying fuel chemistry (Ref 131)

\begin{tabular}{lccccc}
\hline Fuel /oxygen, L/min & Hardness HV0.3 & Fracture toughness & CoF & Track width (mm) & $\mathrm{W}_{2} \mathrm{C}$ to WC \\
\hline $96 / 1020$ & 1012 & 3.8 & 0.53 & 1.16 & 0.21 \\
$106 / 1020$ & 1125 & 4.7 & 0.61 & 1.12 & 0.27 \\
$116 / 1020$ & 1102 & 4.5 & 0.56 & 1.17 & 0.34 \\
$126 / 1020$ & 1102 & 4.2 & 0.49 & 1.21 & 0.37 \\
$136 / 1020$ & 1080 & 3.6 & 0.43 & 1.28 & 0.43 \\
\hline
\end{tabular}

Table 6. Summary of mechanical and wear properties of WC-12Co APS deposited coatings, adopted from (Ref 132, 133)

\begin{tabular}{lcccrr}
\hline Ar- $\mathrm{H}_{2}-\mathrm{He}, \mathrm{L} / \mathrm{min}$ & Hardness HV2.94 $(\mathrm{GPa})$ & Fracture toughness & CoF & Wear rate $\left(\times 10^{-6} \mathrm{~mm}^{3} / \mathrm{Nm}\right)$ & $\mathrm{References}$ \\
\hline $45-11-0$ & 6.02 & 5.45 & 0.58 & $19.00 *$ & $4.47 *$ \\
$51-2-23$ & 10.2 & 6.07 & 0.62 & $4.84 *$ & $($ Ref 132$), 2009$ \\
$30-0-50$ & 11.42 & 5.57 & 0.61 & $17.88 *$ & $($ Ref 132$), 2009$ \\
$0-0-60$ & 9.55 & 5.73 & 0.61 & 9.83 & $($ Ref 132$), 2009$ \\
$48-8-0$ & 7.93 & $\ldots$ & 0.41 & 4.449 & $($ Ref 133$), 2013$ \\
$30-0-50$ & 8.33 & $\ldots$ & 0.48 & $($ Ref 133$), 2013$ \\
\hline
\end{tabular}

*Estimated values from graphs

using He showed the highest porosity of these coatings and revealed the second-highest degree of decarburisation. The porosity was linked to the low impact velocity of the particles due to the low mass flow rate of He. It was suggested that the porosity promoted fracturing since it presented a defective microstructure that incorporated the presence of brittle phases (Ref 132).

A similar study by Girolamo et al. (Ref 133) investigated nanostructured coatings manufactured under different gas compositions. Reported parameters, properties and results are summarised in Table 6 . The Ar- $\mathrm{H}$ gas coating had lower wear resistance than the Ar-He coatings (Ref 133). The Ar-He coating wear performance was similar $\left(\sim 4.4-4.8 \times 10^{-6} \mathrm{~mm}^{3} / \mathrm{Nm}\right)$ in both studies (Ref $132,133)$.

In summary, spray parameter selection is critical for producing a wear resistance coating with high wear resistance. The main aspects that are affected by these parameters are the in-flight temperature of the particles and inflight velocity (Fig. 1). Optimisation of these parameters, therefore, contribute to the bulk mechanical properties and tribo-mechanical performance. A controlled degree of carbide dissolution into the binder is important to reduce carbide pullout during sliding wear of WC-Co coatings (Ref 43, 44, 131).

\section{Influence of Coating Post-treatment on Wear Performance}

Post-treatment of WC-Co coatings improves their wear performance by reducing porosity, and enhancing adhesion between splats and to the substrate (Ref 75, 76). Heat treatment, laser remelting and hot isostatic pressing (HIPing) are the main post-treatment methods used for thermal spray coatings (Ref 15, 75, 102, 134-136). Each of these methods has its respective benefits, as listed below. Heat treatment increases hardness and is cost-effective but does not reduce porosity. Laser remelting reduces porosity to almost zero but is not recommended in a lubrication environment due to the lack of cavities that act as a reservoir for lubricant. Furthermore, the high energy density of the laser creates unwanted heat affected zones and undesirable phase reactions on the surface. HIPing can deliver the benefits of heat treatment and laser remelting, while avoiding their deficiencies.

A WC-NiCrSiBFeC coating was produced (Stoica et al. (Ref 102)) in the form of two layers, an initial layer of WC$40 \mathrm{NiCrSiBFeC}$ that was followed with a top layer of WC10 NiCrSiBFeC. These coatings were HIPed at 850 and $1200{ }^{\circ} \mathrm{C}$ and allowed the elemental species across the distinct boundaries of the as-sprayed coatings to diffuse. The degree of diffusion of the coating with the substrate at the interface increases with higher HIPing temperatures as shown in Figure 16 (Ref 56). A similar influence on the diffusion zone in WC-Co coatings was observed in another study (Ref 75)(Fig. 8b and c). Their work on HIPing of WC-NiCrBSi coatings showed that post-treatment improved the sliding wear resistance of these coatings by $\sim 40-50 \%$ for steel and $\mathrm{Si}_{3} \mathrm{~N}_{4}$ counter body materials, respectively, at a HIP treatment of $1200{ }^{\circ} \mathrm{C}$ (Ref 102). Similar studies also showed improved performance after HIPing for WC-Co coatings in the range of $\sim 15-28 \%$ for a 

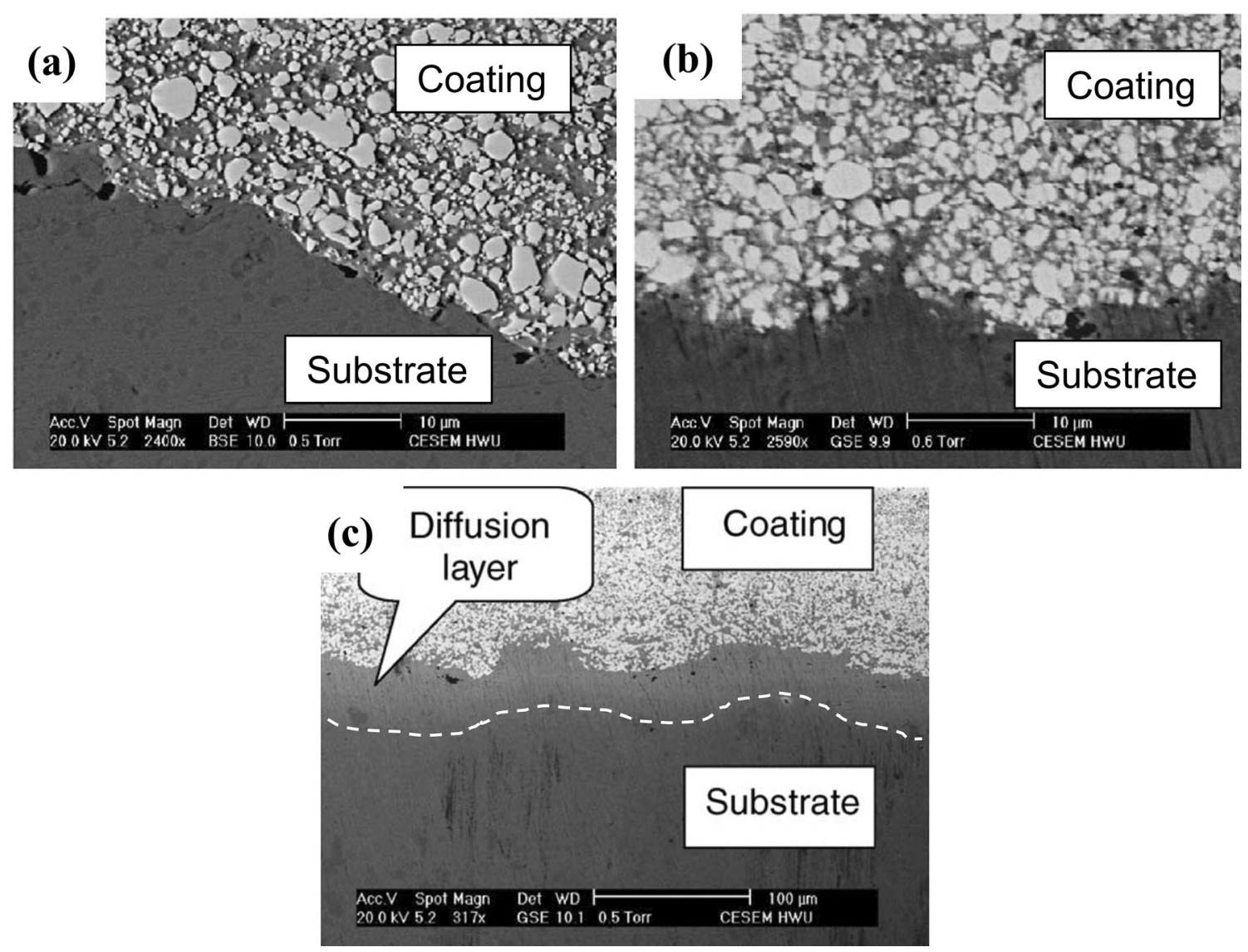

Fig. 16 The increased diffusion of the coating-substrate interface of WC-NiCrBSi coatings with increasing HIPing temperature, (a) as-sprayed coating, (b) HIPed at $850^{\circ} \mathrm{C}$ and (c) HIPed at $1200{ }^{\circ} \mathrm{C}$ (Ref 56)

variety of loading (39 and $59 \mathrm{~N}$ ) and counter body (steel and $\mathrm{Si}_{3} \mathrm{~N}_{4}$ ) materials (Ref 134). These investigations were performed under diverse tribological conditions (Ref $75,98,108,134)$.

Ali et al. HIPed S-HVOF nanostructured WC-C coatings and compared their sliding wear performance against assprayed S-HVOF and conventional HVOF coatings (Ref 15). The two nanostructured coatings exhibited higher average hardness (942 \pm 15 and $998 \pm 73$ HV0.3) than the conventional coating $(924 \pm 127$ HV0.3). HIPing increased the hardness of the nanostructured coatings to $1130 \pm 140$ and $1201 \pm 74$ HV0.3. The conventional coating performed better than both types of nanostructured coatings under counter bodies of $\mathrm{Si}_{3} \mathrm{~N}_{4}$ and AISI 440C stainless steel, whereas the S-HVOF coating performed better against a WC-Co counter body (Ref 15, 16). The HIPed coatings exhibited better performance $(\sim 12-22 \%)$ than the as-sprayed ones when a ceramic counter body was used.

Laser remelting was used by Mateos et al. to treat a plasma sprayed WC-17Co coating (Ref 135). The microstructure of the porous as-sprayed coating showed that carbides were partially dissolved into the binder. The laser-treated coatings indicated that carbides regained their polygonal structure as well as revealing dendritic features in the binder, as shown in Figure 17 (Ref 135). The hardness of the laser-treated coating doubled and the sliding wear performance was enhanced under a variety of loads and sliding speeds. The as-sprayed coating showed that the tribo-film was composed mainly of counter body material. There was crack propagation through the binder that resulted in coating fragmentation, leading to threebody abrasion. The post-treated coating also showed similar mechanisms but wear rate improved (Ref 135) as shown in Figure 18.

Sohi et al. reported the results of heat-treated plasma sprayed WC-12Co coatings in argon, at 650, 900 and $1150{ }^{\circ} \mathrm{C}$ (Ref 136). The coatings treated at 900 and $1150{ }^{\circ} \mathrm{C}$ exhibited better average wear resistances of $\sim 61 \times 10^{-2} \mathrm{mg} / \mathrm{m}$ and $\sim 72 \times 10^{-2} \mathrm{mg} / \mathrm{m}$, respectively, than the as-sprayed coating $\left(\sim 83 \times 10^{-2} \mathrm{mg} / \mathrm{m}\right)$, which has been linked to the formation of eta-phases in the coatings. The coating treated at $900{ }^{\circ} \mathrm{C}$ demonstrated the best wear performance $(\sim 26.5 \%$ reduction in the wear rate when compared to the as-sprayed coating) of all the coatings, whereas the one treated at $650{ }^{\circ} \mathrm{C}$ (average wear rate 
Fig. 17 Microstructure of (a) as-sprayed and (b) laserremelted coatings (Ref 135)
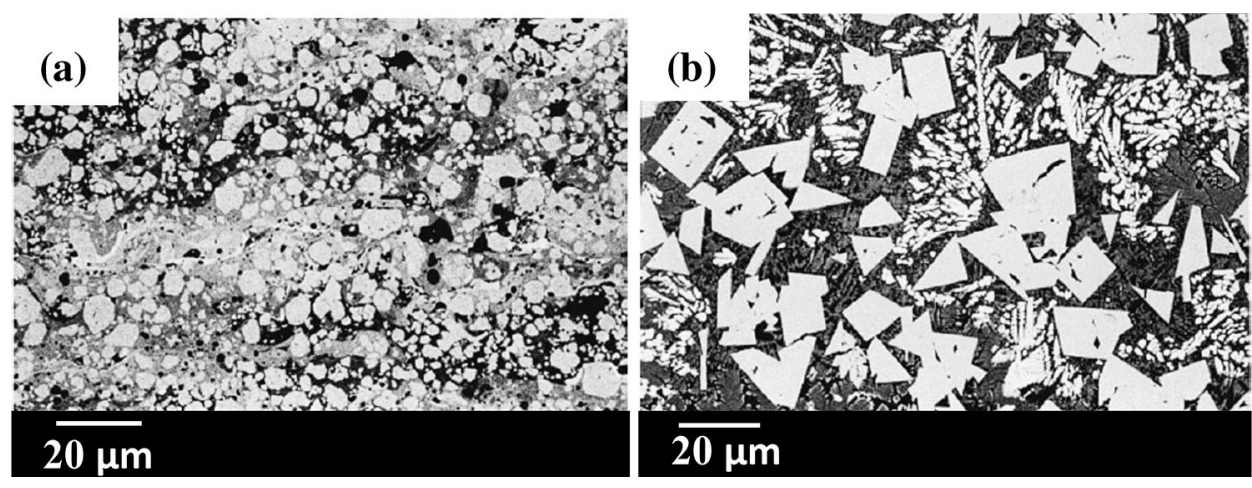

Fig. 18 Wear performance of the as-sprayed and treated coating with respect to the sliding velocity with best fit second-order polynomial trend line with $\mathrm{R}^{2}$-value of 0.9874 for As-sprayed and 0.9794 for Heat-treated (Ref 135)

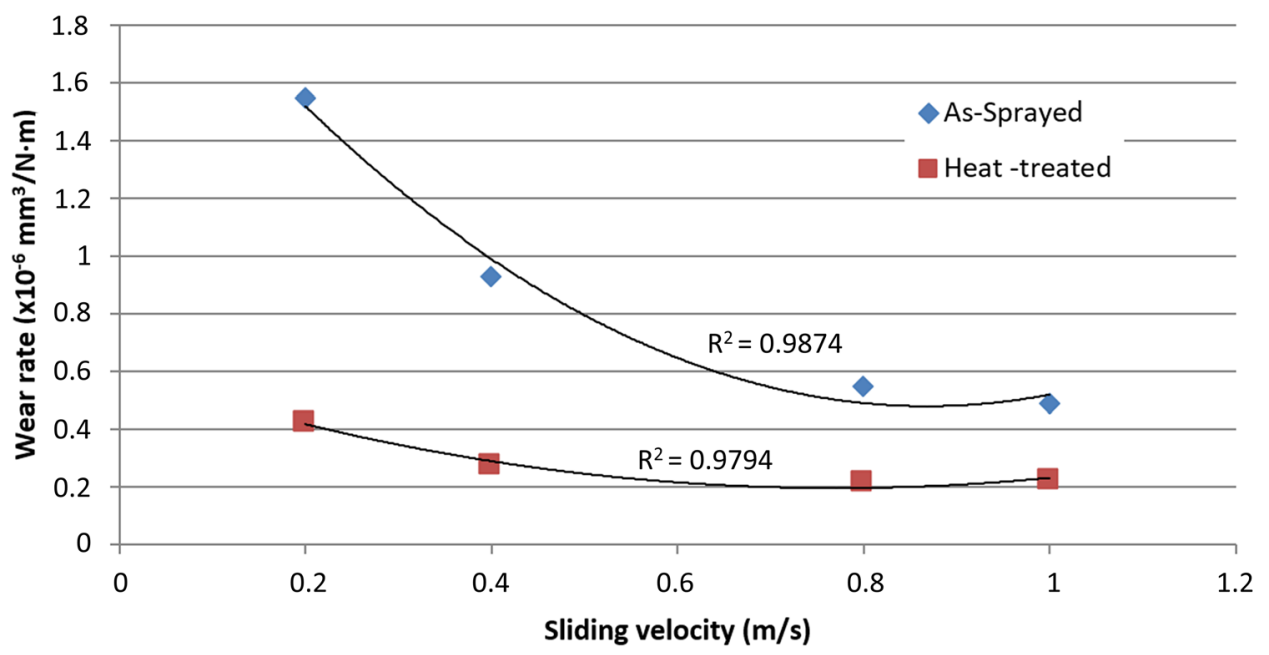

$\sim 128 \times 10^{-2} \mathrm{~g} / \mathrm{m}$ ) showed the worst performance, where the average wear rate increased by $\sim 54 \%$ (Ref 136). A possible cause of this behaviour can be linked to residual stresses that evolved from the heat treatment.

In summary, the post-treatment of thermal sprayed coatings generally improves the wear performance. But there is a technical limit to this improvement, as can be seen from the investigation by Sohi et al. (Ref 136). Most heat treatment methods also enable diffusion of the substrate elements into the coating (Ref 136). Careful selection of post-treatment parameters is critical and must take into account the substrate material and its effect on residual stress (Ref 56, 57, 137).

\section{Comparison of Wear Rates of WC-Co Coatings with Cemented WC-Co Carbides}

Cemented WC-Co carbides have been extensively investigated for their sliding wear performance and wear mechanisms (Ref 6-9, 11). Several investigations, summarised in Table 2, also use a cemented WC-Co counter body against the WC-Co thermal sprayed coatings, which provides a direct comparison of sliding wear performance between these two materials. The hardness of cemented WC-Co varies between 1200 and $1913 \mathrm{HV}$ for cobalt compositions of 6-15wt.\% (Ref 6,7). Typically for WC$12 \mathrm{Co}$, cemented carbides exhibit Vickers hardness of 1240-1253 HV, which is comparable to the hardness values of WC-12Co coatings indicated in Table 2. The fracture toughness of cemented WC-Co carbides varies between 8.8 and 20.6 MPa.m ${ }^{1 / 2}$ for cobalt compositions of 12-6wt.\%, respectively (Ref 7). The anisotropy in thermal sprayed WC-Co coatings presents lower values of fracture toughness parallel to the coating surface (Fig. 12b), and the fracture toughness values in Table 2 are relatively lower than those for cemented carbides (Fig. 3). Despite this difference, the sliding wear rates of cemented WC-Co carbides shown in Figure 19a indicate values of $0.3 \times 10^{-6}$. $0.8 \times 10^{-6} \mathrm{~mm}^{3} / \mathrm{N} \mathrm{m}$ for cobalt contents of $6-20 \mathrm{wt} . \%$. This is a narrow range of wear rate when compared to the wear rate of WC-Co coatings that vary from $0.04 \times 10^{-6}$ to $19.2 \times 10^{-6} \mathrm{~mm}^{3} / \mathrm{N} \mathrm{m}$ for cobalt contents of $9-17 \mathrm{wt} . \%$, respectively, as summarised in Table 2 .

Similar to thermal spray coatings, the wear rates in cemented WC-Co carbides are sensitive to the tribological test conditions. Bonny et al. (Ref 7) investigated the 


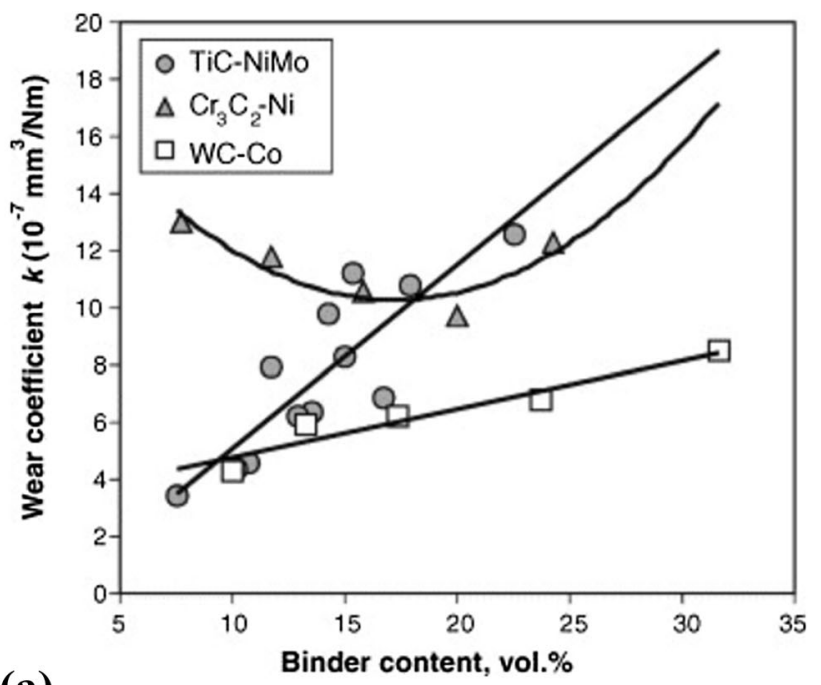

(a)

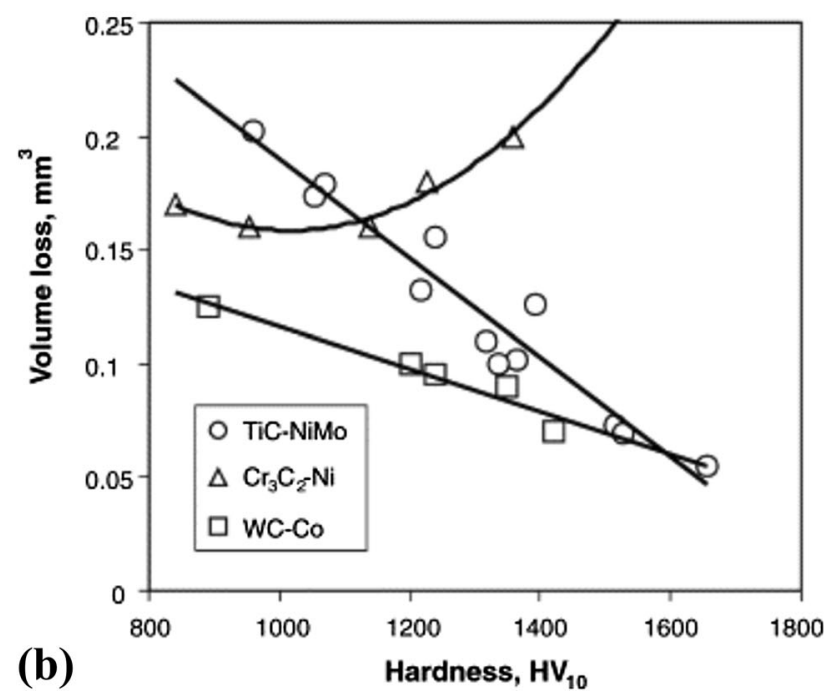

Fig. 19 (a) Sliding wear coefficient of cemented $\mathrm{WC}, \mathrm{Cr}_{3} \mathrm{C}_{2}, \mathrm{TiC}$ carbides vs. binder volume content, (b) wear volume of cemented carbides in sliding wear vs. hardness after sliding distance of 4-km using a block-on-ring test-showing a linear relationship of wear with binder content and hardness for WC and TiC (Ref 6)

influence of test parameters by using ASTM G133 method (Ref 81) for the sliding wear performance of cemented WC-Co carbides. The load was varied between 15 and $100 \mathrm{~N}$, and the reciprocating speed from 10 to $30 \mathrm{~Hz}$ (equivalent to $0.3-0.9 \mathrm{~ms}^{-1}$ ) up to a sliding distance of $10 \mathrm{~km}$. Tests were conducted against WC-6Co pins of $4.08 \mathrm{~mm}$ radius. This study indicated that the increase in the normal load increases the wear rate of cemented WCCo carbides, whereas the friction displayed an opposite trend, whereas both wear and friction increased with the increase in the sliding velocity. Regardless of these changes in the test conditions, the wear rates for cemented WC-
Co carbides stayed in a small range of $0.016 \times 10^{-6}$. $0.022 \times 10^{-6} \mathrm{~mm}^{3} / \mathrm{N} \mathrm{m}$, which is comparable to the lowest values of wear rate in Table 2 for thermal sprayed WC-Co coatings.

In summary, the wear rate of cemented WC-Co carbides is relatively low (Ref 6-9,11). The change in the wear rate with tribological test conditions is also within a narrow range when compared to thermal sprayed WC-Co coatings (Table 2). Similarly, the wear resistance of cemented WCCo carbides is the highest when compared with other carbides such as $\mathrm{Cr}_{3} \mathrm{C}_{2}$-Ni and TiC-NiMo (Ref 6) (Fig. 19). The investigation of these cemented carbides also confirms that the sliding wear volume is almost directly proportional to the Vickers hardness of cemented WC-Co and TiCNiMo, as shown in Figure 19b (Ref 6). Bonny et al. (Ref 7) also indicated that the wear resistance of WC-Co cemented carbides depend on the carbide/binder ratio and carbide grain size, and it increases with an increase in bulk hardness. However, as shown later in "Semiempirical Mathematical Relationship in Sliding Wear of WC-Co Coatings" section, the complex microstructure of WC-Co coatings does not exhibit such dependency of sliding wear rate on coating hardness. Instead, the mechanical and tribological properties of both the coating and counter body material play an important role in the sliding wear behaviour of WC-Co coatings.

\section{Semiempirical Mathematical Relationship in Sliding Wear of WC-Co Coatings}

Figure 4 shows the complex interdependency of sliding wear test conditions on the microstructure and tribo-mechanical properties of coatings. As reported by the authors (Ref 15, 16), correlations of the influential factors dictating the sliding wear performance have not been successful. Wood (Ref 45) indicated that in the case of thermal spray coatings, the dependencies of wear rate on the binder metal, porosity, hardness and Young's modulus were not found. Single variable relationships with the wear rate with all other factors constant have, however, been reported. Mateos et al. (Ref 135) studied the effect of test parameters such as normal load and velocity in a block-on-ring test method with steel as a counter body. In Figure 18, the sliding wear rate is presented against the velocity at a constant load of $377 \mathrm{~N}$. A second-order polynomial relationship exists between these parameters (Ref 135).

Generic relationships that can be applied to a combination of test conditions and tribo-mechanical properties of the test couples during sliding wear of coatings are not available in published literature. Authors have, therefore, extracted these relationships from the available studies, 
Table 2. The following methods have been employed to formulate semiempirical mathematical relationships.

1 The literature on sliding wear indicates that the ball or pin material varies significantly and commonly used counter body materials are steel, WC-Co, $\mathrm{Al}_{2} \mathrm{O}_{3}$ and $\mathrm{Si}_{3} \mathrm{~N}_{4}$. Properties of the ball material that influence the test couple performance are, therefore, considered in this investigation. These properties include (i) the ball hardness $\left(\mathrm{H}_{\text {ball }}\right)$, (ii) the ball Young's modulus $\left(\mathrm{E}_{\text {ball }}\right)$ and (iii) the ball fracture toughness $\left(\mathrm{K}_{\mathrm{IC}}\right.$ ball $)$ when compared to the corresponding (i) coating hardness ( $\left.\mathrm{H}_{\text {coating }}\right)$, (ii) coating Young's modulus $\left(\mathrm{E}_{\text {coating }}\right)$ and (iii) coating fracture toughness ( $\left.\mathrm{K}_{\mathrm{IC} \text { coating }}\right)$.

2 In sliding wear applications, the hardness of the softer counterface in the contact pair is generally used for wear analysis by, for example, the Archard equation (Ref 85, 138), i.e.,

$$
\text { Wear rate }=k_{\mathrm{D}}=\frac{K}{H}=\frac{Q}{N \times l}
$$

where $Q$ is the wear volume depth $\left(\mathrm{mm}^{3}\right), l$ is the sliding distance (m), $N$ is the normal force $(\mathrm{N}), H$ is the hardness of the worn surface, and $K$ is a dimensionless wear coefficient. The term $(\mathrm{K} / \mathrm{H})$ was replaced by a dimensional wear rate $\left(k_{\mathrm{D}}\right)$ in the units of $\mathrm{mm}^{3} / \mathrm{N} \mathrm{m}$. However, in the current analysis of WC-Co coatings, since the relative ball hardness is lower for steel and higher for the WC-Co and $\mathrm{Si}_{3} \mathrm{~N}_{4}$, the ball to the coating hardness ratio $\left(\mathrm{H}_{\text {ball }} / \mathrm{H}_{\text {coating }}\right)$ is considered.

3 The ball or pin diameter and material can vary between the investigations. Therefore, a variable based on the Hertzian contact pressure $\left(C_{p}\right)$ is introduced to cater for the differences in ball geometries and elastic properties of test couples.

4 Fracture of surfaces inevitably leads to the formation of wear debris so the $\mathrm{K}_{\mathrm{IC}}$ of the coatings is considered as another variable. The fracture toughness of the ball or pin material $\left(\mathrm{K}_{\mathrm{IC}}\right.$ ball or $\left.\mathrm{K}_{\mathrm{IC} \text { pin }}\right)$ did not show a strong dependency on the wear rate and is not included in this analysis.

5 The relationship between the coefficient of friction $(\mathrm{CoF})$ is expected to be linear, where an increase in $\mathrm{CoF}$ can lead to an increase in the wear rate. However, this relationship is not always valid for the WC-Co test couples since the role of tribo-film changes for different test couples. As well, wear debris in the wear track can present a complex interdependency. Hence the $\mathrm{CoF}$ is introduced as a variable in the current analysis.

6 The coating porosity can influence the wear performance since dense coatings are more desirable. Hence coating porosity was also included as a variable in the current analysis.
Figure 20(a) shows the relationship between the contact pressure $\left(C_{\mathrm{p}}\right)$ and $\mathrm{CoF}$ against the wear rate for a variety of test couples. The wear rates lie within the $C_{\mathrm{p}} \times \mathrm{CoF}$ envelope of 0.5-2.5. Differences between plasma spray and HVOF coatings can be separated using the ' $C_{\mathrm{p}} \times \mathrm{CoF}$ ' parameter; however, there is no correlation with respect to the wear rate. An alternative graphical representation of this combined data set relates the wear rate with another parameter that includes the hardness of the ball and coating materials; i.e., ' $\left(C_{\mathrm{p}} \times H_{\text {coating }} \times \mathrm{CoF}^{0.1}\right) /\left(H_{\text {ball }} \times v^{0.5}\right)$ ', Figure 20(b). Although there is no straightforward relationship between the wear rate and $\left(C_{\mathrm{p}} \times H_{\text {coating }} \times-\right.$ $\left.\mathrm{CoF}^{0.1}\right) /\left(H_{\text {ball }} \times v^{0.5}\right)$, this figure facilitates comparisons of WC-Co coatings performance with other wear-resistant coatings or cemented carbides.

Figure 21 shows the values of wear rate against coating hardness and indicates that there is no direct relationship between the coating hardness and sliding wear rate. This behaviour is significantly different to cemented WC-Co carbides, where sliding wear rate is proportional to hardness (Fig. 16). However, if $C_{\mathrm{p}}$ and the ratio of 'ball to coating hardness' are considered, as shown in Figure 22, there is a trend for an increase in the wear rate with $C_{\mathrm{p}} \times\left(H_{\text {ball }} / H_{\text {coating }}\right)$. The analyses presented in Fig. 20, 21, and 22 are based on physical quantities of CoF, hardness and contact pressure that are generally reported.

Relationships between wear rates and extrinsic materials properties would be clearer with the introduction of the coating fracture toughness, $K_{\text {IC }}$, which is often not available within published literature. Figure 23(a) presents a compilation of data in cases where the $K_{\mathrm{IC}}$ values for the coating material can be inferred from published literature. The wear rate is plotted against $\left(H_{\text {ball }} / H_{\text {coating }}\right)^{3 / 4} \times\left(C_{\mathrm{p}} /\right.$ $\left.H_{\text {ball }}\right)^{2 / 3} /\left(K_{\text {IC }} \text { coating }\right)^{1 / 2} /\left(H_{\text {ball }} / E_{\text {ball }}\right)^{1 / 7}$, which was previously applied to S-HVOF coatings (Ref 15) with success. A linear trend is more distinct for the plasma sprayed coatings when using this relationship.

The correlation between the wear rate and tribo-mechanical properties of test couples and test conditions is not clear, primarily due to the way in which the wear rate is defined in the published literature. The force term in the wear rate equation depends on the geometry and material. For example, a load of $25 \mathrm{~N}$ on a steel ball of $10 \mathrm{~mm}$ diameter is not the same as a load of $25 \mathrm{~N}$ on a WC or ceramic ball in terms of the contact pressure. Even for the same ball material, as the load changes the contact pressure changes nonlinearly.

The analysis is more complex when comparing the results with ASTM G77 (Ref 83) block-on-ring tests because the loads are relatively higher, but the contact geometry is more conforming, so the contact pressure is relatively low. Hence, the influence of geometry in the 
Fig. 20 Information from literature, (a) wear performance reported against the product of the contact pressure and $\mathrm{CoF}$ and (b) wear performance against an algorithm constituent of multiple parameters of the sliding test parameters and material properties $(\sim$ value estimated from graphs, *value converted to $\times 10^{-6} \mathrm{~mm}^{3} / \mathrm{Nm}$, $p l$ plasma-sprayed coating, $h v$ HVOF-sprayed coating, shv S-HVOF-sprayed coating)
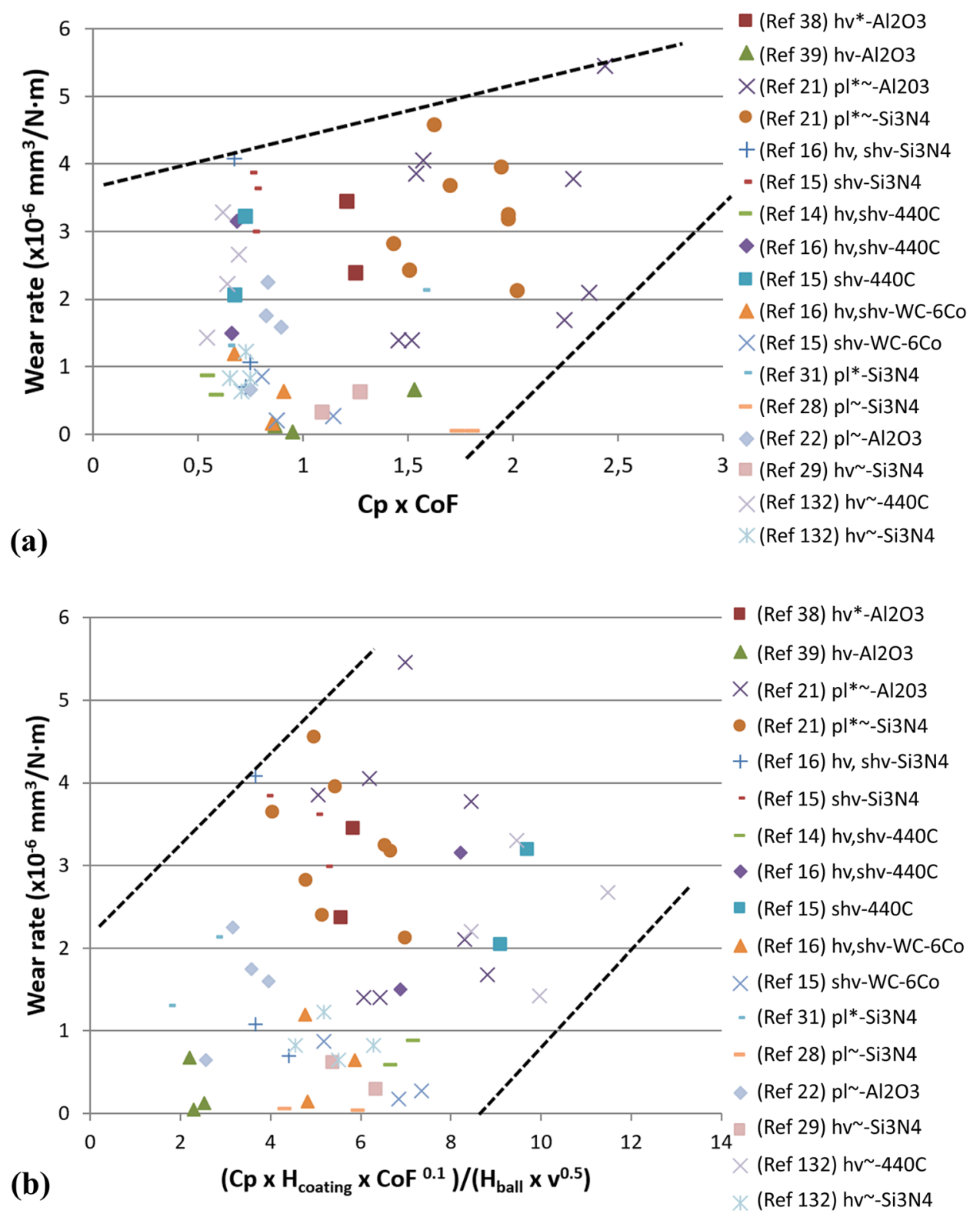

wear rate calculation can be included by replacing the force term with the Hertzian contact pressure $\left(C_{\mathrm{p}}\right)$. This approach enables a comprehensive analysis of wear rate and permits differentiation between coating processes. Therefore, the wear rate has been expressed in terms of contact pressure instead of load, i.e., in units of ' $\mathrm{mm}^{3} / \mathrm{GPa} \mathrm{m}$ ' instead of ' $\mathrm{mm}^{3} / \mathrm{N} \mathrm{m}$ ', and it is possible to differentiate the HVOF and plasma sprayed coating behaviours. The change of wear rate from load to contact pressure is more rigorous because it includes the dimensions and elastic properties of both the coating and ball or pin materials. This is represented in Figure 23(b) where the oval-shaped envelope distinguishes the HVOF and APS coatings, much in the same fashion depicted by Ashby schematic diagrams for materials selection. The $\mathrm{x}$-axis is presented as a log scale to identify differences among the coating types that display wide ranges of material properties. Figure 23(c) shows a modification to this relationship where coating porosity is also incorporated into the mathematical construct. Here the distinction between the HVOF and APS coatings is more subtle, as APS coatings generally exhibit higher porosity and relatively lower fracture toughness due to carbon loss.

\section{Computational Wear Modelling}

"Structure-Property Relationship in Sliding Wear" and "Semiempirical Mathematical Relationship in Sliding Wear of WC-Co Coatings" sctions discussed the experimental evaluation of failure modes and semiempirical 
Fig. 21 Wear rate of coatings from literature against their respective Vickers hardness, the counter bodies used are mentioned as well ( $\sim$ value estimated from graphs, *value converted to $\times 10^{-6} \mathrm{~mm}^{3} / \mathrm{Nm}$, $p l$ plasma-sprayed coating, $h v$ HVOF-sprayed coating, shv S-HVOF-sprayed coating)

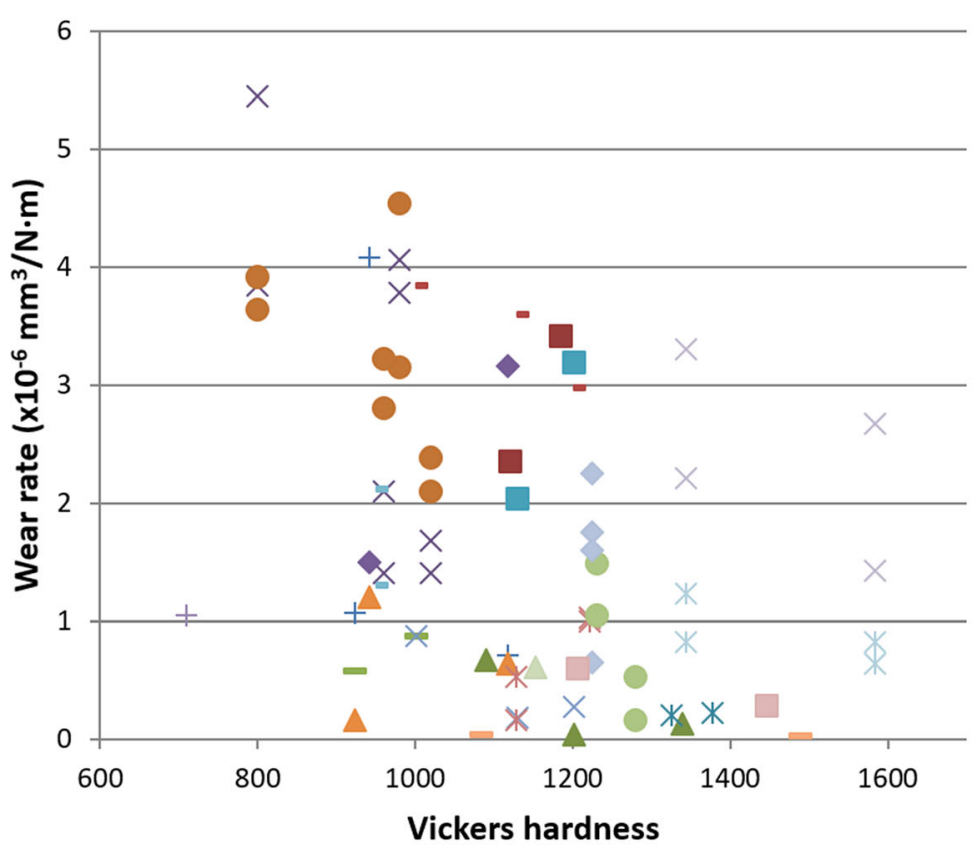

(Ref 38) hv*-Al2O3 $\triangle$ (Ref 39) hv-Al2O3 $\times(\operatorname{Ref} 21)$ pl* -Al203 * (Ref 44) hv -Si3N4 (Ref 21) pl* -Si3N4 $+(\operatorname{Ref} 16) \mathrm{hv}$, shv-Si3N4 - (Ref 15) shv-Si3N4 - (Ref 14) hv,shv-440C $\rightarrow($ Ref 16) hv,shv-440C (Ref 15) shv-440C $\triangle($ Ref 16) hv,shv-WC-6Co $\times($ Ref 15) shv-WC-6Co * (Ref 78) hv* Al2O3 (Ref 43) hv -Al2O3 $+(\operatorname{Ref} 113)$ hv $^{\sim}-$ Si3N4 - (Ref 31) pl*-Si3N4 - (Ref 28) pl $\sim$ Si3N4 $\rightarrow\left(\right.$ Ref 22) pl ${ }^{\sim}-\mathrm{Al} 2 \mathrm{O} 3$ (Ref 29) hv ${ }^{\sim}-$ Si3N4 $\triangle(\operatorname{Ref} 74)$ hv $\sim$ Si3N4

$\times($ Ref 132) hv $-440 \mathrm{C}$

* (Ref 132) hv -Si3N4

Fig. 22 Wear rate from literature against the product of maximum contact pressure $(\mathrm{Cp})$ in $\mathrm{GPa}$ with the ratio of the hardness of the ball $\left(H_{\text {ball }}\right)$ to the coating $\left(H_{\text {coating }}\right)$ ( value estimated from graphs, *value converted to $\times 10^{-6} \mathrm{~mm}^{3} / \mathrm{Nm}$, $p l$ plasma-sprayed coating, $h v$ HVOF-sprayed coating, $s h v$ S-HVOF-sprayed coating)

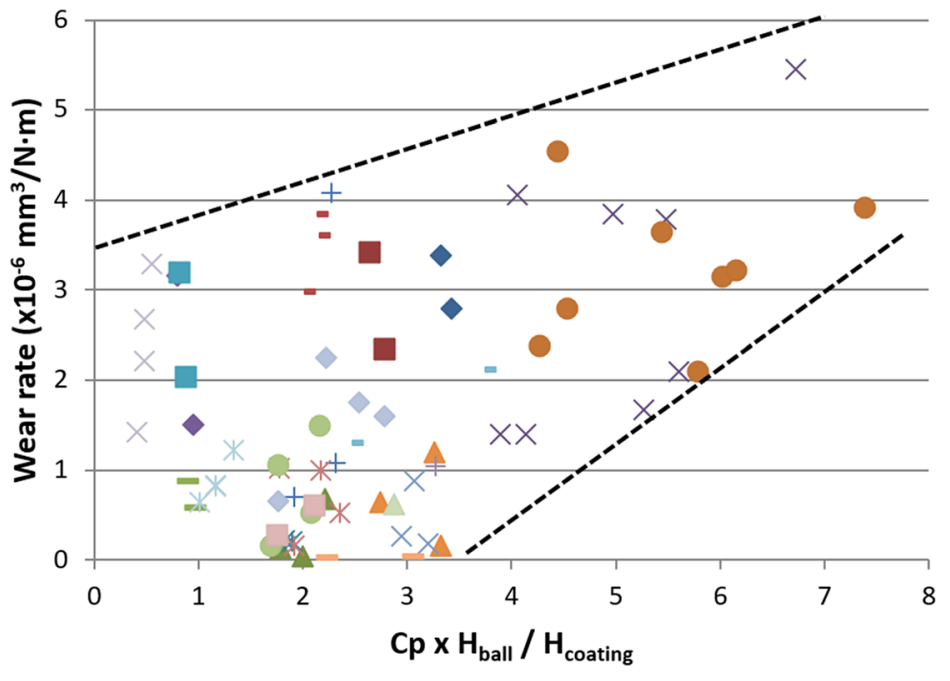

(Ref 38) hv*-Al2O3

(Ref 39) hv-Al2O3

$\times\left(\right.$ Ref 21) pl $\left.\right|^{* \sim-A l 203}$

* (Ref 44) hv $\sim-S i 3 N 4$

(Ref 21) pl* -Si3N4

+ (Ref 16) hv, shv-Si3N4

- (Ref 15) shv-Si3N4

- (Ref 14) hv,shv-440C

- (Ref 16) hv,shv-440C

(Ref 15) shv-440C

$\Delta$ (Ref 16) hv,shv-WC-6Co

$\times($ Ref 15) shv-WC-6Co

* (Ref 78) hv* -Al2O3

(Ref 43) hv -Al2O3

+ (Ref 113) hv - Si3N4

- (Ref 31) pl*-Si3N4

- (Ref 28) pl - Si3N4

(Ref 22) pl -Al2O3

(Ref 29) hv ${ }^{\sim}-$ Si3N4

$\triangle$ (Ref 74) hv-Si3N4

$\times($ Ref 132) hv -440C

* (Ref 132) hv $\sim-S i 3 N 4$ mathematical modelling of wear rates. In this section, the numerical modelling of sliding wear rate is considered. Finite element numerical models that consider the evolution of wear volume during sliding contacts, and hence predict the wear rate, can provide useful predictions of the wear rate.

Two approaches can model sliding wear by a finite element method (FEM), i.e., mesh deletion and node adjustment (Ref 139-144). The mesh deletion method is based on the failure of elements that are then removed from the model to estimate the wear rate. This method is illustrated in Figure 24(a), where the elements within the contact zone are assigned a failure criteria based on the stress, strain or energy within the element (Ref 139-141).
Once the failure criteria is reached within the element, the element is deleted from the model as wear debris and new surfaces are created. This iterative approach has also modelled machining processes such as milling or the interaction of the cutting tool on workpiece leading to the formation of chips and a newly machined surface (Ref 139141). This approach can be applied to the sliding wear process using an algorithm that redefines the contact interactions when new surfaces are formed after mesh deletion for continuous modelling of the wear process (Ref 139, 140). The minimum amount of wear volume that can be removed depends on the mesh density, or the size of elements, which need to be considered in terms of the computing cost and required dimensional precision. The 
second approach adjusts the nodes in the contact zone based on the contact pressure (Fig. 24b). As the body wears, the nodes are adjusted to account for the worn material (Ref 85, 93, 142-144). The dependency of mesh density indicated above for the mesh deletion technique can, therefore, be reduced using the node adjustment technique.

Although the finite element technique has not yet modelled the prediction of sliding wear rate in thermal spray coatings, Bolelli et al. (Ref 145) have investigated the influence of microstructure using thermo-mechanical modelling in ABAQUS (Dassault Systems) (Ref 52, 141). They predicted the progressive stiffening of porous plasma sprayed $\mathrm{Cr}_{2} \mathrm{O}_{3}$ due to crack closure under compressive loading. Similarly, Lyphout et al. (Ref 146) conducted finite element simulations of a single-asperity sliding process and showed that large WC grains concentrate contact stresses, thus undergoing localised deformation in WC-Co$\mathrm{Cr}$ coatings. Prediction of the sliding wear rate in other materials, however, provides useful insights about the modelling of sliding wear in thermal spray coatings. Figure 25 compares experimental and numerical results of sliding wear for values of $k_{\mathrm{D}}$, where $k_{\mathrm{D}}$ represents the value of wear rate used in the model (Ref 85). The wear rate originates from the Archard's wear equation (Eq 12) and is considered a constant, which provides agreement between theory and experimental results (Ref 138). Although the model is specific to sliding wear of Stellite ${ }^{\mathrm{TM}} 6$, it shows the application of the modelling approach where there exists a reasonable agreement between the experimental and numerical values (Ref 85 ). These numerical models require experimental data that is often difficult to attain, and, in principle, this approach can be applied to thermal spray coatings. An SEM image of the cast Stellite ${ }^{\mathrm{TM}}$ alloy is shown (Fig. 25b) since it should always be recalled that FEM models must always be related to the microstructure.

Wear modelling using computational methods are based on the Archard's wear rate which is further defined in "Influence of Spray Parameters on Sliding Wear Performance" section (Ref 138). The FEM approach requires that the wear rate needs to be in a form where it can be applied to the nodes in the model. Archard's wear rate is used in FEM to simplify the computational model. Nevertheless, the FEM approach depends on experimentally measured values of wear coefficient. Williams (Ref 147) describes that wear can be generally categorised as ductile or brittle. However, brittle wear can transition into ductile wear under high compressive stress, thereby adding to the complexities of a predictive wear model. Figure 26 (Ref 148) illustrates the evolution of wear mechanisms with increasing load and indicates the transition of wear mechanisms under different loading conditions.
Lim and Ashby (Ref 149) developed a wear mechanism map for steel-on-steel contacts using pin-on-disc experiments. This was based on Archard's wear law using velocity and contact pressure as the sliding wear experimental parameters. Williams also suggested using such a wear map for accurate computational modelling, but it was essential to select the appropriate wear coefficient based on experimental parameters (Ref 147). It is, however, challenging to identify transitions in wear mechanisms due to changes in the experimental parameters. Therefore, developing a model that simulates wear based on wear mechanism is not currently feasible by a FEM approach. Numerical models based on the Archard's wear rate $\left(k_{\mathrm{D}}\right)$ are therefore employed in FEM (Ref 65, 143, 144).

Investigators have proposed models for predicting wear for materials, and the outcome is a compromise by exploiting Archard's wear law. Meng and Ludema (Ref 150) identified nearly 200 'wear equations' that were based on material properties, thermodynamic quantities and experimental parameters. Equations based on empirical data were common until 1970 (Ref 150). The decade after that was dominated by contact-based wear equations where Archard's approach and other similar equations became prominent (Ref 150). It was also recognized that standard mechanical properties were not the only properties affecting wear. The inclusion of other properties such as material flow, fracture toughness, fracture strain, etc., was therefore incorporated into equations (Ref 150).

Expanding wear mechanism map methodology to other materials is challenging. There are no wear maps, especially for composite materials such as thermal sprayed cermets, where coating microstructure depends not only on the coating process but also on process parameters and powder characteristics (Fig. 4). Wear maps are subject to change based on the type of sliding wear test, such as pinon-disc, ball-on-flat or block-on-ring. The proposed semiempirical mathematical approach in "Semiempirical Mathematical Relationship in Sliding Wear of WC-Co Coatings" section may develop into a computational wear model. Such a model, for instance, may be applied to thermal sprayed WC-12Co coatings as a predictive tool for the Archard's wear rate (Fig. 25). However, currently there are no such models available in the literature for thermal spray coatings.

\section{Archard's Wear Rate in FEM}

In FEM modelling, the elements are defined by nodes. Archard's wear rate $\left(k_{\mathrm{D}}\right)$ introduced in Eq 12 (Ref $85,138,150)$ for the sliding wear rate can be expressed in terms of the displacement of nodes in FEM. The surface nodes need to be displaced appropriately based on the wear 




(Ref 38) hv*-Al2O3

$\Delta$ (Ref 39) hv-Al2O3

$\times(\operatorname{Ref} 21) \mathrm{p}^{* \sim}$-Al203

* (Ref 44) hv ${ }^{\sim}$-Si3N4

(Ref 21) p|* _Si3N4

$+($ Ref 16) hv, shv-Si3N4

- (Ref 15) shv-Si3N4

- (Ref 14) hv,shv-440C

- (Ref 16) hv,shv-440C

(Ref 15) shv-440C

$\triangle$ (Ref 16) hv,shv-WC-6Co

$\times$ (Ref 15) shv-WC-6Co

(a) $\log _{10}\left(\left(\left(\mathrm{H}_{\text {ball }} / \mathrm{H}_{\text {coating }}\right)^{3 / 4} \times\left(\mathrm{Cp} / \mathrm{H}_{\text {ball }}\right)^{2 / 3}\right) /\left(\left(\mathrm{K} 1 \mathrm{c}_{\text {coating }}\right)^{1 / 2} \mathrm{x}\left(\mathrm{H}_{\text {ball }} / \mathrm{E}_{\text {ball }}\right)^{1 / 7}\right)\right)$

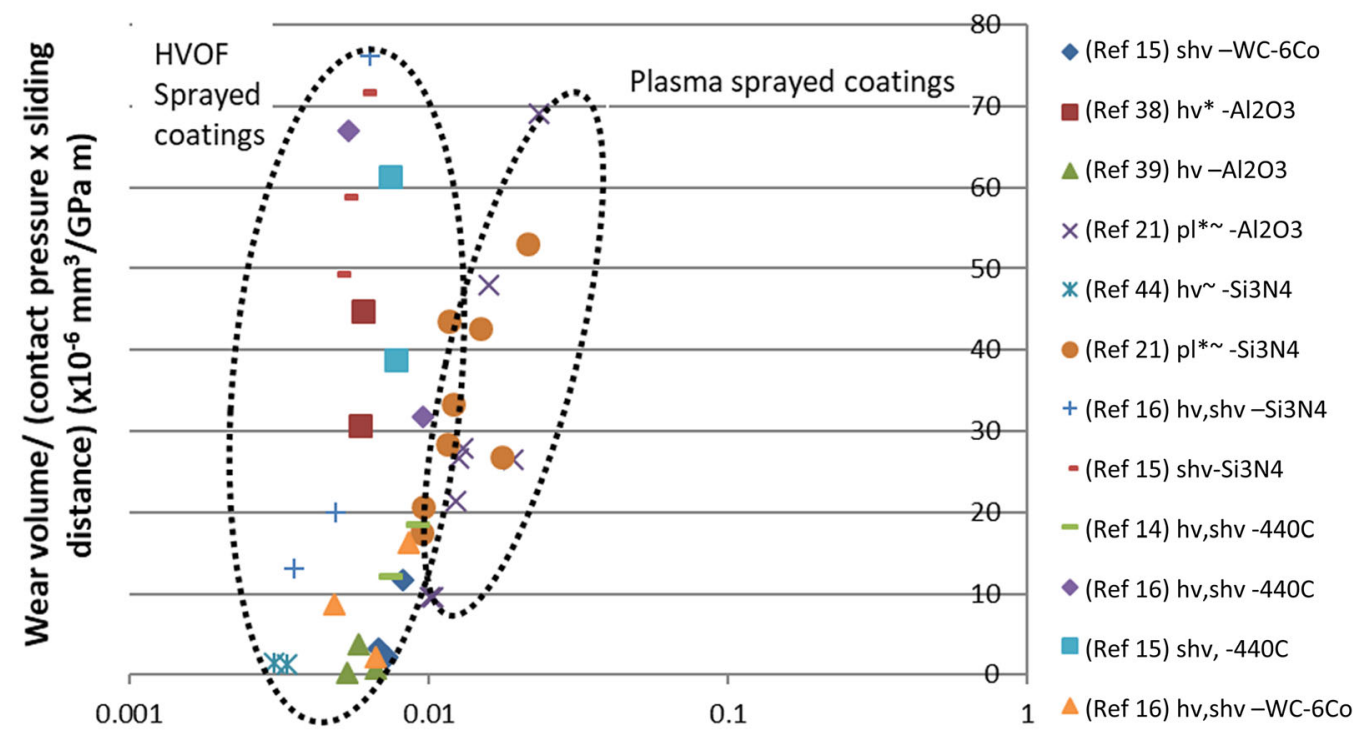

(b) $\quad \log _{10}\left(\left(\left(\mathrm{H}_{\text {ball }} / \mathrm{H}_{\text {coating }}\right)^{3 / 4} \times\left(\mathrm{Cp} / \mathrm{H}_{\text {ball }}\right)^{2 / 3}\right) /\left(\left(\mathrm{K} 1 \mathrm{c}_{\text {coating }}\right)^{1 / 2} \times\left(\mathrm{H}_{\text {ball }} / \mathrm{E}_{\text {ball }}\right)^{1 / 7}\right)\right)$

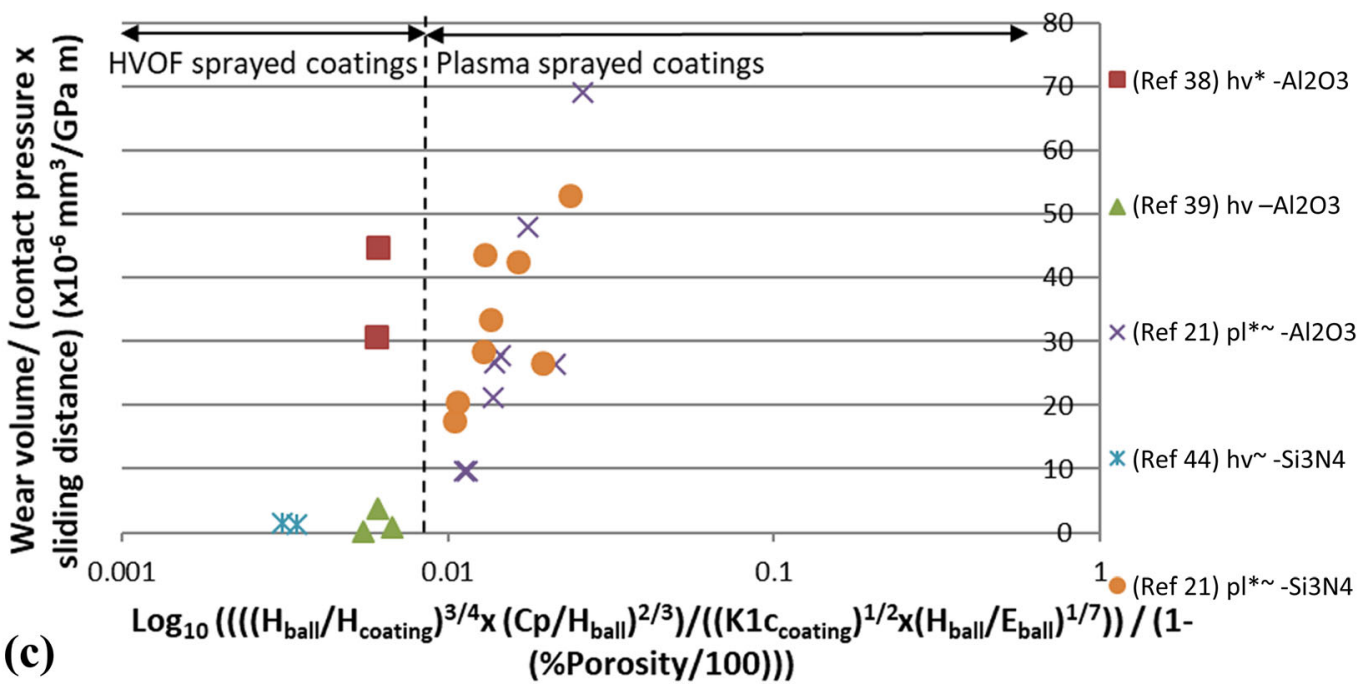


4Fig. 23 (a) Wear rate from literature against the logarithmic scale of the algorithm, (b) adjusted wear rate parameter against the algorithm and (c) adjusted wear rate parameter against the algorithm values further corrected with non-porosity factor for WC-12Co coatings. ( $\sim$ value estimated from graphs, *value converted to $\times 10^{-6} \mathrm{~mm}^{3}$ ) $\mathrm{Nm}, p l$ plasma-sprayed coating, $h v$ HVOF-sprayed coating, $s h v$ S-HVOF-sprayed coating)

rate. The following equation allows for the calculation of the nodal displacement.

$\frac{h}{l}=k_{D} P_{n}$

where $h$ is the linear wear and $P_{n}$ is the contact pressure at the node. The term $h$ is further discretized concerning the sliding distance.

$\frac{\mathrm{d} h}{\mathrm{~d} l}=k_{D} P_{n}$

Equation 14 provides the change in the height of individual nodes based on the nodal contact pressure. The adjustment of the node has the magnitude of $d h$, in the direction of the inward surface normal, which is calculated with regard to the local contact pressure and local sliding distance. The Euler integration scheme integrates the wear law over the sliding distance (Ref 138, 151).

$h_{j}=h_{j-1}+\Delta h_{j}$

$(\mathrm{Eq} 15)$ where $h_{j}$ is the total wear up to the $j$ th increment, $h_{j-1}$ is the total wear up to the $(j-1)$ th increment, and $\Delta h_{j}$ is the wear depth of the current increment.

This approach calculates the adjustment of the surface nodes that undergo wear with variations due to different wear test modelling (Ref 143, 152-161). The contact region undergoes several wear mechanisms concurrently under service loading. The experimentally measured Archard's wear rate is assumed to cover this aspect of wear (Ref 85, 138). Another limitation of computational wear modelling is the transition from severe wear to mild wear after the running-in period. Thus, a comparison between simulation and experimental data is difficult because FEM simulation uses a constant global wear rate, whereas the wear rate changes with test duration (Ref 85) and tribological test conditions (Fig. 25, 26) (Ref 148).

\section{Wear Simulation Methodology}

Different wear strategies have resulted in varying sliding wear rates in the literature. Hegadekatte et al. (Ref 152) proposed a strategy where the surface nodes are continuously adjusted during wear until the size of any surface element is reduced to a pre-defined fraction. Then the model is remeshed and the simulation continues until the intended number of cycles are complete (Ref 152). These authors also proposed a method where the linear wear is
Fig. 24 Approaches to numerical modelling of sliding wear in the finite element method (FEM), (a) mesh deletion method, (b) node adjustment method (Ref 85)

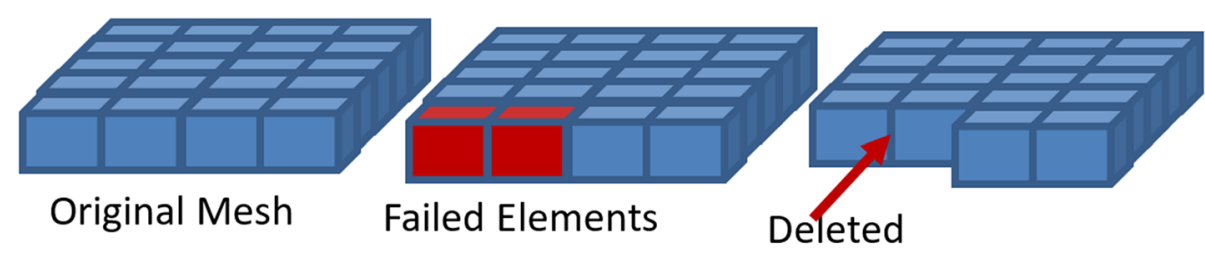

for Deletion

(a)

new surface

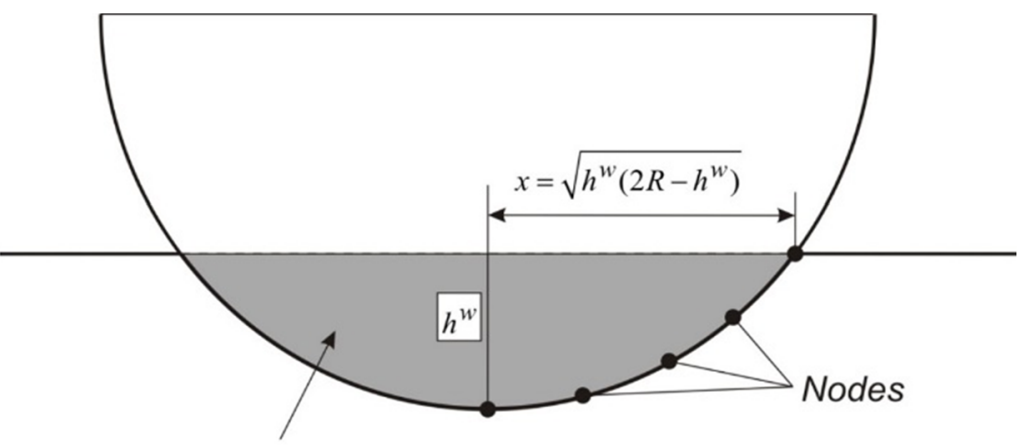

(b) Area $=R^{2} \arcsin \left(\frac{\sqrt{h^{w}\left(2 R-h^{w}\right)}}{R}\right)-\left(R-h^{w}\right) \sqrt{h^{w}\left(2 R-h^{w}\right)}$ 
Fig. 25 (a) A comparison of sliding wear prediction using node adjustment method and experimental values for Cast Stellite 6 for various values of $k_{\mathrm{D}}$ (wear rate), (b) SEM image of cast Stellite 6 (Ref 85)

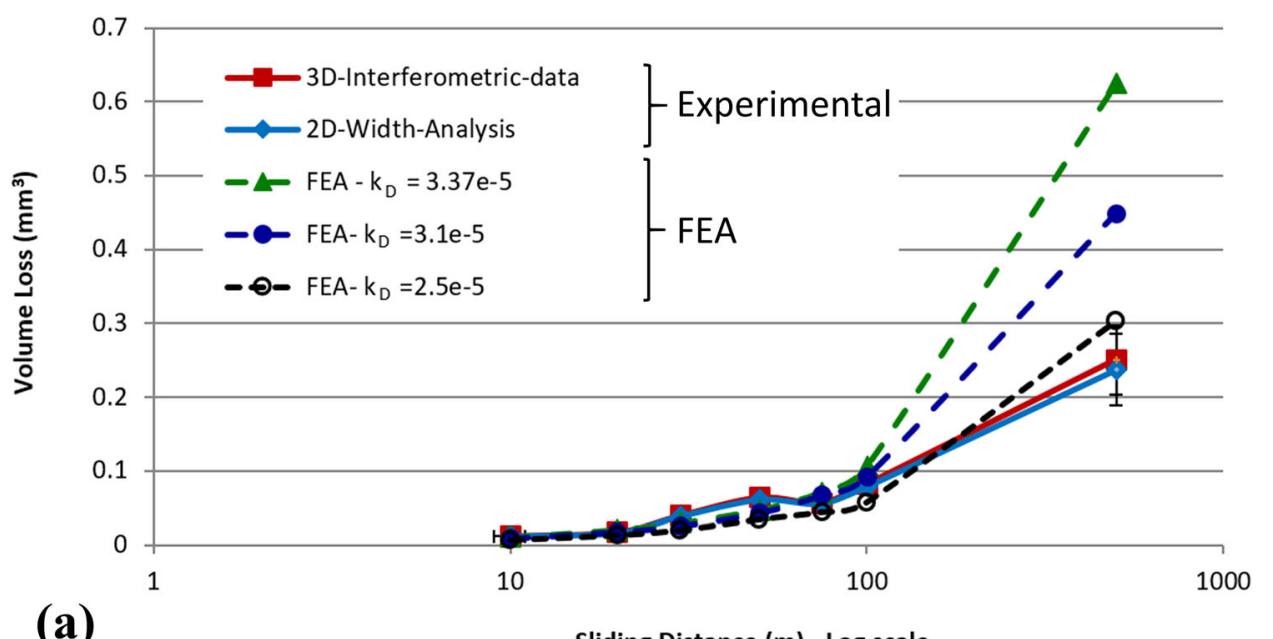

(a)

Sliding Distance (m) - Log scale

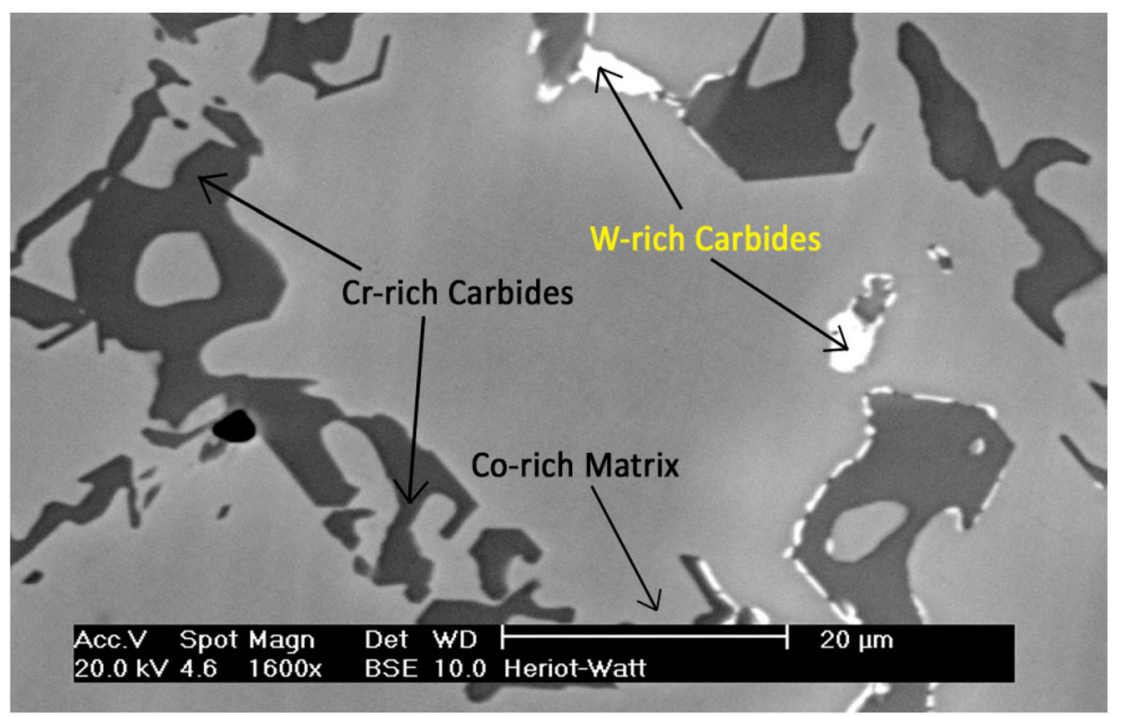

calculated based on the global contact pressure rather than the local contact pressure on the nodes (Ref 162). This reduces the computational time, but it comes at the cost of accuracy.

Another approach is to use the ABAQUS/standard user subroutine UMESHMOTION (based on FORTRAN script) (Ref 155, 158). In this approach, for every wear increment, the counter body is displaced on the basis of the wear coefficient, and the contact node is, respectively, displaced (Ref 153, 155-157). This method allows the translation of surface nodes that is followed by adaptive meshing and advection. The adaptive meshing avoids severe deformation of elements that causes errors where the model fails to converge. The mesh is re-located without creating new elements, therefore keeping the number of elements constant. Advection is the process of transferring the nodal and elemental data after the adaptive meshing has taken place, allowing for the re-mapping of the previous solution onto

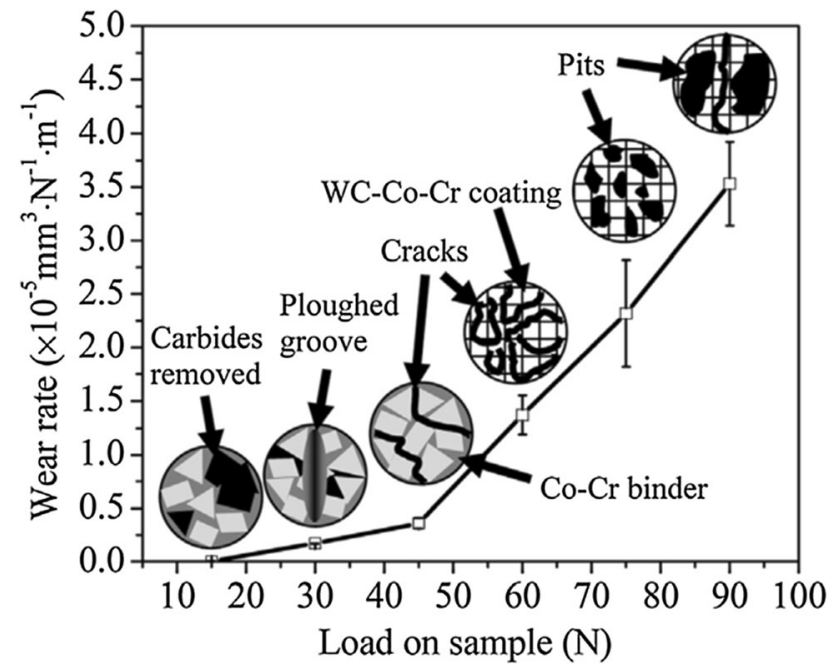

Fig. 26 Diagram showing the transition of wear rate and wear mechanism with normal load for WC-Co-Cr coatings (Ref 148) 
the new mesh. This procedure is termed as arbitrary Lagrangian-Eulerian (ALE) adaptive meshing within ABAQUS software. Figure 27 depicts the method used in wear simulations that are based on Archard's wear rate in Eq 14. Variations to this method depend on the type of sliding wear experiment. Similar methods can be used in other software such as ANSYS (Ref 143).

\section{Computation Time Management}

The wear modelling described in Fig. 27 has been described as a computationally expensive simulation process, and there is a need to reduce the computation time (Ref 155, 158). Põdra and Andersson (Ref 144) tackled this by using the Winkler model to determine the contact pressure distribution. This method was limited to flat surfaces, and model was restricted to one surface only, that is, rotational sliding environments cannot be simulated. Although this method was of high accuracy, the limitations outweighed the benefit of computational cost. Mukras et al. (Ref 159) proposed extrapolation and parallel computation schemes to reduce computational time at the cost of some accuracy. The standard method had an error of $6.65 \%$ with respect to actual experiments. The introduction of the parallel computation scheme resulted in a $34 \%$ reduction in computation time with an error of $7.3 \%$ (Ref 159). Hegadekatte et al. (Ref 152) described the challenges in computation time for simulations in terms of 'wear step'. With a small wear step, the accuracy will be high and computation time longer, but if the wear step was too big then the model will lose accuracy. One such wear step is defined as the execution of the loop described in Fig. 27.

\section{Validation of Wear Modelling}

An important aspect of modelling sliding wear for any material concerns validating the results. McColl et al. (Ref 157) developed a model for fretting wear with line contact loading for a high strength steel alloy where the flat part was nitrided to increase hardness. In Figure 28, the profile of the worn surface is compared with the simulation data under loading conditions (Ref 157). The profiles do not match well when the load is high, but fits well at the lowest load (Ref 157). This discrepancy in the profiles also extends to the total volume loss error as shown in Figure 29. McColl et al. (Ref 157) described that the underprediction of wear at higher loads arose from debris retention on the cylindrical part, which leads to higher contact pressure and results in higher volume loss (Fig. 28).

Bortoleto et al. (Ref 156) also reported a similar challenge where the model over-estimated the volume loss for a pin-on-disc simulation. The model could not include the effects of adhesion of disc material to the pin. This highlights the limitations of depending solely on the wear coefficient to simulate accurately the wear performance of a material.
Fig. 27 General flowchart for wear simulation methodology (Ref 155, 158) adopted from the literature

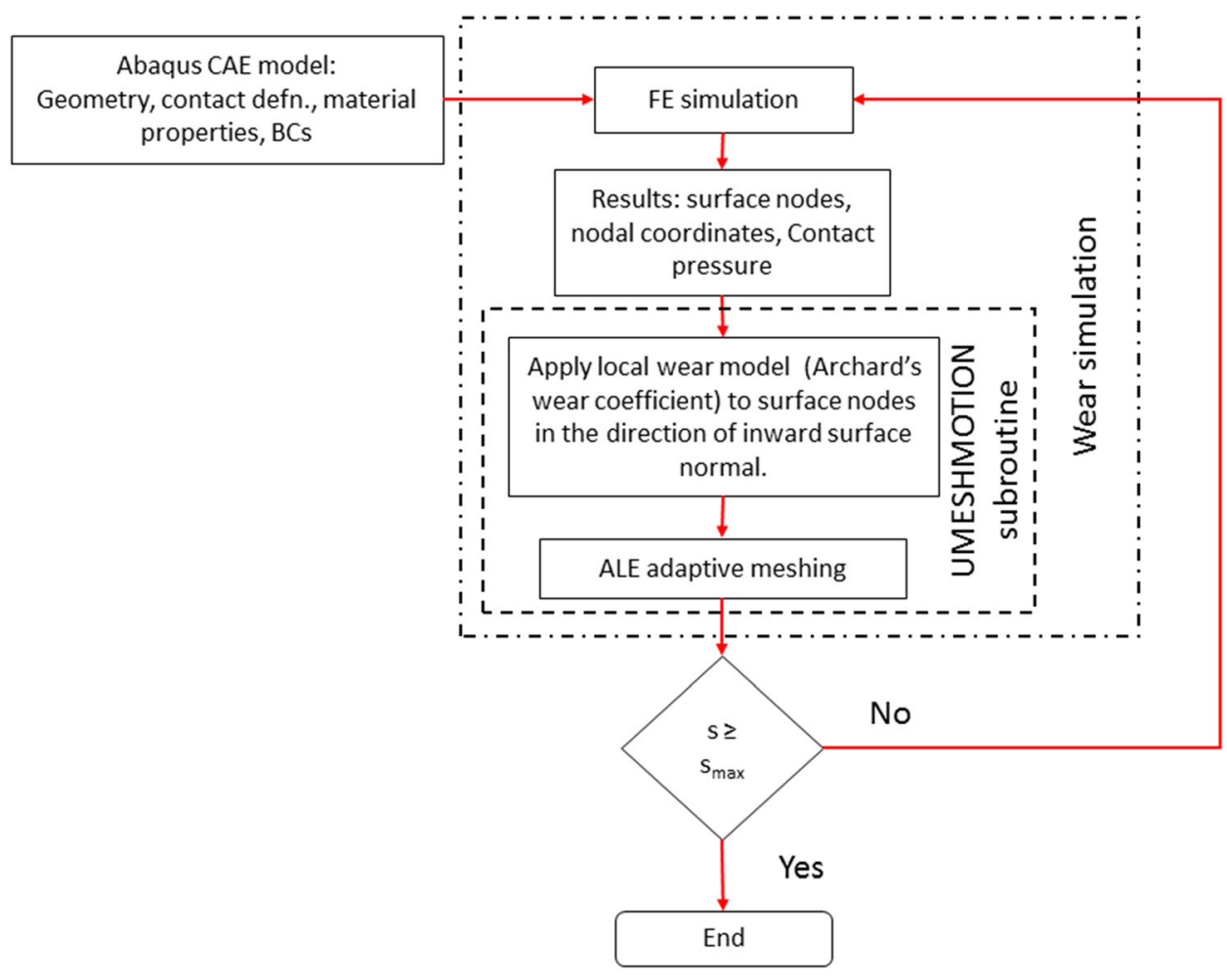




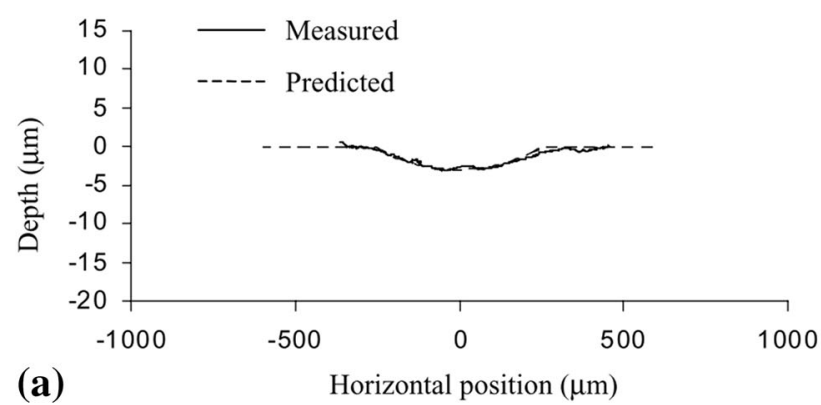

(b)
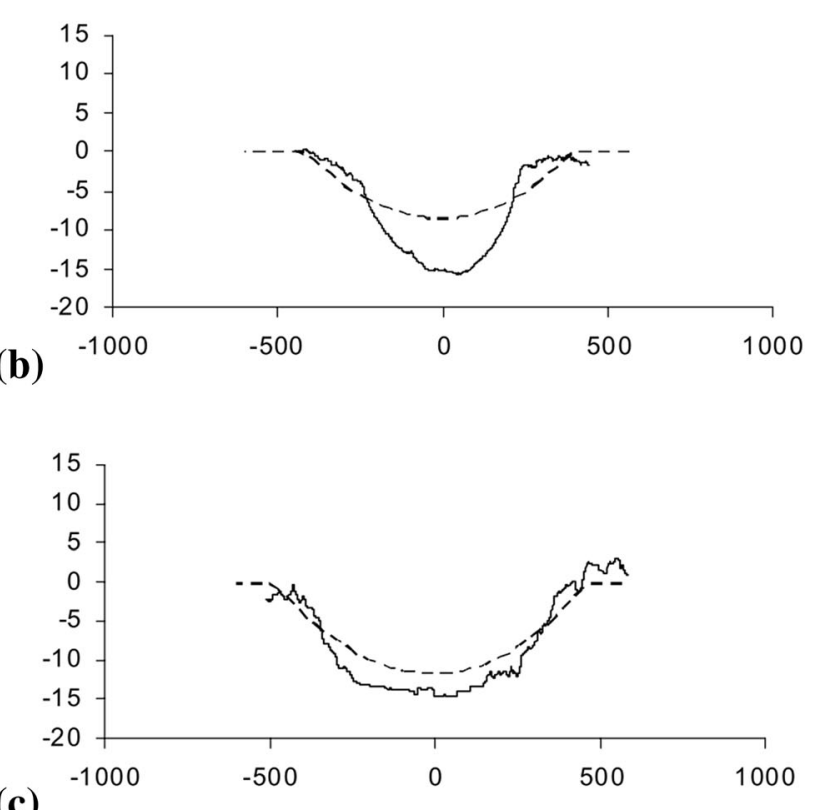

(c)

Fig. 28 Comparison of worn surface of experimental and simulation data for 18,000 cycles for a normal load of (a) $185 \mathrm{~N}$, (b) $500 \mathrm{~N}$ and (c) $1670 \mathrm{~N}($ Ref 157$)$

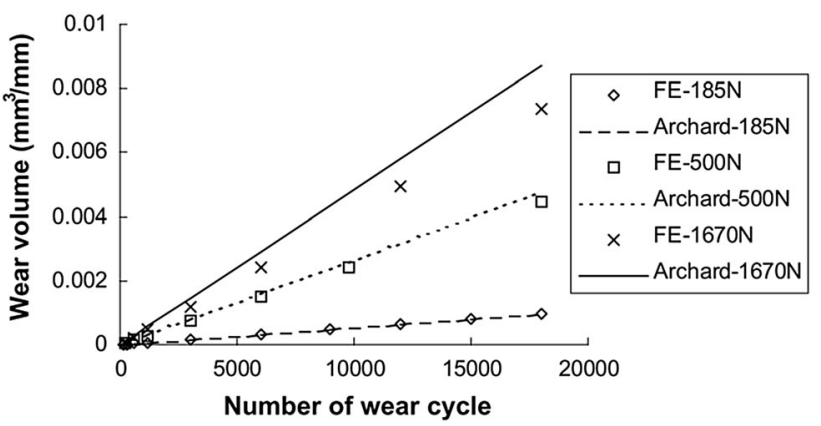

Fig. 29 Volume loss from simulation results and experimental data (Ref 157)

As discussed above, although it is assumed that the global wear coefficient would cover the effects of wear mechanisms, it cannot account for the transitions in wear mechanisms as the number of cycles increase. One possible solution is to use different wear coefficients at different stages of the model, but that would negate the purpose of a computational model since the wear coefficient is derived from empirical data. Another limitation of these models is their inability to account for phase transformations and the formation or removal of a tribo-layer during the sliding wear process (Fig. 4 and 10) (Ref 50, 85). Bolelli et al. (Ref 145), however, have indicated progress towards the inclusion of existing microstructural phases during FEM of the wear process.

\section{Role of Residual Stress in Modelling Wear}

The semiempirical mathematical relationship of the wear rate in "Semiempirical Mathematical Relationship in Sliding Wear of WC-Co Coatings" section and the FEM modelling in "Archard's Wear Rate in FEM" to "Validation of Wear Modelling" sections does not consider the role of residual stress. For a given coating substrate system, the measured through-thickness residual stress profile in thermal spray coatings depends not only on the coating process and process parameters, but also on the stress measurement technique (Ref 58, 163-166). The throughthickness magnitude of residual stress can be significant, as shown for the WC-Co coatings in Figure 30(a) (Ref 59). Compressive residual stress prohibits mode one crack initiation and propagation, whereas tensile residual stress can be detrimental to the coating performance. Higher velocity in HVOF spraying not only reduces the dwell time but also increases the beneficial peening effect leading to compressive residual stress in the deposit and increasing coating density (Ref 52, 53, 56, 57). Figure 30(a) shows compressive residual stress of a few hundred megapascals (MPa) in the as-sprayed and HIPed conditions, which can be advantageous in resisting fracture and delamination.

Measurement of residual stress is sensitive to the measurement method as shown in Figure 30(b) (Ref 57). This figure provides a comparison of residual stress measured by the non-destructive neutron diffraction and the destructive hole drilling techniques. The difference between the two results lies in the type of stress being measured, specifically, macro stress contrasted to stress based on lattice deformation. The choice of the residual stress measurement technique for wear analysis should be based on the accuracy of the measurement. For example, if the as-received residual stress profile is intended to be compared to the profile generated after the wear test, then a non-destructive technique such as X-ray, synchrotron or neutron diffraction is preferred (Ref 134). However, the surface roughness of the specimen created by the wear test method increases the standard deviation of the measured stress. Thus, the penetration depth of the diffraction method should be selected so that the measurement is representative of the material just beneath the surface. Consequently, care is necessary 


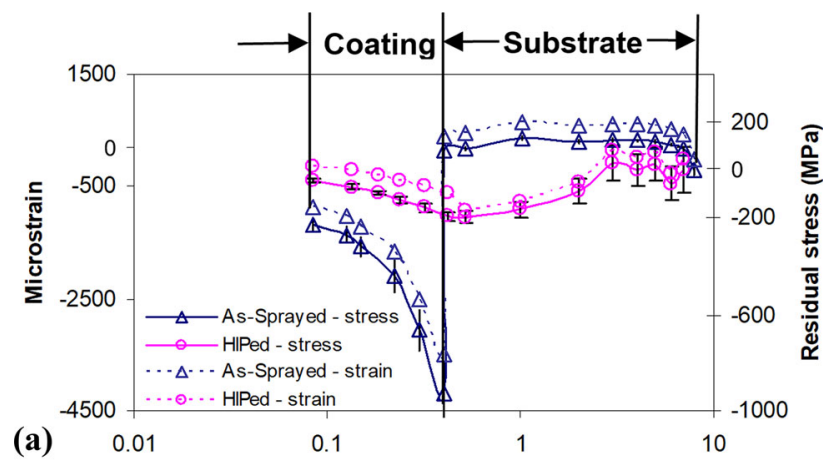

(b)

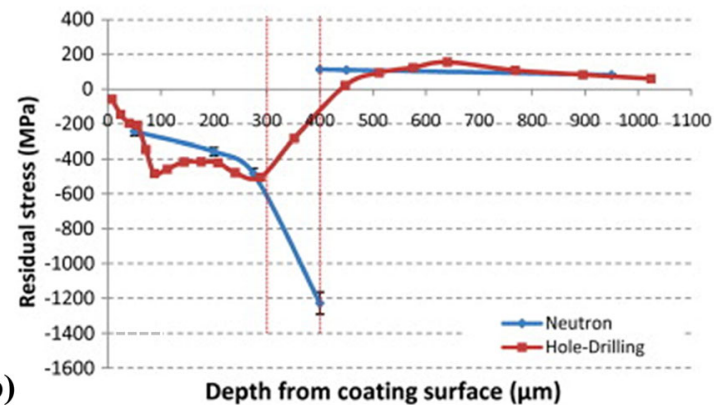

Fig. 30 (a) Residual strain measurements using neutron diffraction in HVOF-sprayed WC-Co coatings in the as-sprayed and HIPed conditions (Ref 59), (b) a comparison of residual stress measurement in WC-NiCrBSi coatings using neutron diffraction and hole drilling technique (Ref 57)

when superimposing the residual stress field under sliding or rolling contact conditions (Ref 163).

Savarimuthu et al. (Ref 167) considered the role of residual stress when comparing the use of WC-Co coatings for replacement of hazardous chrome plating. Stoica et al. (Ref 134) reported the findings of residual stress changes after the sliding wear process in both as-sprayed and HIPed conditions. This investigation stated that the compressive residual stress in the coating either reduces slightly or increases significantly during the sliding wear process (Ref 134). Yu et al. (Ref 168) in their investigation of NiCrBSi coatings also reported that the tensile residual stress in the coating material leads to coating failure. This trend is similar to the rolling contact fatigue studies of WC-Co and WC-NiCrBSi coatings, where compressive residual stress improves fatigue life ( $\operatorname{Ref} 53,88)$. This is consistent with the investigation of Luo et al. (Ref 166), where the authors reported that compressive stress in the HVOF-sprayed WCCo coatings has a significant positive influence on the wear resistance whereas the tensile stress has a negative effect. Ho et al. (Ref 54) considered the evolution of stress in sliding wear of steel. They verified that the residual stresses build up in the early stages of wear and any initial stress pattern is eliminated. This result, while accurate for both the annealed and the hardened steel samples, was not valid for the hardened and shot-peened sample.
The role of residual stress in the sliding wear process has been investigated (Ref 54, 134, 166); however, it has not been included in the semiempirical mathematical models of sliding wear rate or numerical modelling. Note though that the numerical approach discussed in "Computational Wear Modelling" section can be adapted to include the throughthickness residual stress profile incorporated within the FEM of sliding wear. This approach can further reduce the error between the experimentally measured and numerically predicted values of sliding wear (Ref 52, 5558, 163, 166). Furthermore, the resulting microstructure associated with the numerical models of residual stress during spray coatings (Ref 50) can serve as the ab initio point to integrate sliding wear models and investigate both the influence of residual stress and coating architecture.

\section{Influence of Test Temperature on Modelling the Sliding Wear Resistance of WC-Co Coatings}

As shown in Figure 15(c) and (d) and discussed in "Influence of Binder Composition, Content and Test Temperature On Sliding Wear Performance" section, two aspects influence wear mechanisms as the test temperature increases for sliding. The first one relates changes in the mechanical properties such as elastic modulus, hardness and fracture toughness: factors that can be captured in the FEM models using temperature-dependent mechanical properties. The second factor is related to phase transformations occurring with respect to temperature during the sliding wear test. As it is not possible to model temperature-dependent phase transformations using FEM, the result of these phase changes on material properties may also be approximated using temperature-dependent material properties. The significant influence caused by the stability of the beneficial tribo-film can only be captured in the global wear rate $\left(k_{\mathrm{D}}\right)$, which contributes to complex mechanisms since the tribo-film properties change with temperature and load. Further work in this area will benefit both room temperature and higher temperature predictions of sliding wear rate using FEM.

\section{Conclusion}

The sliding wear performance of WC cermet coatings depends on parameters that link structure-property relationships to the tribological test conditions (Fig. 4). This review focuses on the effects of coating microstructure, carbide size, binder content, binder composition, spray manufacturing method, post-treatment, wear testing environments and counter body on the sliding wear of WC12Co thermal-sprayed coatings. Sliding wear mechanisms 
and wear rates are also compared with cemented WC-Co carbides. The specific conclusions are as follows.

1. Coating process parameter optimisation is critical in reducing the thermal loading of $\mathrm{WC}$ particles, which can result in carbon loss leading to $\mathrm{M}_{2} \mathrm{C}, \mathrm{M}_{6} \mathrm{C}, \mathrm{M}_{12} \mathrm{C}$ phase transformations (Fig. 5 and 6). A controlled amount of carbide dissolution is, however, desirable in improving the wear resistance of WC-Co coatings because it reduces carbide pullout by strengthening the matrix and improving the interface bonding between the matrix and carbide constituents. Strategies of reducing carbon loss due to thermal loading are discussed, which include cladding of WC particles and heat treatment of WC-Co coatings leading to precipitation of dissolved carbides. Heat treatment of WC-Co coatings can also lead to crystallisation of amorphous phases and improved mechanical properties, which enhances the sliding wear resistance. There is a relatively higher carbon loss in S-HVOF coatings. However, S-HVOF coatings provide a dense microstructure with hardness and elastic modulus similar to or better than the conventional HVOF coatings.

2. The sliding wear mechanism of WC-Co coatings (Fig. 10 and 11) include carbide pullout, subsurface delamination, carbide cracking, preferential wear of the matrix and three-body abrasion caused by wear debris in the contact region. Formation and stability of tribo-films $\left(\mathrm{WO}_{\mathrm{x}}\right)$ on the surface of the wear track is critical in reducing wear and friction during the sliding wear of WC-Co coatings. The stability of this tribofilm depends not only on the tribological test conditions but also on the chemical composition of the counter body material in both WC-Co coatings and cemented WC-Co carbides. Some mechanisms of sliding wear in WC-Co coatings such as carbide fracture/pullout, matrix erosion and three-body abrasion are consistent with the sliding wear of cemented WC-Co carbides, whereas subsurface delamination and wear related to carbon loss and the formation of etaphases is unique to thermal spray WC-Co coatings.

3. The sliding wear rate of WC-Co coatings varies significantly based not only on the structure-property relationship but also the tribological test methodology and test parameters. This leads to large variations in sliding wear rates. The sliding wear rate of $\mathrm{WC}-\mathrm{Co}$ coatings varies between $0.04 \times 10^{-6}$ and $19.2 \times 10^{-6} \mathrm{~mm}^{3} / \mathrm{N} \mathrm{m}$ (Table 2). On the other hand, the wear rates of cemented WC-Co carbides vary in a narrow range of $0.03 \times 10^{-6}-0.8 \times 10^{-6} \mathrm{~mm}^{3} / \mathrm{N} \mathrm{m}$ regardless of the tribological test conditions (Fig. 19a). The hardness and wear resistance increase in WC-Co coatings as the carbide size is reduced and decarburisation is controlled. The sliding wear rate of S-HVOF coating is similar or slightly better than the conventional HVOF coatings under specific tribological conditions.

4. The contact stress related to the load term in sliding wear rate calculation is geometry dependent. Thus, the wear rate is re-defined in terms of contact pressure $\left(\mathrm{mm}^{3} / \mathrm{GPa} \mathrm{m}\right)$. Semiempirical mathematical models based on this modified wear rate are developed to link sliding wear with the structure-property relationship using (i) coating fracture toughness, (ii) the hardness of the coating and counter body material and (iii) elastic modulus of the counter body material (Fig. 23). This interdependency is substantially different to the sliding wear rate of cemented WC-Co carbides that show an inversely proportional relationship between sliding wear rate and hardness (Fig. 19b).

5. In sliding wear under non-corrosive environments up to a temperature of $\sim 500^{\circ} \mathrm{C}$, WC-Co coatings provide the best wear performance. Other binder compositions of $\mathrm{Ni}$ and $\mathrm{Cr}$ are more justified for corrosive environments (Fig. 15). In terms of the wear mechanism, the oxidation of WC becomes dominant as the sliding test temperature increases. This behaviour is both beneficial and counterproductive: i.e., oxidation at higher temperatures stabilises the tribo-film, thereby reducing friction and wear rate. But this also reduces the mechanical strength of the coating, which increases the wear rate due to oxidation. A stable tribo-film at higher temperature has a more dominant effect in controlling both the wear mechanism and wear rate than the reduction in mechanical strength. A higher $\mathrm{Co}$ binder content of $17 \%$ instead of $12 \%$, increases the sliding wear resistance by almost $50 \%$ at $\sim 500{ }^{\circ} \mathrm{C}$ (Fig. 15d) at high temperatures. The sliding wear resistance decreases according to the progression "WC-17Co (best) $\rightarrow \mathrm{Cr} 3 \mathrm{C} 2-25 \mathrm{NiCr} \rightarrow \mathrm{WC}-12 \mathrm{Co} \rightarrow$ WC-10Co-4Cr (worst)" at $\sim 500{ }^{\circ} \mathrm{C}$.

In terms of coating processes, cracking and delamination has been observed for APS coatings at $\sim 250{ }^{\circ} \mathrm{C}$. This behaviour was not observed for the HVOF, HVAF and LPPS coatings due to their improved microstructure until a higher temperature of $\sim 650{ }^{\circ} \mathrm{C}$. The corrosion resistance, however, shows an opposite trend to the high-temperature sliding wear rate, where the corrosion resistance increases as WC-17Co (worst) $\rightarrow$ WC-12Co $\rightarrow$ WC$10 \mathrm{Co}-4 \mathrm{Cr} \rightarrow$ WC-Ni (best), Fig. 15(a).

6. The numerical modelling of sliding wear rate using FEM can be implemented using strategies of mesh deletion and node adjustment, which have been applied 
to other materials. These models are in their infancy and are based on experimentally evaluated wear rate $\left(k_{\mathrm{D}}\right)$. They have the potential to superimpose the residual stress profile and microstructural phases during sliding wear. Some aspects of sliding wear at higher temperatures, such as the variation in the temperature-dependent material properties, can also be captured by the FEM analysis. However, challenges remain when modelling the stability of the tribo-film at higher temperatures and loads.

\section{Future Projections}

Several developments can further improve the microstructural quality and sliding wear of WC coatings. These developments include the following five areas of science and technology.

(1) Closed-loop monitoring and feedback control of the thermal spray process can link the coating process parameters with particle temperatures, their velocity distributions and the generation of thermal residual stresses. This knowledge will lead to optimisation of coating powders and process parameters to reduce carbon loss, especially in the emerging technological area of nanocomposite coatings.

(2) New material developments are needed to design coatings that can perform as well as WC-Co coatings in sliding wear and, in addition, include corrosion and high-temperature tribological environments.

(3) Numerical modelling of the sliding wear process is in its infancy. Multiscale modelling in this area, along with the optimisation of these models to reduce computational cost and improve the accuracy of results, will enable the design of improved wearresistant coatings for existing and new markets.

(4) A better understanding of residual stress is needed to understand its role during the service loading of WCCo coatings in sliding contacts. The influence of residual stress also impacts heavily on fatiguerelated failure mechanisms of components. The intention is to design a through-thickness residual stress profile in the coating substrate system by controlling the coating deposition process and parameters and post-spray heat treatment of coatings, for improved wear resistance.

(5) Further development of thermal spray processes such as 'warm spray' of WC-Co coatings can be coupled with an in situ heat treatment to improve the tribomechanical properties of WC-Co coatings.
Acknowledgements CCB has the support of the Australian Research Council under the Industrial Transformation Training Centre Project IC180100005 that is titled "Surface Engineering for Advanced Materials", SEAM.

Open Access This article is licensed under a Creative Commons Attribution 4.0 International License, which permits use, sharing, adaptation, distribution and reproduction in any medium or format, as long as you give appropriate credit to the original author(s) and the source, provide a link to the Creative Commons licence, and indicate if changes were made. The images or other third party material in this article are included in the article's Creative Commons licence, unless indicated otherwise in a credit line to the material. If material is not included in the article's Creative Commons licence and your intended use is not permitted by statutory regulation or exceeds the permitted use, you will need to obtain permission directly from the copyright holder. To view a copy of this licence, visit http://creativecommons. org/licenses/by/4.0/.

\section{References}

1. K. Holmberg and A. Erdemir, Influence of Tribology on Global Energy Consumption, Costs and Emissions, Friction, 2017, 5(3), p 263-284.

2. Grand View Research, "Thermal Spray Coatings Market Size, Share \& Trends Analysis Report By Product (Metal, Ceramic, Intermetallic), By Technology (Plasma Spray, Cold Spray, Flame Spray), By Region, And Segment Forecasts, 2020-2027," (San Francisco), 2020, https://www.grandviewresearch.com/ industry-analysis/thermal-spray-coatings-market.

3. L.M. Berger, Hardmetals as Thermal Spray Coatings, Powder Metall., 2007, 50(3), p 205-214.

4. A.S.M. Ang, and C.C. Berndt, A Review of Testing Methods for Thermal Spray Coatings, Int. Mater. Rev., 2014, 59(4), p 179223. https://doi.org/10.1179/1743280414Y.0000000029

5. P. Fauchais and A. Vardelle, Thermal Sprayed Coatings Used Against Corrosion and Corrosive Wear, Adv. Plasma Spray Appl., 2012, 10, p 34448.

6. J. Pirso, M. Viljus, and S. Letunovitš, Friction and Dry Sliding Wear Behaviour of Cermets, Wear, 2006, 260(7-8), p 815-824.

7. K. Bonny, P. De Baets, Y. Perez, J. Vleugels, and B. Lauwers, Friction and Wear Characteristics of WC-Co Cemented Carbides in Dry Reciprocating Sliding Contact, Wear, 2010, 268(11-12), p 1504-1517.

8. H. Zhang, L. Chen, J. Sun, W. Wang, and Q. Wang, An Investigation of Cobalt Phase Structure in WC-Co Cemented Carbides Before and After Deep Cryogenic Treatment, Int. J. Refract. Met. Hard Mater, 2015, 51, p 201-206.

9. H. Saito, A. Iwabuchi, and T. Shimizu, Effects of Co Content and WC Grain Size on Wear of WC Cemented Carbide, Wear, 2006, 261(2), p 126-132.

10. J. García, V. Collado Ciprés, A. Blomqvist, and B. Kaplan, Cemented Carbide Microstructures: A Review, Int. J. Refract. Met. Hard Mater., 2019, 80, p 40-68.

11. P. Stoyanov, P. Stemmer, T.T. Järvi, R. Merz, P.A. Romero, M. Scherge, M. Kopnarski, M. Moseler, A. Fischer, and M. Dienwiebel, Friction and Wear Mechanisms of Tungsten-Carbon Systems: A Comparison of Dry and Lubricated Conditions, ACS Appl. Mater. Interfaces, 2013, 5(13), p 6123-6135.

12. Oerlikon, "Oerlikon Metco," 2020. 
13. Š Houdková, F. Zahálka, M. Kašparová, and L.M. Berger, Comparative Study of Thermally Sprayed Coatings under Different Types of Wear Conditions for Hard Chromium Replacement, Tribol. Lett., 2011, 43(2), p 139-154.

14. R. Ahmed, N.H. Faisal, N.M. Al-Anazi, S. Al-Mutairi, F.L. Toma, L.M. Berger, A. Potthoff, E.K. Polychroniadis, M. Sall, D. Chaliampalias and M.F.A. Goosen, Structure Property Relationship of Suspension Thermally Sprayed WC-Co Nanocomposite Coatings, J. Therm. Spray Technol., 2014, 24(3), p 357-377.

15. O. Ali, R. Ahmed, N.H. Faisal, N.M. Alanazi, L.M. Berger, A. Kaiser, F.L. Toma, E.K. Polychroniadis, M. Sall, Y.O. Elakwah, and M.F.A. Goosen, Influence of Post-Treatment on the Microstructural and Tribomechanical Properties of Suspension Thermally Sprayed WC-12 Wt\%Co Nanocomposite Coatings, Tribol. Lett., 2017, 65(2), p 33.

16. R. Ahmed, O. Ali, N.H. Faisal, N.M. Al-Anazi, S. Al-Mutairi, F.L. Toma, L.M. Berger, A. Potthoff, and M.F.A. Goosen, Sliding Wear Investigation of Suspension Sprayed WC-Co Nanocomposite Coatings, Wear, 2015, 322-323, p 133-150.

17. S.F. Wayne and S. Sampath, Structure/Property Relationships in Sintered and Thermally Sprayed WC-Co, J. Therm. Spray Technol., 1992, 1(4), p 307-315.

18. E. López Cantera and B.G. Mellor, Fracture Toughness and Crack Morphologies in Eroded WC-Co-Cr Thermally Sprayed Coatings, Mater. Lett., 1998, 37(4-5), p 201-210.

19. R.J.K. Wood, S. Herd, and M.R. Thakare, A Critical Review of the Tribocorrosion of Cemented and Thermal Sprayed Tungsten Carbide, Tribol. Int., 2018, 119, p 491-509.

20. L.M. Berger, Coatings by Thermal Spray, Comprehensive Hard Materials. V.K. Sarin Ed., Elsevier, Amsterdam, 2014, p 471506. https://doi.org/10.1016/B978-0-08-096527-7.00017-9

21. E. Sánchez, E. Bannier, M.D. Salvador, V. Bonache, J.C. García, J. Morgiel, and J. Grzonka, Microstructure and Wear Behavior of Conventional and Nanostructured Plasma-Sprayed WC-Co Coatings, J. Therm. Spray Technol., 2010, 19(5), p 964974.

22. Y.C. Zhu, K. Yukimura, C.X. Ding, and P.Y. Zhang, Tribological Properties of Nanostructured and Conventional WC-Co Coatings Deposited by Plasma Spraying, Thin Solid Films, 2001, 388(1-2), p 277-282.

23. L. Thakur and N. Arora, Sliding and Abrasive Wear Behavior of WC-CoCr Coatings with Different Carbide Sizes, J. Mater. Eng. Perform., 2013, 22(2), p 574-583.

24. G.C. Saha, A. Mateen,, and T.I. Khan, Tribological Studies of Conventional Microcrystalline and Engineered Near-Nanocrystalline WC-17CO HVOF Coatings. Nanotechnology 2010: Advanced Materials, CNTs, Particles, Films and CompositesTechnical Proceedings of the 2010 NSTI Nanotechnology Conference and Expo, NSTI-Nanotech 2010, NSTI, 2010, p 592-595.

25. W. Zórawski, The Microstructure and Tribological Properties of Liquid-Fuel HVOF Sprayed Nanostructured WC-12Co Coatings, Surf. Coatings Technol., 2013, 220, p 276-281.

26. C. Lyphout, K. Sato, S. Houdkova, E. Smazalova, L. Lusvarghi, G. Bolelli, and P. Sassatelli, Tribological Properties of Hard Metal Coatings Sprayed by High-Velocity Air Fuel Process, $J$. Therm. Spray Technol., 2016, 25(1-2), p 331-345.

27. H. Chen, G. Gou, M. Tu, and Y. Liu, Research on the Friction and Wear Behavior at Elevated Temperature of Plasma-Sprayed Nanostructured WC-Co Coatings, J. Mater. Eng. Perform., 2010, 19(1), p 1-6.

28. X.Q. Zhao, H. Di Zhou, and J.M. Chen, Comparative Study of the Friction and Wear Behavior of Plasma Sprayed Conventional and Nanostructured WC-12\%Co Coatings on Stainless Steel, Mater. Sci. Eng. A, 2006, 431(1-2), p 290-297.
29. B. Yin, H.D. Zhou, D.L. Yi, J.M. Chen, and F.Y. Yan, Microsliding Wear Behaviour of HVOF Sprayed Conventional and Nanostructured WC-12CO Coatings at Elevated Temperatures, Surf. Eng., 2010, 26(6), p 469-471.

30. D. Mohanty, S. Kar, S. Paul, and P.P. Bandyopadhyay, Carbon Nanotube Reinforced HVOF Sprayed WC-Co Coating, Mater. Des., 2018, 156, p 340-350.

31. Z. Geng, D. Duan, S. Hou, and S. Li, Tribological Behavior of WC-12Co Air Plasma-Sprayed Coating at Elevated Temperatures, Tribol. Trans., 2016, 59(1), p 55-61.

32. P. Mi, H. Zhao, T. Wang, and F. Ye, Sliding Wear Behavior of HVOF Sprayed WC-(Nano-WC-Co) Coating at Elevated Temperatures, Mater. Chem. Phys., 2018, 206, p 1-6.

33. J.M. Guilemany, S. Dosta, J. Nin, and J.R. Miguel, Study of the Properties of WC-Co Nanostructured Coatings Sprayed by High-Velocity Oxyfuel, J. Therm. Spray Technol., 2005, 14(3), p 405-413.

34. A. Lekatou, D. Sioulas, A.E. Karantzalis, and D. Grimanelis, A Comparative Study on the Microstructure and Surface Property Evaluation of Coatings Produced from Nanostructured and Conventional WC-Co Powders HVOF-Sprayed on A17075, Surf. Coat. Technol., 2015, 276, p 539-556.

35. J.M. Guilemany, S. Dosta, and J.R. Miguel, The Enhancement of the Properties of WC-Co HVOF Coatings Through the Use of Nanostructured and Microstructured Feedstock Powders, Surf. Coat. Technol., 2006, 201(3-4), p 1180-1190.

36. G.C. Saha, A. Mateen, and T.I. Khan, Tribological Performance Study of HVOF-Sprayed Microstructured and Nanostructured WC-17wt.\%Co Coatings, ASME Int, Mech. Eng. Congr. Expo. Proc., 2010, 12, p 153-162.

37. P.H. Shipway, D.G. McCartney, and T. Sudaprasert, Sliding Wear Behaviour of Conventional and Nanostructured HVOF Sprayed WC-Co Coatings, Wear, 2005, 259(7-12), p 820-827.

38. M. Jafari, M.H. Enayati, M. Salehi, S.M. Nahvi, S.N. Hosseini, and C.G. Park, Influence of Nickel-Coated Nanostructured WCCo Powders on Microstructural and Tribological Properties of HVOF Coatings, J. Therm. Spray Technol., 2014, 23(8), p 14561469.

39. W. Tillmann, I. Baumann, P.S. Hollingsworth, and L. Hagen, Sliding and Rolling Wear Behavior of Hvof-Sprayed Coatings Derived from Conventional, Fine and Nanostructured WC-12Co Powders, J. Therm. Spray Technol., 2014, 23(1-2), p 262-280.

40. Q. Yang, T. Senda, and A. Ohmori, Effect of Carbide Grain Size on Microstructure and Sliding Wear Behavior of HVOFSprayed WC-12\% Co Coatings, Wear, 2003, 254(1-2), p 23-34.

41. S. Usmani, S. Sampath, D.L. Houck, and D. Lee, Effect of Carbide Grain Size on the Sliding and Abrasive Wear Behavior of Thermally Sprayed WC-Co Coatings, Tribol. Trans., 1997, 40(3), p 470-478.

42. N. Ma, L. Guo, Z. Cheng, H. Wu, F. Ye, K. Zhang, M. Jafari, M.H. Enayati, M. Salehi, S.M. Nahvi, and C.G. Park, Improvement on Mechanical Properties and Wear Resistance of HVOF Sprayed WC-12Co Coatings by Optimizing Feedstock Structure, Appl. Surf. Sci., 2014, 320, p 364-371.

43. T. Sudaprasert, P.H. Shipway, and D.G. McCartney, Sliding Wear Behaviour of HVOF Sprayed WC-Co Coatings Deposited with Both Gas-Fuelled and Liquid-Fuelled Systems, Wear, 2003, 255(7-12), p 943-949.

44. Y. Qiao, T.E. Fischer, and A. Dent, The Effects of Fuel Chemistry and Feedstock Powder Structure on the Mechanical and Tribological Properties of HVOF Thermal-Sprayed WC-Co Coatings with Very Fine Structures, Surf. Coatings Technol., 2003, 172(1), p 24-41.

45. R.J.K. Wood, Tribology of Thermal Sprayed WC-Co Coatings, Int. J. Refract. Met. Hard Mater., 2010, 28(1), p 82-94. 
46. General Carbide, "The Designer's Guide to Tungsten Carbide," (Greensburg), 2014, https://www.generalcarbide.com/wp-con tent/uploads/2019/04/GeneralCarbide-Designers_Guide_Tung stenCarbide.pdf.

47. L.M. Berger, P. Ettmayer, P. Vuoristo, T. Mäntylä, and W. Kunert, Microstructure and Properties of WC-10\%Co-4\% Cr Spray Powders and Coatings: Part 1. Powder Characterization, J. Therm. Spray Technol., 2001, 10(2), p 311-325.

48. H.P. Offer, Y.-C. Lau, Y.J. Kim,, and A.S. Nelson. Plasma Coating Process for Improved Bonding of Coatings on Substrates (United States), 1996, p 1-9, https://patents.google.com/ patent/US5770273.

49. H. Jiménez, J.J. Olaya, J.E. Alfonso, and C.A. Pineda-Vargas, Corrosion Resistance of Ni-Based Coatings Deposited by Spray and Fuse Technique Varying Oxygen Flow, Surf. Coat. Technol., 2017, 321, p 341-349. https://doi.org/10.1016/j.surfcoat. 2017.04.068

50. A. Fardan, C.C. Berndt, and R. Ahmed, Numerical Modelling of Particle Impact and Residual Stresses in Cold Sprayed Coatings: A Review, Surf. Coat. Technol., 2021, 409, p 126835. https:// doi.org/10.1016/j.surfcoat.2021.126835

51. G.-J. Yang, P.-H. Gao, C.-X. Li, and C.-J. Li, Mechanical Property and Wear Performance Dependence on Processing Condition for Cold-Sprayed WC-(NanoWC-Co), Appl. Surf. Sci., 2015, 332, p 80-88. https://doi.org/10.1016/j.apsusc.2015.01.138

52. A. Fardan and R. Ahmed, Modeling the Evolution of Residual Stresses in Thermally Sprayed YSZ Coating on Stainless Steel Substrate, J. Therm. Spray Technol., 2019, 28(4), p 717-736.

53. R. Ahmed and M. Hadfield, Experimental Measurement of the Residual Stress Field within Thermally Sprayed Rolling Elements, Wear, 1997, 209(1-2), p 84-95.

54. J.W. Ho, C. Noyan, J.B. Cohen, V.D. Khanna, and Z. Eliezer, Residual Stresses and Sliding Wear, Wear, 1983, 84(2), p 183202.

55. T. Varis, T. Suhonen, J. Laakso, M. Jokipii, and P. Vuoristo, Evaluation of Residual Stresses and Their Influence on Cavitation Erosion Resistance of High Kinetic HVOF and HVAFSprayed WC-CoCr Coatings, J. Therm. Spray Technol., 2020, 29(6), p 1365-1381.

56. R. Ahmed, H. Yu, V. Stoica, L. Edwards, and J.R. Santisteban, Neutron Diffraction Residual Strain Measurements in PostTreated Thermal Spray Cermet Coatings, Mater. Sci. Eng. A, 2008, 498(1-2), p 191-202. https://doi.org/10.1016/j.msea.2008. 08.023

57. R. Ahmed, M.E. Fitzpatrick, and N.H. Faisal, A Comparison of Neutron Diffraction and Hole-Drilling Residual Strain Measurements in Thermally Sprayed Coatings, Surf. Coat. Technol., 2012, 206, p 4180-4185.

58. J. Stokes and L. Looney, Residual Stress in HVOF Thermally Sprayed Thick Deposits, Surf. Coat. Technol., 2004, 177-178, p 18-23.

59. R. Ahmed, H. Yu, S. Stewart, L. Edwards,, and J.R. Santisteban, Residual Strain Measurements in Thermal Spray Cermet Coatings via Neutron Diffraction, J. Tribol., 2007, 129(2), p 411-418. https://doi.org/10.1115/1.2647503.

60. A.S.M. Ang, N. Sanpo, M.L. Sesso, S.Y. Kim, and C.C. Berndt, Thermal Spray Maps: Material Genomics of Processing Technologies, J. Therm. Spray Technol., 2013, 22(7), p 1170-1183. https://doi.org/10.1007/s11666-013-9970-3

61. C. Verdon, A. Karimi, and J.L. Martin, A Study of High Velocity Oxy-Fuel Thermally Sprayed Tungsten Carbide Based Coating.s Part 1: Microstructures, Mater. Sci. Eng. A, 1998, 246(1-2), p 11-24.

62. D.A. Stewart, P.H. Shipway, and D.G. McCartney, Abrasive Wear Behaviour of Conventional and Nanocomposite HVOFSprayed WC-Co Coatings, Wear, 1999, 225-229, p 789-798.
63. P. Vuoristo, K. Niemi, T. Maentylae, L.M. Berger,, and M. Nebelung, Comparison of Different Hard, Metal-like Coatings Sprayed by Plasma and Detonation Gun Processes. National thermal spray conference, (Houston, Texas, USA), ASM International, 1995.

64. H.L. de VilliersLovelock, Powder/Processing/Structure Relationships in WC-Co Thermal Spray Coatings: A Review of the Published Literature, J. Therm. Spray Technol., 1998, 7(3), p 357-373. https://doi.org/10.1361/105996398770350846

65. S. Matthews, J. Ansbro, C.C. Berndt,, and A.S.M. Ang, Carbide Dissolution in WC-17Co Thermal Spray Coatings: Part 1-Project Concept and as-Sprayed Coatings, J. Alloys Compd., 2020, p 157464.

66. C.J. Li and G.J. Yang, Relationships between Feedstock Structure, Particle Parameter, Coating Deposition, Microstructure and Properties for Thermally Sprayed Conventional and Nanostructured WC-Co, Int. J. Refract. Met. Hard Mater., 2013, 39, p 2-17.

67. Z.G. Ban and L.L. Shaw, Characterization of Thermal Sprayed Nanostructured WC-Co Coatings Derived from Nanocrystalline WC-18wt.\%Co Powders, J. Therm. Spray Technol., 2003, 12(1), p 112-119.

68. S. Osawa, T. Itsukaichi and R. Ahmed, Influence of Substrate Properties on the Impact Resistance of WC Cermet Coatings, $J$. Therm. Spray Technol., 2005, 14(4), p 495-501.

69. S. Stewart and R. Ahmed, Contact Fatigue Failure Modes in Hot Isostatically Pressed WC-12\%Co Coatings, Surf. Coatings Technol., 2003, 172(2-3), p 204-216.

70. J.A. Gan and C.C. Berndt, Nanocomposite Coatings: Thermal Spray Processing, Microstructure and Performance, Int. Mater. Rev., 2015, 60(4), p 195-244. https://doi.org/10.1179/ 1743280414Y.0000000048

71. J. Karthikeyan, C.C. Berndt, J. Tikkanen, J.Y. Wang, A.H. King, and H. Herman, Nanomaterial Powders and Deposits Prepared by Flame Spray Processing of Liquid Precursors, Nanostruct. Mater., 1997, 8(1), p 61-74. https://doi.org/10.1016/S09659773(97)00066-4

72. P. Fauchais, A. Joulia, S. Goutier, C. Chazelas, M. Vardelle, A. Vardelle, and S. Rossignol, Suspension and Solution Plasma Spraying, J. Phys. D. Appl. Phys., 2013, 46(22), p 224015. https://doi.org/10.1088/0022-3727/46/22/224015

73. J.O. Berghaus, B. Marple, and C. Moreau, Suspension Plasma Spraying of Nanostructured WC-12Co Coatings, Proc. Int. Therm. Spray Conf., 2006, 15, p 676-681.

74. V. Chawla, S. Prakash, and B.S. Sidhu, State of the Art: Applications of Mechanically Alloyed Nanomaterials-A Review, Mater. Manuf. Process., 2007, 22(4), p 469-473.

75. V. Stoica, Sliding Wear of Post-Treated Thermal Spray Cermet Coatings, Ph.D. Thesis, Heriot-Watt University, 2005.

76. S. Stewart, The Rolling Contact Fatigue of Post-Treated Thermal Spray Coatings, Ph.D. Thesis, Heriot-Watt University, 2004.

77. K. Nishimura, T. Fujii, K. Yubuta,, and S. Shinozaki, Process for Producing Oxide Coated Fine Metal Particles (United States), 2003, p 1-18, https://patents.google.com/patent/US6582763.

78. R. Ahmed and M. Gerard, Coating Method (United States), 2016, p 1-11, https://patents.google.com/patent/US9421151B2/ en.

79. J. Yuan, C. Ma, S. Yang, Z. Yu, and H. Li, Improving the Wear Resistance of HVOF Sprayed WC-Co Coatings by Adding Submicron-Sized WC Particles at the Splats' Interfaces, Surf. Coat. Technol., 2016, 285, p 17-23.

80. S. Matthews, Development of High Carbide Dissolution/Low Carbon Loss $\mathrm{Cr} 3 \mathrm{C} 2-\mathrm{NiCr}$ Coatings by Shrouded Plasma Spraying, Surf. Coatings Technol., 2014, 258, p 886-900. https:// doi.org/10.1016/j.surfcoat.2014.07.062 
81. ASTM G133-05(2016), Standard Test Method for Linearly Reciprocating Ball-on-Flat Sliding Wear, 2016. https://doi.org/ 10.1520/G0133-05R16.

82. ASTM G99-17, Standard Test Method for Wear Testing with a Pin-on-Disk Apparatus, 2017. https://doi.org/10.1520/G009917.

83. ASTM G77-17, Standard Test Method for Ranking Resistance of Materials to Sliding Wear Using Block-on-Ring Wear Test, 2017. https://doi.org/10.1520/G0077-17.

84. K. Holmberg, H. Ronkainen, and A. Matthews, Wear Mechanisms of Coated Sliding Surfaces, Tribol. Ser., 1993, 25(C), p 399-407.

85. M.A. Ashraf, R. Ahmed, O. Ali, N.H. Faisal, A.M. El-Sherik, and M.F.A. Goosen, Finite Element Modeling of Sliding Wear in a Composite Alloy Using a Free-Mesh, J. Tribol., 2015, 137(3), p 031605. https://doi.org/10.1115/1.4029998

86. Y. Qiao, Y. Liu, and T.E. Fischer, Sliding and Abrasive Wear Resistance of Thermal-Sprayed WC-CO Coatings, J. Therm. Spray Technol., 2001, 10(1), p 118-125. https://doi.org/10.1361/ 105996301770349583

87. J. Williams, Engineering Tribology, Cambridge University Press, Cambridge., 2005 https://doi.org/10.1017/CBO9780511805905

88. R. Ahmed, Rolling Contact Fatigue, ASM Handbook, Vol 11Failure Analysis and Prevention, Section 6E, 2002.

89. J.M. Guilemany, J.M. Miguel, S. Vizcaino, and F. Climent, Role of Three-Body Abrasion Wear in the Sliding Wear Behaviour of WC-Co Coatings Obtained by Thermal Spraying, Surf. Coatings Technol., 2001, 140(2), p 141-146.

90. P. Tolédano, G. Krexner, M. Prem, H.-P. Weber, and V.P. Dmitriev, Theory of the Martensitic Transformation in Cobalt, Phys. Rev. B., 2001, 64(14), p 144104. https://doi.org/10.1103/ PhysRevB.64.144104

91. R. Ahmed and H.L.D.V. Lovelock, Friction and Wear of CobaltBase Alloys, ASM Handbook, Vol 18-Friction, Lubrication, and Wear Technology, 2018, p 487-501.

92. R. Ahmed, H.L. De Villiers Lovelock, N.H. Faisal, and S. Davies, Structure-Property Relationships in a CoCrMo Alloy at Micro and Nano-Scales, Tribol. Int., 2014, 80, p 98-114.

93. R. Ahmed, A. Ashraf, M. Elameen, N.H. Faisal, A.M. El-Sherik, Y.O. Elakwah, and M.F.A. Goosen, Single Asperity Nanoscratch Behaviour of HIPed and Cast Stellite 6 Alloys, Wear, 2014, 312(12), p 70-82. https://doi.org/10.1016/j.wear.2014.02.006

94. R. Ahmed, H.L. De Villiers Lovelock, S. Davies, and N.H. Faisal, Influence of Re-HIPing on the Structure-Property Relationships of Cobalt-Based Alloys, Tribol. Int., 2013, 57, p 8-21.

95. H. Yu, R. Ahmed, H. deLovelock, and S. Davies, Influence of Manufacturing Process and Alloying Element Content on the Tribomechanical Properties of Cobalt-Based Alloys, J. Tribol., 2009, 131(1), p 1-12.

96. M. Bauccio, ASM Engineered Materials Reference Book, 2nd ed. ASM International, Materials Park OH, 1994.

97. N.H. Faisal, R. Ahmed, A.K. Prathuru, S. Spence, M. Hossain, and J.A. Steel, An Improved Vickers Indentation Fracture Toughness Model to Assess the Quality of Thermally Sprayed Coatings, Eng. Fract. Mech., 2014, 128(C), p 189-204.

98. R. Ahmed, S. Stewart, V. Stoica,, and T. Itsukaichi, Influence of Post-Treatment on the Tribo-Mechanical Properties of Cermet Coatings, Proceedings of the International Thermal Spray Conference, (Osaka, Japan), 2004, p 912-917.

99. Q. Yang, T. Senda, and A. Hirose, Sliding Wear Behavior of WC-12\% Co Coatings at Elevated Temperatures, Surf. Coat. Technol., 2006, 200(14-15), p 4208-4212.

100. R.C. Dante and C.K. Kajdas, A Review and a Fundamental Theory of Silicon Nitride Tribochemistry, Wear, 2012, 288, p 27-38.
101. H. Engqvist, H. Högberg, G.A. Botton, S. Ederyd, and N. Axén, Tribofilm Formation on Cemented Carbides in Dry Sliding Conformal Contact, Wear, 2000, 239(2), p 219-228.

102. V. Stoica, R. Ahmed, T. Itsukaichi, and S. Tobe, Sliding Wear Evaluation of Hot Isostatically Pressed (HIPed) Thermal Spray Cermet Coatings, Wear, 2004, 257(11), p 1103-1124.

103. V.A. Muratov and T.E. Fischer, Tribochemical Polishing, Annu. Rev. Mater. Sci., 2000, 30(1), p 27-51. https://doi.org/10.1146/ annurev.matsci.30.1.27

104. R. Ahmed, H.L. de Villiers Lovelock, and S. Davies, Sliding Wear of Blended Cobalt Based Alloys, Wear, 2020 https://doi. org/10.1016/j.wear.2020.203533

105. P.H. Shipway and J.J. Hogg, Dependence of Microscale Abrasion Mechanisms of WC-Co Hardmetals on Abrasive Type, Wear, 2005, 259(1-6), p 44-51.

106. R. Schwetzke and H. Kreye, Microstructure and Properties of Tungsten Carbide Coatings Sprayed with Various HighVelocity Oxygen Fuel Spray Systems, J. Therm. Spray Technol., 1999, 8, p 433-439.

107. O. Ali, R. Ahmed, H. Alawadhi, M. Shameer, N.H. Faisal, N.M. Al-Anazi,, and M.F.A. Goosen, Comparison of Wear Performance of Thermal Sprayed Cermet (WC-Co) Coatings from Suspension and Feedstock Powders, Proceedings of the International Thermal Spray Conference, (Düsseldorf, GErmany), ASM International, 2017, p 681-686.

108. V. Stoica, R. Ahmed, and T. Itsukaichi, Influence of HeatTreatment on the Sliding Wear of Thermal Spray Cermet Coatings, Surf. Coat. Technol., 2005, 199(1), p 7-21.

109. M. Couto, S. Dosta, M. Torrell, J. Fernández, and J.M. Guilemany, Cold Spray Deposition of WC-17 and 12Co Cermets onto Aluminum, Surf. Coat. Technol., 2013, 235, p 54-61.

110. L.P. Ward, B. Hinton, D. Gerrard, and K. Short, Corrosion Behaviour of Modified HVOF Sprayed WC Based Cermet Coatings on Stainless Steel, J. Miner. Mater. Charact. Eng., 2011, 10(11), p 989-1005.

111. AzoM.com, Nickel (Ni)—Properties, Applications, 2001.

112. AzoM.com, Chromium, 2001.

113. AzoM.com, Cobalt, 2001.

114. D.H. Buckley and R.L. Johnson, Marked Influence of Crystal Structure on the Friction and Wear Characteristics of Cobalt and Cobalt-Base Alloys in Vacuum to 10-9 Millimeter of Mercury. i- Polycrystalline and Single Crystal Cobalt, (Cleveland, $\mathrm{OH}$, United States), 1964, https://ntrs.nasa.gov/citations/ 19650003010.

115. Z. Geng, S. Li, D.L. Duan, and Y. Liu, Wear Behaviour of WCCo HVOF Coatings at Different Temperatures in Air and Argon, Wear, 2015, 330-331, p 348-353.

116. M. Xie, S. Zhang, and M. Li, Comparative Investigation on HVOF Sprayed Carbide-Based Coatings, Appl. Surf. Sci., 2013, 273, p 799-805.

117. L.M. Berger, S. Saaro, T. Naumann, M. Wiener, V. Weihnacht, S. Thiele, and J. Suchánek, Microstructure and Properties of HVOF-Sprayed Chromium Alloyed WC-Co and WC-Ni Coatings, Surf. Coat. Technol., 2008, 202(18), p 4417-4421.

118. R. Ahmed, G. Vourlias, A. Algoburi, C. Vogiatzis, D. Chaliampalias, S. Skolianos, L.M. Berger, S. Paul, N.H. Faisal, F.L. Toma, N.M. Al-Anazi, and M.F.A. Goosen, Comparative Study of Corrosion Performance of HVOF-Sprayed Coatings Produced Using Conventional and Suspension WC-Co Feedstock, J. Therm. Spray Technol., 2018, 27(8), p 1579-1593.

119. L.P. Ward and A. Pilkington, The Dry Sliding Wear Behavior of HVOF-Sprayed WC: Metal Composite Coatings, J. Mater. Eng. Perform., 2014, 23(9), p 3266-3278.

120. L. Jacobs, M.M. Hyland, and M. De Bonte, Study of the Influence of Microstructural Properties on the Sliding-Wear Behavior 
of HVOF and HVAF Sprayed WC-Cermet Coatings, J. Therm. Spray Technol., 1999, 8(1), p 125-132.

121. Z. Geng, H. Huang, B. Lu, S. Wu, and G. Shi, Tribological Behaviour of Low-Pressure Plasma Sprayed WC-Co Coatings at Elevated Temperatures, Ind. Lubr. Tribol., 2019, 71(2), p 258266.

122. S.H. Yao, Tribological Behaviour of NiCrBSi-WC(Co) Coatings, Mater. Res. Innov., 2014, 18(S2), p S232-S337.

123. I. Hulka, I.D. Uţu, V.A. Şerban, P. Vuoristo, K. Niemi, and H. Koivuluoto, Properties and Microstructure of HVOF Thermally Sprayed Carbide Based Coatings, Solid State Phenom., 2014, 216, p 261-266.

124. D. Kekes, P. Psyllaki, and M. Vardavoulias, Tribology in Industry Wear Micro-Mechanisms of Composite WC-Co/CrNiCrFeBSiC Coatings. Part I: Dry Sliding, Tribol. Ind., 2014, 36(4), p 375-383.

125. V. Katranidis, S. Kamnis, B. Allcock, and S. Gu, Effects and Interplays of Spray Angle and Stand-off Distance on the Sliding Wear Behavior of HVOF WC-17Co Coatings, J. Therm. Spray Technol., 2019, 28(3), p 514-534.

126. J. Yuan, Y. Zhu, H. Ji, X. Zheng, Q. Ruan, Y. Niu, Z. Liu, and Y. Zeng, Microstructures and Tribological Properties of Plasma Sprayed WC-Co-Cu-BaF2/CaF2 Self-Lubricating Wear Resistant Coatings, Appl. Surf. Sci., 2010, 256(16), p 4938-4944.

127. J. Voyer and B.R. Marple, Sliding Wear Behavior of High Velocity Oxy-Fuel and High Power Plasma Spray-Processed Tungsten Carbide-Based Cermet Coatings, Wear, 1999, 225229, p 135-145.

128. G. Bolelli, T. Börner, A. Milanti, L. Lusvarghi, J. Laurila, H. Koivuluoto, K. Niemi, and P. Vuoristo, Tribological Behavior of HVOF- and HVAF-Sprayed Composite Coatings Based on FeAlloy + WC-12\% Co, Surf. Coat. Technol., 2014, 248, p 104112.

129. T. Teppernegg, T. Klünsner, C. Kremsner, C. Tritremmel, C. Czettl, S. Puchegger, S. Marsoner, R. Pippan, and R. Ebner, High Temperature Mechanical Properties of WC-Co Hard Metals, Int. J. Refract. Met. Hard Mater., 2016, 56, p 139-144. https://doi.org/10.1016/j.ijrmhm.2016.01.002

130. R.W. Armstrong, The Hardness and Strength Properties of WCCo Composites, Materials (Basel), Mol. Divers. Preserv. Int. , 2011, 4(7), p 1287-1308.

131. Q. Wang, J. Xiang, G. Chen, Y. Cheng, X. Zhao, and S. Zhang, Propylene Flow, Microstructure and Performance of WC-12Co Coatings Using a Gas-Fuel HVOF Spray Process, J. Mater. Process. Technol., 2013, 213(10), p 1653-1660.

132. G. Di Girolamo, L. Pilloni, G. Pulci, and F. Marra, Tribological Characterization of WC-Co Plasma Sprayed Coatings, J. Am. Ceram. Soc., 2009, 92(5), p 1118-1124.

133. G. Di Girolamo, F. Marra, L. Pilloni, G. Pulci, J. Tirillò, and T. Valente, Microstructure and Wear Behavior of Plasma-Sprayed Nanostructured WC-Co Coatings, Int. J. Appl. Ceram. Technol., 2013, 10(1), p 60-71.

134. V. Stoica, R. Ahmed, M. Golshan, and S. Tobe, Sliding Wear Evaluation of Hot Isostatically Pressed Thermal Spray Ceramet Coatings, J. Therm. Spray Technol., 2004, 13(1), p 93-107.

135. J. Mateos, J.M. Cuetos, E. Fernández, and R. Vijande, Tribological Behaviour of Plasma-Sprayed WC Coatings with and without Laser Remelting, Wear, 2000, 239(2), p 274-281.

136. M. Heydarzadeh Sohi and F. Ghadami, Comparative Tribological Study of Air Plasma Sprayed WC-12\%Co Coating versus Conventional Hard Chromium Electrodeposit, Tribol. Int., 2010, 43(5-6), p 882-886.

137. S.K. Asl, M.H. Sohi, and S.M.M. Hadavi, The Effect of the Heat Treatment on Residual Stresses in HVOF Sprayed WC-Co Coating, Mater. Sci. Forum, 2004, 427, p 427-432.
138. P. Põdra and S. Andersson, Simulating sliding wear with finite element method, Tribol. Int., 1999, 32(2), p 71-81. https://doi. org/10.1016/S0301-679X(99)00012-2

139. R.G. Buentello Hernandez and B. Hernandez, 3D Finite Element Modeling of Sliding Wear, Air Force Institute of Technology, 2013, https://scholar.afit.edu/etd/503?utm_source=scholar.afit. edu\%2Fetd\%2F503\&utm_medium=PDF\&utm_campaign= PDFCoverPages.

140. E.G. Ng and D.K. Aspinwall, Modelling of Hard Part Machining, J. Mater. Process. Technol., 2002, 127, p 222-229.

141. S. Atlati, B. Haddag, M. Nouari, and M. Zenasni, Thermomechanical Modelling of the Tool-Workmaterial Interface in Machining and Its Implementation Using the ABAQUS VUINTER Subroutine, Int. J. Mech. Sci., 2014, 87, p 102-117.

142. A.M. Rajesh, S. Doddamani, and K.N. Bharath, Dry Sliding Wear Simulation of Hybrid Aluminum Metal Matrix Composites, Adv. Compos. Hybrid Mater., 2020, 3(1), p 120-126.

143. M. Azeem Ashraf, B. Sobhi-Najafabadi, Ö. Göl, and D. Sugumar, Numerical Simulation of Sliding Wear for a PolymerPolymer Sliding Contact in an Automotive Application, Int. J. Adv. Manuf. Technol., 2009, 41(11-12), p 1118-1129.

144. P. Põdra and S. Andersson, Wear Simulation with the Winkler Surface Model, Wear, 1997, 207(1-2), p 79-85.

145. G. Bolelli, A. Candeli, H. Koivuluoto, L. Lusvarghi, T. Manfredini, and P. Vuoristo, Microstructure-Based Thermo-Mechanical Modelling of Thermal Spray Coatings, Mater. Des., 2015, 73, p 20-34. https://doi.org/10.1016/j.matdes.2015.02.014

146. C. Lyphout, G. Bolelli, E. Smazalova, K. Sato, J. Yamada, Š Houdková, L. Lusvarghi, and T. Manfredini, Influence of Hardmetal Feedstock Powder on the Sliding Wear and Impact Resistance of High Velocity Air-Fuel (HVAF) Sprayed Coatings, Wear, 2019, 430-431, p 340-354.

147. J.A. Williams, Wear Modelling: Analytical, Computational and Mapping: A Continuum Mechanics Approach, Wear, 1999, 225229(1), p 1-17.

148. H. Wang, X. Wang, X. Song, X. Liu, and X. Liu, Sliding Wear Behavior of Nanostructured WC-Co-Cr Coatings, Appl. Surf. Sci., 2015, 355, p 453-460.

149. S.C. Lim and M.F. Ashby, Wear-Mechanism Maps, Acta Metall., 1987, 35(1), p 1-24.

150. H.C. Meng and K.C. Ludema, Wear Models and Predictive Equations: Their Form and Content, Wear, 1995, 181-183(2), p 443-457.

151. L. Euler, Institutionum Calculi Integralis, Petropoli: Impensis Academiae Imperialis Scientiarum, 1768.

152. V. Hegadekatte, N. Huber, and O. Kraft, Finite Element Based Simulation of Dry Sliding Wear, Model. Simul. Mater. Sci. Eng., 2004, 13(1), p 57-75. https://doi.org/10.1088/0965-0393/13/1/005

153. F.J. Martínez, M. Canales, S. Izquierdo, M.A. Jiménez, and M.A. Martínez, Finite Element Implementation and Validation of Wear Modelling in Sliding Polymer-Metal Contacts, Wear, 2012, 284-285, p 52-64.

154. V. Hegadekatte, S. Kurzenhäuser, N. Huber, and O. Kraft, A Predictive Modeling Scheme for Wear in Tribometers, Tribol. Int., 2008, 41(11), p 1020-1031.

155. B. Kanavalli, Application of User Defined Subroutine UMESHMOTION in ABAQUS for Simulating Dry Rolling/ Sliding Wear, KTH Royal Institute of Technology, 2006.

156. E.M. Bortoleto, A.C. Rovani, V. Seriacopi, F.J. Profito, D.C. Zachariadis, I.F. Machado, A. Sinatora, and R.M. Souza, Experimental and Numerical Analysis of Dry Contact in the Pin on Disc Test, Wear, 2013, 301(1-2), p 19-26.

157. I.R. McColl, J. Ding, and S.B. Leen, Finite Element Simulation and Experimental Validation of Fretting Wear, Wear, 2004, 256(11-12), p 1114-1127. 
158. A. Söderberg and S. Andersson, Simulation of Wear and Contact Pressure Distribution at the Pad-to-Rotor Interface in a Disc Brake Using General Purpose Finite Element Analysis Software, Wear, 2009, 267(12), p 2243-2251.

159. S. Mukras, N.H. Kim, W.G. Sawyer, D.B. Jackson, and L.W. Bergquist, Numerical Integration Schemes and Parallel Computation for Wear Prediction Using Finite Element Method, Wear, 2009, 266(7-8), p 822-831.

160. X. Shen, L. Cao, and R. Li, Numerical Simulation of Sliding Wear Based on Archard Model, 2010 Int. Conf. Mech. Autom. Control Eng. MACE2010, 2010, (D), p 325-329.

161. A. Rezaei, W. Van Paepegem, P. De Baets, W. Ost, and J. Degrieck, Adaptive Finite Element Simulation of Wear Evolution in Radial Sliding Bearings, Wear, 2012, 296(1-2), p 660671.

162. V. Hegadekatte, N. Huber, and O. Kraft, Modeling and Simulation of Wear in a Pin on Disc Tribometer, Tribol. Lett., 2006, 24(1), p 51-60.

163. M.S. Zoei, T. Farizeh, M.H. Sadeghi, and M. Salehi, Residual Stress Distribution Through the Thickness of WC-10Co-4Cr Coating Deposited by HVOF: Experimental and Simulation Study, J. Therm. Spray Technol., 2020, 29(6), p 1351-1364.

164. Y.Y. Santana, P.O. Renault, M. Sebastiani, J.G. La Barbera, J. Lesage, E. Bemporad, E. Le Bourhis, E.S. Puchi-Cabrera, and
M.H. Staia, Characterization and Residual Stresses of WC-Co Thermally Sprayed Coatings, Surf. Coat. Technol., 2008, 202(18), p 4560-4565.

165. T.C. Totemeier and J.K. Wright, Residual Stress Determination in Thermally Sprayed Coatings-A Comparison of Curvature Models and X-Ray Techniques, Surf. Coat. Technol., 2006, 200(12-13), p 3955-3962.

166. W. Luo, U. Selvadurai, and W. Tillmann, Effect of Residual Stress on the Wear Resistance of Thermal Spray Coatings, $J$. Therm. Spray Technol., 2016, 25(1), p 321-330. https://doi.org/ 10.1007/s11666-015-0309-0

167. A.C. Savarimuthu, H.F. Taber, I. Megat, J.R. Shadley, E.F. Rybicki, W.C. Cornell, W.A. Emery, D.A. Somerville, and J.D. Nuse, Sliding Wear Behavior of Tungsten Carbide Thermal Spray Coatings for Replacement of Chromium Electroplate in Aircraft Applications, J. Therm. Spray Technol., 2001, 10(3), p 502-510.

168. H. Yu, W. Zhang, H. Wang, Y. Guo, M. Wei, Z. Song, and Y. Wang, Bonding and Sliding Wear Behaviors of the Plasma Sprayed NiCrBSi Coatings, Tribol. Int., 2013, 66, p 105-113.

Publisher's Note Springer Nature remains neutral with regard to jurisdictional claims in published maps and institutional affiliations. 